Aus dem Institut für Klinische Pharmakologie

(Prof. Dr. med. J. Brockmöller)

der Medizinischen Fakultät der Universität Göttingen

\title{
Comparative Analysis of Opioids as \\ Substrates and Inhibitors of the Human \\ Organic Cation Transporter 1 (OCT1)
}

\author{
INAUGURAL-DISSERTATION \\ zur Erlangung des Doktorgrades \\ der Medizinischen Fakultät der \\ Georg-August-Universität zu Göttingen
}

vorgelegt von

Viktoria Elisabeth Neumann

aus

Göttingen

Göttingen 2018 
Dekan:

Referent:

Ko-Referent:

Promotor:
Prof. Dr. rer. nat. H.K. Kroemer

Prof. Dr. Mladen Tzvetkov

PD Dr. Johannes Uhlig

Prof. Dr. Martin Oppermann

Datum der mündlichen Prüfung: 18.08 .2020 


\section{Table of Content}

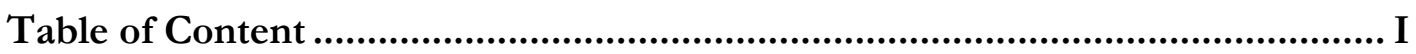

List of figures …............................................................................................ III

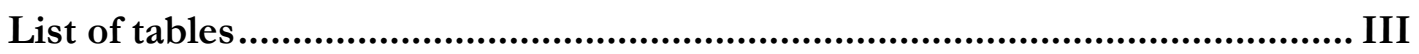

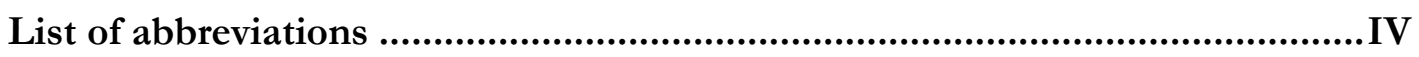

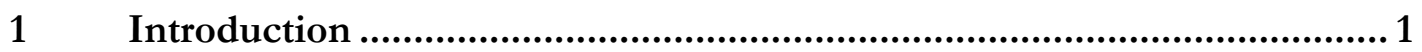

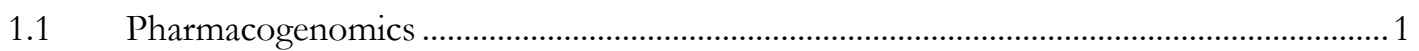

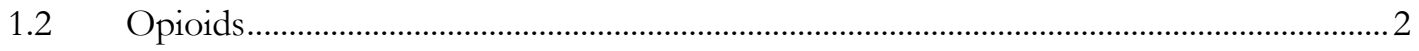

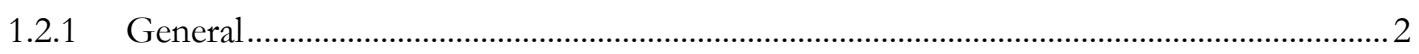

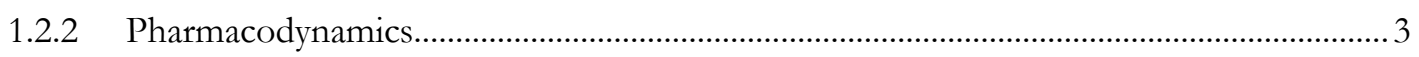

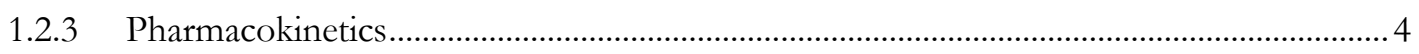

1.2.4 Effects of opioids and their role in clinical application..................................................... 6

1.2.5 Role of OCT1 in opioid metabolism ………..............................................................

$1.3 \quad H u m a n$ organic cation transporter 1 (OCT1) ................................................................ 8

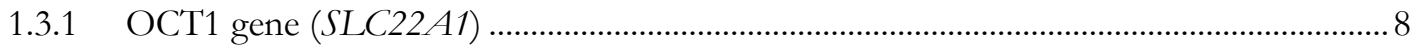

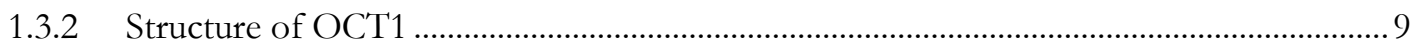

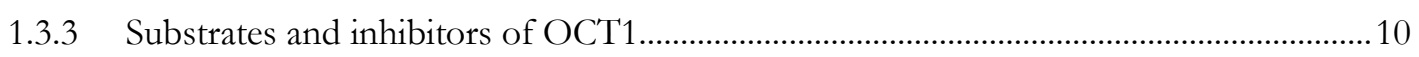

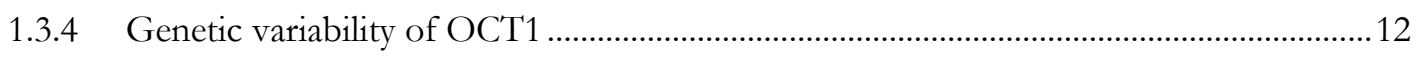

1.3.5 OCT1 and pharmacogenetics research ……………………….................................13

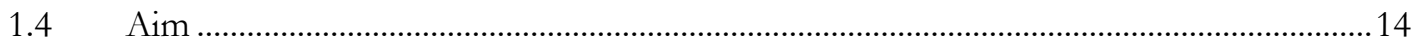

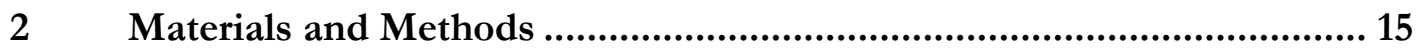

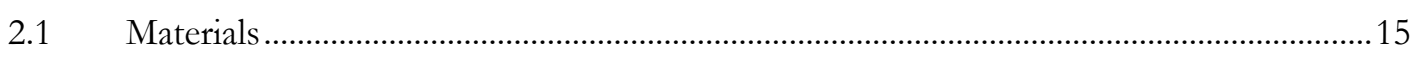

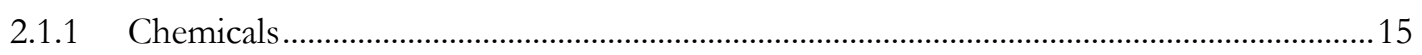

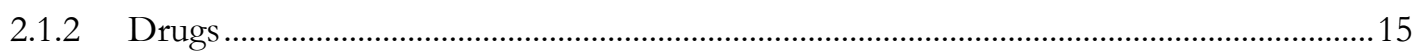

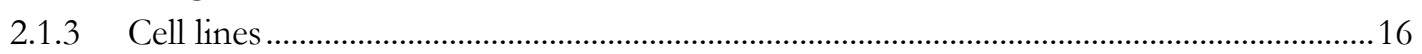

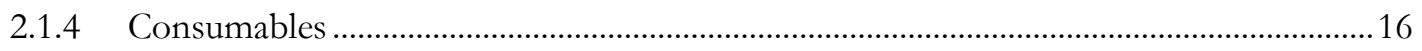

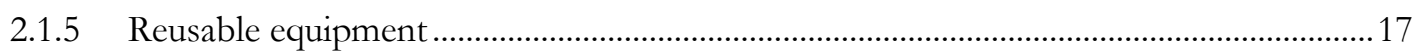

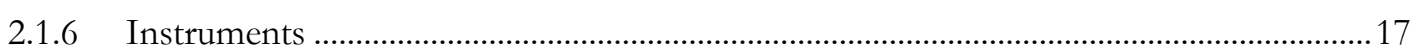

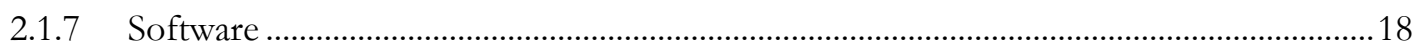

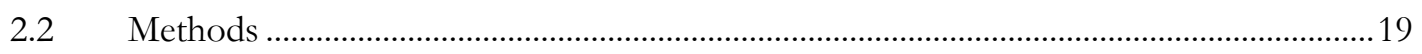

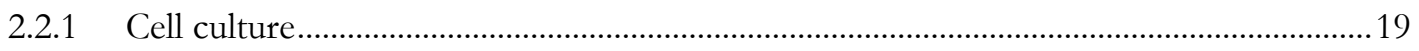

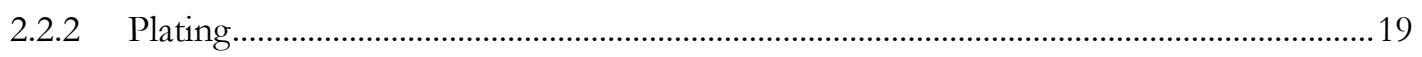

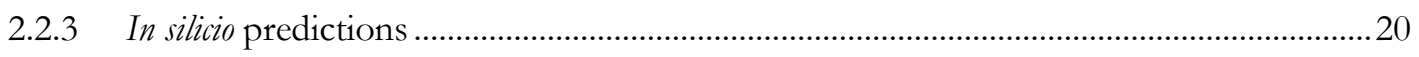

2.2.4 Parallel artificial membrane permeability assays (PAMPAs) .............................................20

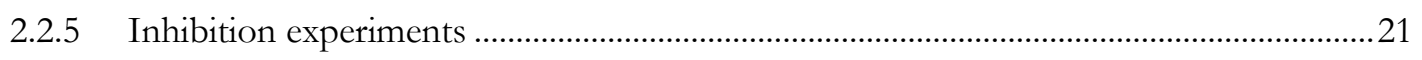

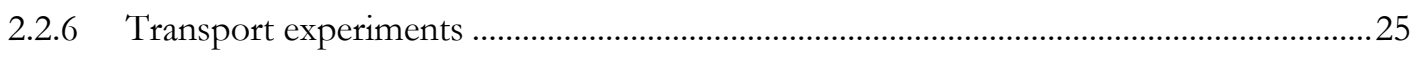

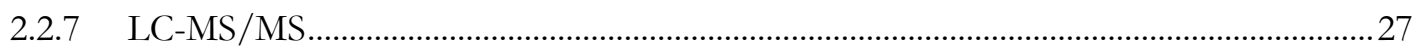




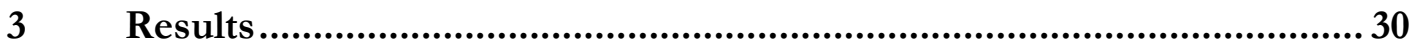

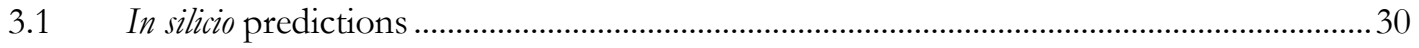

3.2 Parallel artificial membrane assays (PAMPAs) ……………………………………........

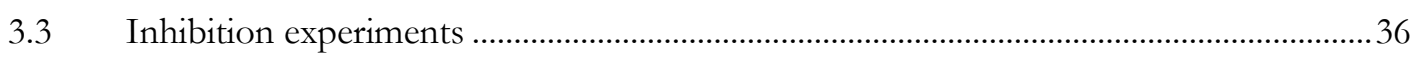

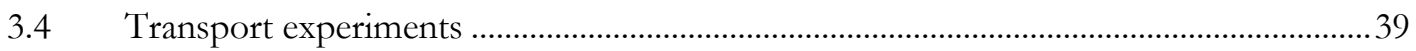

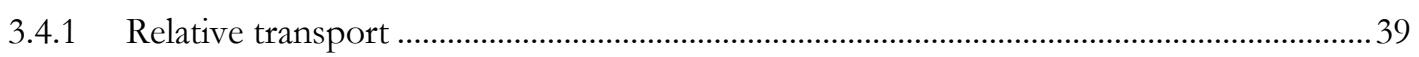

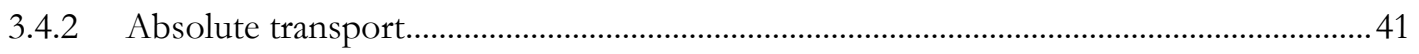

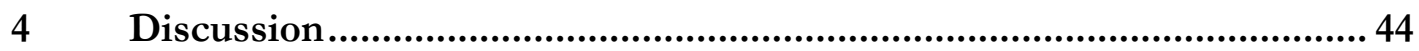

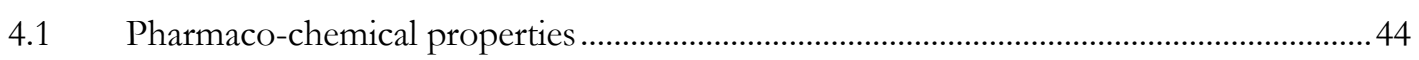

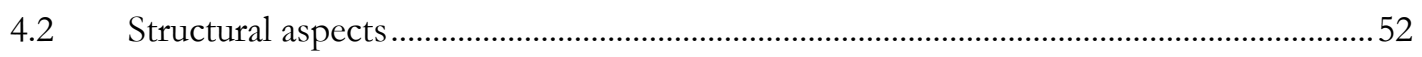

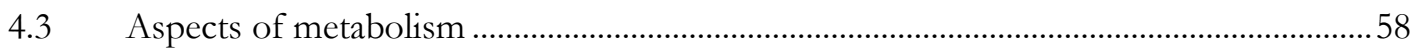

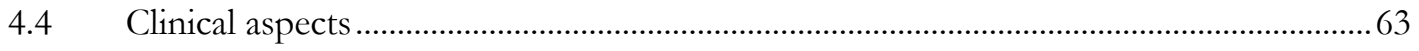

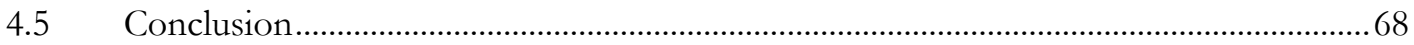

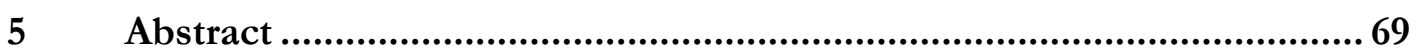

$6 \quad$ Appendix

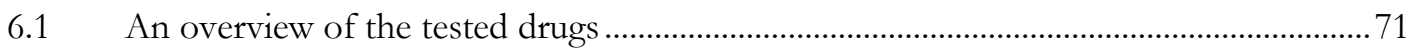

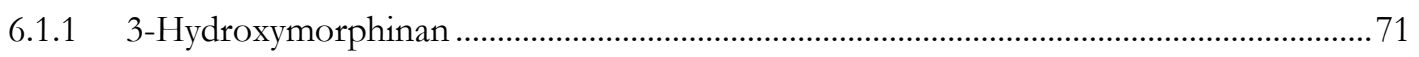

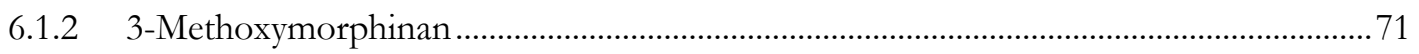

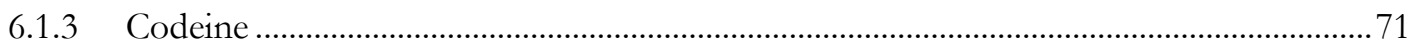

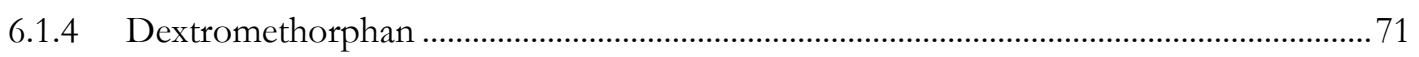

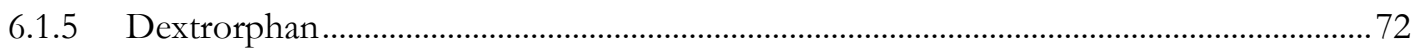

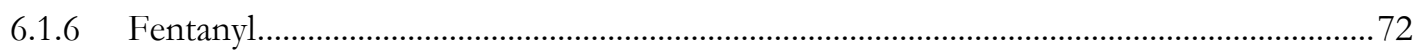

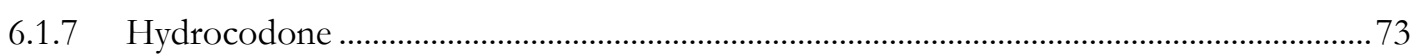

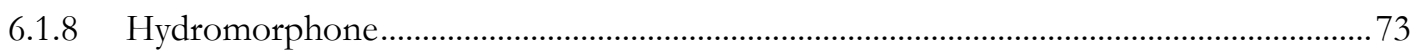

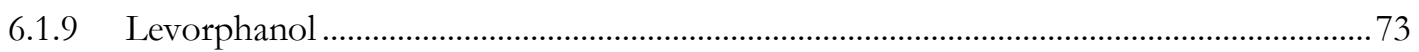

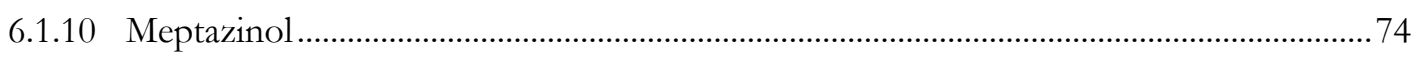

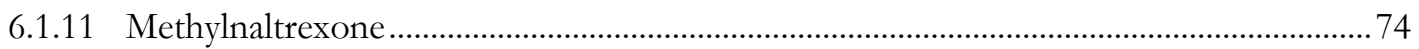

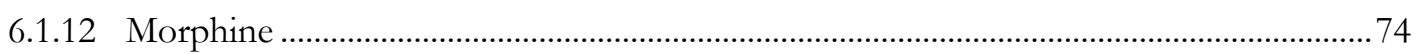

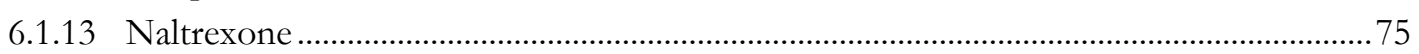

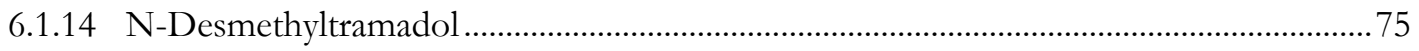

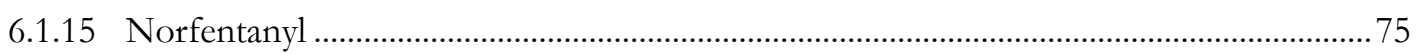

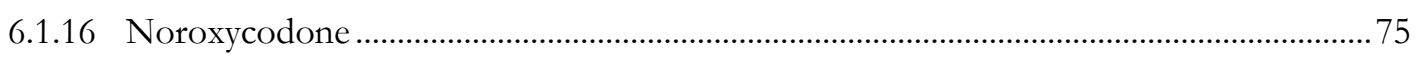

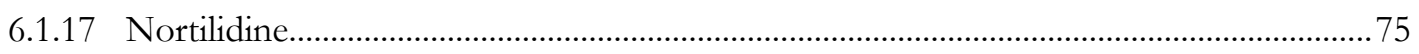

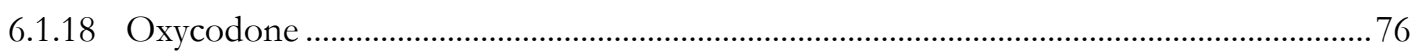

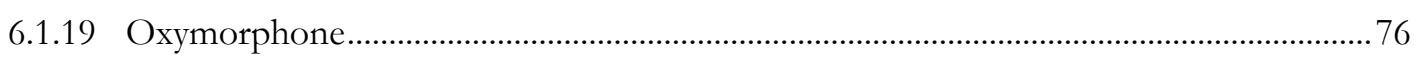

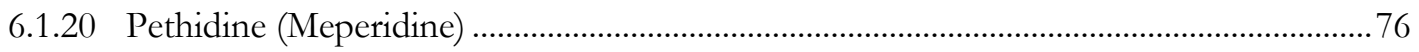

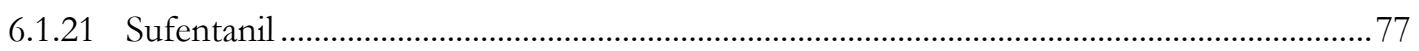

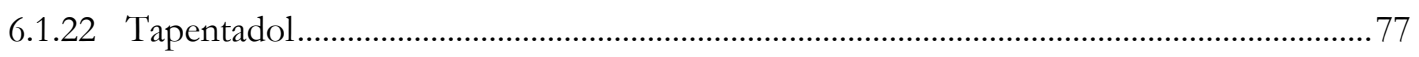

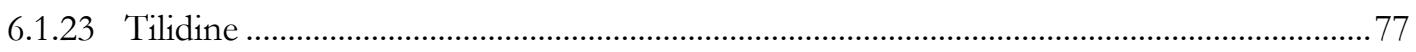

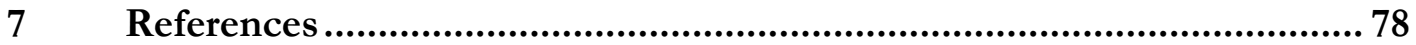




\section{List of figures}

Figure 1: Chemical structures of selected substrates of OCT1 ……………………......................11

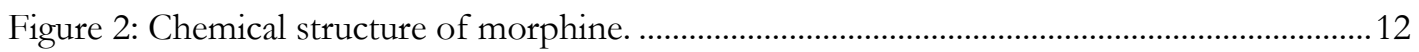

Figure 3: Plating and pipetting scheme for inhibition experiments, concentrations in $\mu \mathrm{M}$.......23

Figure 4: Plating and pipetting scheme for transport experiments, concentrations in $\mu \mathrm{M}$........26

Figure 5: Comparative analyses of opioids as inhibitors of OCT1 ………………………..........38

Figure 6: Relative increase in uptake of methylnaltrexone ............................................................40

Figure 7: Histograms of pKa values for OCT1 substrates and non-substrates, morphinans and synthetic opioids, and OCT1 inhibitors and non-inhibitors..............................................4 48

Figure 8: Histograms of $\log \mathrm{D}_{(7.4)}$ values for OCT1 substrates and non-substrates, morphinans and synthetic opioids, and OCT1 inhibitors and non-inhibitors ....................................4 49

Figure 9: Histograms of $\mathrm{P}_{\mathrm{e}}$ values for OCT1 substrates and non-substrates, morphinans and synthetic opioids, and OCT1 inhibitors and non-inhibitors.............................................50

Figure 10: Histograms of $\mathrm{IC}_{50}$ values for OCT1 substrates and non-substrates, morphinans and synthetic opioids, and OCT1 inhibitors and non-inhibitors ...................................... 51

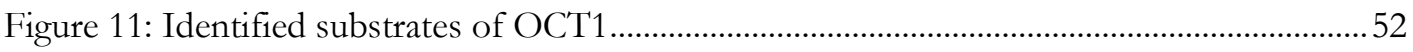

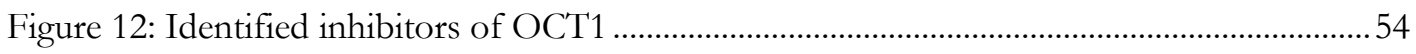

Figure 13: Synthetic opioids and their respective $\mathrm{IC}_{50}$ values .......................................................5

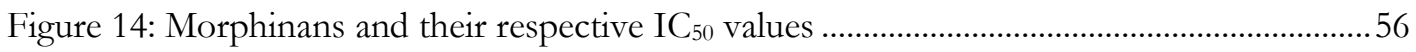

Figure 15: Opioids with no observed interaction with OCT1 ……………………………….......57

Figure 16: Uptake of parent compounds and their metabolites ....................................................62

\section{List of tables}

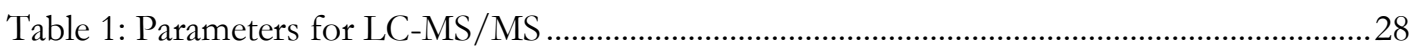

Table 2: Opioids and their predicted $\mathrm{pK}_{\mathrm{a}}, \log \mathrm{P}$ and $\log \mathrm{D}_{(7.4)}$ values, in alphabetical order ........31

Table 3: $\mathrm{P}_{\mathrm{e}}$ (mean) and SEM(mean) in comparison to $\log \mathrm{D}_{(7.4)}$ values ............................................. 35

Table 4: Tested substances sorted by $\mathrm{IC}_{50}$ from lowest to highest .................................................36

Table 5: Relative increase in uptake of tested substances ............................................................. 41

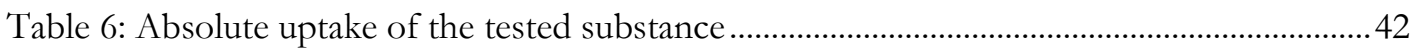

Table 7: $\mathrm{pKa}, \log \mathrm{D}_{(7.4)}$, and $\mathrm{P}_{\mathrm{e}}$ values and their significance........................................................4

Table 8: Inhibition of OCT1-mediated uptake by opioids identified as inhibitors of OCT1 in vitro 


\section{List of abbreviations}

\begin{tabular}{|c|c|}
\hline Abbreviation & Full term \\
\hline${ }^{\circ} \mathrm{C}$ & temperature in degree Celsius \\
\hline$\mu \mathrm{g}$ & microgramm $\left(10^{-6}\right)$ \\
\hline$\mu \mathrm{l}$ & microliter $\left(10^{-}-\right)$ \\
\hline$\mu \mathrm{M}$ or $\mu \mathrm{Mol} / 1$ & micromolar $\left(10^{-0}\right)$ \\
\hline ASAM & $\begin{array}{l}\text { American Society on Addiction } \\
\text { Medicine }\end{array}$ \\
\hline $\mathrm{ASP}^{+}$ & $\begin{array}{l}\text { (4-(dimethylamino)steryl)-N- } \\
\text { methylpyridinium iodine }\end{array}$ \\
\hline $\mathrm{bp}$ & base pair \\
\hline BSA & bovine serum albumin \\
\hline $\mathrm{CO}_{2}$ & carbondioxide \\
\hline CYP & $\begin{array}{l}\text { cytochrome P450 monooxygenase } \\
\text { family }\end{array}$ \\
\hline $\mathrm{ddH}_{2} \mathrm{O}$ & double distilled water \\
\hline DMEM & Dulbecco's modified eagle medium \\
\hline DNA & deoxyribonucleic acid \\
\hline DOP & delta opioid peptide receptor \\
\hline EBM & evidence-based medicine \\
\hline EDTA & ethylenediaminetetraacetic acid \\
\hline $\mathrm{EM}$ & extensive metabolizer \\
\hline ER & endoplasmatic reticulum \\
\hline FCS & fetal calf serum \\
\hline $\mathrm{g}$ & gramm \\
\hline$g$ & gravitational constant \\
\hline $\mathrm{h}$ & hour(s) \\
\hline $\mathrm{HBSS}^{+}$ & Hank's balanced salt solution \\
\hline HEK293 & human embryoic kidney cells 293 \\
\hline HEPES & $\begin{array}{l}\text { 4-(2-hydroxyethyl)-1- } \\
\text { piperazineethanesulfonic acid }\end{array}$ \\
\hline i.v. & intravenous (application of drug) \\
\hline $\mathrm{IC}_{50}$ & half maximal inhibitory concentration \\
\hline IS & internal standard \\
\hline $\mathrm{KOP}$ & kappa opioid peptide receptor \\
\hline 1 & liter \\
\hline LC-MS & $\begin{array}{l}\text { liquid tomography-mass } \\
\text { spectrography }\end{array}$ \\
\hline$\underline{\log \mathrm{D}_{(7.4)}}$ & distribution coefficient at $\mathrm{pH} 7.4$ \\
\hline $\log \mathrm{P}$ & partition coefficient \\
\hline $\mathrm{M}$ & $\operatorname{molar}(\mathrm{mol} / \mathrm{l})$ \\
\hline MFS & major facilitator superfamily \\
\hline $\mathrm{mg}$ & milligramm $\left(10^{-3}\right)$ \\
\hline $\min$ & minute(s) \\
\hline $\mathrm{ml}$ & milliliter $\left(10^{-3}\right)$ \\
\hline
\end{tabular}




\begin{tabular}{|c|c|}
\hline $\mathrm{mM}$ or $\mathrm{mMol} / \mathrm{l}$ & millimolar $\left(10^{-3}\right)$ \\
\hline MOP & mu opioid peptide receptor \\
\hline $\mathrm{MPP}+$ & 1-methyl-4-phenylpyridinium \\
\hline mRNA & messenger RNA \\
\hline MS & mass spectrography \\
\hline N.A. & not available \\
\hline ng & nanogramm $\left(10^{-9}\right)$ \\
\hline $\mathrm{nl}$ & nanoliter $\left(10^{-9}\right)$ \\
\hline $\mathrm{nM}$ or $\mathrm{nmol} / \mathrm{l}$ & nanomolar $\left(10^{-9}\right)$ \\
\hline NMDA receptor & $\mathrm{N}$-methyl-D-aspartate receptor \\
\hline NOP & nociceptin opioid peptide receptor \\
\hline NP-40 & tergitol-type $N P-40$ \\
\hline OCT1 & $\begin{array}{l}\text { Organic Cation Transporter } 1 \\
\text { (SLC22A1) }\end{array}$ \\
\hline OIBD & opioid induced bowel dysfunction \\
\hline ORL1 & opioid receptor-like 1 \\
\hline p.o. & per os (oral intake of a drug) \\
\hline PAMPA & $\begin{array}{l}\text { parallel artificial membrane } \\
\text { permeability assay }\end{array}$ \\
\hline $\mathrm{P}_{\mathrm{e}}$ & membrane permeability \\
\hline PBS & phosphate buffered saline \\
\hline PCR & polymerase chain reaction \\
\hline $\mathrm{P}_{\mathrm{e}}$ & membrane permeability \\
\hline pg & picogramm $\left(10^{-12}\right)$ \\
\hline $\mathrm{pK}_{\mathrm{a}}$ & dissociation constant \\
\hline $\mathrm{pM}$ or $\mathrm{pmol} / \mathrm{l}$ & picomolar $\left(10^{-12}\right)$ \\
\hline $\mathrm{PM}$ & poor metabolizer \\
\hline $\mathrm{rfu}$ & relative fluorescence unit \\
\hline rOct1 & rat organic cation transporter 1 \\
\hline RIPA & radioimmunoprecipitation assay buffer \\
\hline RNA & ribonucleic acid \\
\hline SDS & sodium dodecyl sulfate \\
\hline $\mathrm{s}(\mathrm{ec})$ & second(s) \\
\hline SEM & standard error of the mean \\
\hline SNP & single nucleotide polymorphism \\
\hline t.c. & transcutaneous (application of a drug) \\
\hline t.m. & transmucosal (absorption of a drug) \\
\hline TMH & transmembrane helix \\
\hline UGT & $\begin{array}{l}\text { uridine diphosphate- } \\
\text { glucuronosyltransferase }\end{array}$ \\
\hline WHO & World Health Organization \\
\hline XTris-HCl & tris-buffered saline \\
\hline
\end{tabular}




\section{Introduction}

\subsection{Pharmacogenomics}

For most of its history, medicine has been considered an art. Medical practitioners' personal experience and their culture's prevailing belief systems dominated the way medicine was executed, spawning practices that were backed by little or no scientific evidence whatsoever. It is not possible to date the exact moment that medicine transgressed from being a healing art to a scientific discipline. In the Western European part of the world we can narrow it down to the nineteenth century, when empiricism relieved the practice of treating by anecdote and paved the way for what we consider modern medicine (Claridge and Fabian 2005). Though clinical experience remains an invaluable accessory in delivering good patient care, evidence-based medicine (EBM) -clinical observations supplemented and explained by scientific data- constitutes the mainstay of medicine these days.

However, despite the advances made in medical research over the past 150 years, we often still lack a comprehensive or even basic understanding of the mechanisms that govern our body in health and disease. As multi-morbidity and polypharmacy become the rule rather than the exception, a better understanding of pharmacodynamics (the effects a drug has on the body) and pharmacokinetics (the mechanisms by which the body processes and alters the drug) is necessary to avoid over- and underdosing the individual patient. Elucidating the correlations between clinically observed drug responses and specific quirks in our genetic makeup is the domain of a branch of pharmacology known as "pharmacogenetics".

Pharmacogenetics explores how genetic variations alter the function of those receptors, enzymes, transporters, and downstream signaling elements that ultimately affect drug response and metabolism. The term, coined by Friedrich Vogel in 1959, is often used interchangeably with the term "pharmacogenomics", which cropped up much later in the 1990s (Motulsky and Qi 2006). Strictly speaking, pharmacogenetics focuses on the exploration of single genes and their products, while pharmacogenomics takes a more holistic, i.e. genome-wide, approach. Budding in the 1950s, the field of pharmacogenetics only came into bloom at the turn of the millennium, when the advent of novel DNA sequencing methods accelerated genetic sequencing and capped its costs (Motulsky and Qi 2006). Since then, scanning patients for specific heritable genetic variants has become a viable option in clinical settings, adding a new dimension to the playing field of personalized medicine. 
Generally, heritable genetic variants can affect gene products in two ways: the function of the gene product is either enhanced or impeded. The impact such altered functionality can have on metabolism is illustrated by the enzyme CYP2D6 of the cytochrome P450 family, which is involved in the metabolism of many opioids. Individuals with an impaired CYP2D6, so called "poor metabolizers" (PMs), are inefficient at metabolizing codeine into morphine. In consequence, they are exposed to codeine-related side effects without benefiting from morphine's analgesic effects (Eckhardt et al. 1998). At the other extreme, people with rapid variants of CYP2D6 may metabolize codeine to morphine at such high rates that the accumulating morphine reaches undesirably high levels, with potentially lethal outcome (Ciszkowski et al. 2009; Crews et al. 2012).

As DNA sequencing becomes faster and more readily accessible, pharmacogenetics can be an important tool in making personalized medicine more viable and efficient.

\subsection{Opioids}

\subsubsection{General}

Opioids are a class of drugs defined by their ability to bind to endogenous opioid receptors. They are best known for their analgesic properties, though they are capable of eliciting a wide array of responses, depending on their chemical properties and their receptor affinities. The term "opioid" comprises the opiates, their metabolites, and semi-synthetic derivatives, as well as the newer classes of structurally unrelated synthetic opioids, and opioid receptor antagonists. Opioids should not be confused with endorphins, endogenous peptides synthesized in the brain and the original ligands for opioid receptors (Davis and Pasternak 2009). Opiates morphine, codeine, and thebaine are plant alkaloids derived from Papaver somniferum, the opium poppy, and therefore considered "natural", as opposed to those substances artificially designed to bind to opioid receptors such as fentanyl, sufentanil, or pethidine (Freye and Levy 2008).

The analgesic properties of the juice won from the opium poppy have been exploited for thousands of years. The Ebers Papyrus, which dates back to 1500 BCE, documents the use of poppy seeds in sedative preparations, and the Sumerians are thought to have cultivated poppies as early as the third millennium BCE, supposedly to use them as euphoria-inducing stimulant in religious ceremonies- the Sumerian word for the poppy plant, "hul gil", translates to "plant of joy" (Brownstein 1993; Freye and Levy 2008). Although an opium tincture called "laudanum" was frequently employed by chemists from the $16^{\text {th }}$ century 
onwards (with the first reports of abuse and addiction cropping up at about the same time), the active compound of opium was only isolated and described in 1806 by Friedrich Sertürner, who named it morphium (morphine) after one of the Ancient Greek gods of dreams, Morpheus (Brownstein 1993). First marketed in 1817 by Sertürner and Company, the commercial production of morphine began in 1827 (Wikipedia 2018b). Bayer made heroin (diacetylmorphine) commercially available in 1898, and in 1939 pethidine (meperidine) was discovered, making it the first synthetic opioid with a structure unrelated to that of morphine (Brownstein 1993).

\subsubsection{Pharmacodynamics}

An opioid's effects depend on receptor affinity and intrinsic activity of the opioid, i.e. on how well it binds to a given receptor, and of what nature and magnitude the elicited response is, respectively.

To date, four classes of opioid receptors have been identified. They are known as MOP $(\mu$ or mu), DOP ( $\delta$ or delta), KOP ( $x$ or kappa), and NOP (nociceptin or nociceptin/orphanin FQ peptide), in which “-OP” is shorthand for "opioid peptide receptor" (Freye and Levy 2008; Dietis et al. 2011). Binding of an agonist to MOP is associated with analgesia, euphoria, respiratory depression, constipation, and itching, while KOP is thought to induce modest analgesia and feelings of dysphoria and displacement (Freye and Levy 2008; Dietis et al. 2011). Opioids receptors -DOR and KOR in particular- are also emerging as targets in the treatment of mood disorders (Lutz and Kieffer 2013). All four opioid receptor classes are 7TM receptors that mediate their effects via G-class proteins, especially the Gi family, which inhibits the release of neurotransmitter from the presynaptic neuron in pain-transmitting fibers and thus accounts for much of the opioids' analgesic effect (Freye and Levy 2008).

A variety of MOP, DOP and KOP subtypes have been proposed. Originally, the existence of subtypes served to explain why the application of MOP agonists in combination with MOP antagonist selectively reversed some MOP-mediated effects while not affecting others (Dietis et al. 2011). The exploration of putative subtypes generated especial interest because it spurred hopes to tailor opioids that would bind to a receptor subset that induced analgesia but not to the ones implicated e.g. in respiratory depression (Dietis et al. 2011). However, knock-out experiments in mice yielded that the loss of the gene encoding for one opioid receptor caused the loss of all putative subtypes, leading to a reassessment of the traditional understanding of opioid receptor action (Dietis et al. 2011). Receptor heterodimerization, alternative splicing, and the interaction of downstream opioid receptor signaling pathways 
with other signaling cascades have been proposed by more recent research to explain the observed differences in pharmacological responses (Corbett et al. 2006; Dietis et al. 2011).

Apart from their receptor profiles, opioids also differ in how strongly they bind to the individual receptors, a property termed "affinity". The stronger the affinity the opioids exhibit towards their respective receptors, the more potent is the response they elicit. Depending on their potency, opioids are roughly categorized as either weak or strong opioids. Codeine, dihydrocodeine, and tramadol are typical weak opioid analgesics, while morphine, oxycodone, levorphanol, methadone, hydromorphone, and fentanyl are considered strong opioids (WHO 1996; Brayfield 2014).

Additionally, and irrespective of their receptor affinity, opioids can also be classified depending on the effect they have on a receptor, i.e. whether they elicit a response or inhibit it. Opioids act either as agonists (e.g. morphine, fentanyl), antagonists (e.g. naltrexone, naloxone), or mixed agonist-antagonist (e.g. buprenorphine, pentazocine).

Due to their varied binding properties, opioids differ vastly in their pharmacological profile. While their ability to interact with opioid receptors classifies them as opioids, they do not bind to opioid receptors exclusively. The antitussive dextrorphan, for instance, binds little if at all to opioid receptors; it does, however, act as a NMDA-receptor antagonist. Morphine, the "classic" opioid, was shown to inhibit the release of the neurotransmitter acetylcholine and cause mast cell degranulation (Hermens et al. 1985; Davis 2009d).

Subsequently, each opioid has to be assessed individually with regard to pharmacologic and pharmacokinetic parameters.

\subsubsection{Pharmacokinetics}

The pharmacological response ultimately depends not only on the opioid, but also on its pharmacokinetics. The pharmacokinetics of any given drug -and thus its impact on an organism- are influenced by four factors: absorption, distribution, metabolism, and elimination (ADME).

Absorption of a drug depends on its chemical properties and the route of administration. While compounds such as fentanyl can be applied transdermally as patches, other opioids are best administered intravenously, either because they are absorbed poorly via the intestine (e.g. methylnaltrexone) or because they undergo extensive first-pass metabolism (e.g. morphine). 
Distribution describes the compartments (vasculature, cells, extracellular space) a drug can access and is especially relevant in the context of the brain-blood barrier. Many opioids exert their desirable -and undesirable- effects by acting upon the central nervous system. Access to the brain is limited by the blood-brain barrier, and only highly lipophilic compounds are thought capable of penetrating the barrier. Distribution is, therefore, a matter of a compound's chemical properties. A highly lipophilic compound may diffuse into cells and accumulate in adipose tissue, whereas a highly polar substance will remain in the blood stream and be subjected to quick elimination through the kidneys. Thus, distribution affects half-life as much as the time and dose required to reach a steady state.

Metabolism determines to what extent a given substance will be present in either activated or inactivated form. Most metabolic transformations - so called biotransformations - take place in the liver, where enzymes located within the hepatocytes prime xenobiotics for elimination by introducing modifications that render the drugs more hydrophilic. CYP2D6 and CYP3A4 of the cytochrome P450 (CYP) family of enzymes are especially involved in opioid metabolism. For example, duplication of the CYP2D6 gene results in such accelerated metabolization of codeine that ultra-fast metabolizers have 50\% higher plasma concentrations of morphine, a metabolite of codeine, than extensive metabolizers (Kirchheiner et al. 2007).

Elimination, like distribution, has a major impact on a drug's half-life. Since superfluous substances are excreted in bile and urine to a varying extent, especial care has to be taken in the application of drugs in patient suffering from liver or kidney disease. A number of commonly administered opioids, such as morphine, hydrocodone, or oxycodone, have higher bioavailability in patients with liver cirrhosis due to diminished metabolization. But while the effects of diminished CYP activity as well as that of other enzymes on opioid elimination and bioavailability have been extensively studied, the effects of diminished transporter activity have been less so. It is important to remember that non-membrane permeable substances rely on transporter proteins to shuttle them into the cell before they can be honed towards elimination. A study by Namisaki et al. showed that the expression of OCT1, among other transporters, was diminished in patients with hepatocellular carcinoma; however, chemotherapeutics employed in the treatment of this type of tumor depend on OCT1-mediated uptake into liver cells to reach their target (Namisaki et al. 2014). These findings indicate that not only phases 1 and 2, but also phases 0 and 3 of biotransformation -transporter-mediated uptake of drugs into cells and excretion from them, respectively- may be impaired in liver disease. 


\subsubsection{Effects of opioids and their role in clinical application}

Opioids are mainly employed for their analgesic properties, though weaker opioids are also used as antitussives and anti-diarrheal agents. Despite a wide range of available non-opioid analgesics, opioids continue to be the mainstay of perioperative pain treatment (Brayfield 2014). Patients in chronic pain, such as cancer patients, also profit immensely from opioid therapy.

The importance of opioids is also reflected in the rise in global opioid consumption. Between 1989 and 2009 the consumption of morphine has risen sevenfold, that of oxycodone 26fold, and that of fentanyl 100-fold (International Narcotics Control Board 2011). This trend is mainly observed for countries with high gross domestic income, but as the fields of pain medicine and palliative care advance and more people in so-called developing countries gain better access to adequate treatment of (chronic) pain, it can be expected that the global consumption of opioids will continue to rise.

Aside from the desired analgesic properties, opioids elicit a wide array of effects. Where opioids act upon the periphery, these effects take the shape of constipation, xerostomia (dry mouth), reduced libido, urinary retention, and pruritus (itching), while central nervous manifestations include sedation, respiratory depression, euphoria, dysphoria, and myoclonus. In general, opioids are consumed in two manners: either sporadically, such as in a perioperative setting, or chronically, such as in protracted pain states. It is important to distinguish these two groups, since opioid-native patients will react more sensitively to even small doses of opioid, while patients accustomed to opioids will require higher doses and be more resilient towards certain side effects (e.g. respiratory depression).

When consumed on a regular basis, opioids cause gastrointestinal side effects. These side effects -often summarized as opioid-induced constipation, or opioid-induced bowel dysfunction (OIBD) - are the most pertinent to a patient's immediate well-being since they cause the greatest discomfort (Leppert 2015). Laxatives, such as lactulose or senna, are firstline therapies, but they can be supplemented with opioid receptor antagonists such as methylnaltrexone or alvimopan, both of whose effects are limited to the periphery since they cannot cross the brain-blood barrier (Davis 2009b). Nausea and vomiting are further common side effects when patients are started on opioids, but tolerance develops quickly, as it does in respiratory depression (Davis 2009b). Xerostomina (dry mouth) is caused by the anticholinergic effects of some opioids, especially morphine. 
The most dreaded side effect of opioid therapy is respiratory depression. Depression of the respiratory center is dose-dependent, which is why opioids with high potency, such as sufentanil, are only titrated under closely monitored conditions, e.g. during general anesthesia. Accidental opioid overdosing that leads to respiratory depression can also happen when the opioid in question is insufficiently cleared from the bloodstream, such as in acute kidney injury (Conway et al. 2006). Although nociceptive stimuli counteract respiratory depression by increasing respiratory rate, respiratory depression continues to be a serious problem in patients who are either very old or very young, opioid-naïve, or already suffering from respiratory impairment (Davis 2009b). In this context, knowledge of genetic variations in the metabolic pathway of opioids can be helpful in averting a potentially life-threatening accumulation of opioids.

Addiction is another major adverse effect to bear in mind when administering opioids. The term "addiction" describes a chronic disease with a strong psychological component and detrimental socioeconomic consequences for affected individuals (in contrast to "tolerance" and "dependence", which describe physical adaptation to drug consumption) (ASAM 2001; Rosenblum et al. 2008). In 2013, 37\% of the 44,000 drug-related deaths in the US were attributed to prescription opioids, an additional 19\% to heroin (Volkow and McLellan 2016). While substance abuse in cancer patients under chronic opioid medication with no prior history of drug abuse is rare, and addiction is not known to develop in patients who receive opioids for a short time as part of their peri-operative analgesic treatment, the prevalence of opioid addiction and dependence among patients on (recklessly prescribed) long-term opioid therapy is high (Kirsh et al. 2009; Volkow and McLellan 2016).

\subsubsection{Role of OCT1 in opioid metabolism}

All the effects mentioned above -the desirable as well as the undesirable- depend on the bioavailability of opioids. Pharmacists and physicians have begun to recognize that bioavailability is influenced not only by route of application and co-medication, but also by genetics. The ideal dose of medication may differ significantly between individuals, or even within an individual, depending on whether they receive additional medication or supplements that interfere with signaling cascades and drug metabolism.

Since the vast majority of opioids are weak bases, which are protonated and carry a charge at physiological $\mathrm{pH}$, the OCT family of organic cation transporters have come to attention as likely mediators of phase 0 biotransformation in opioid metabolism. For instance, Tzvetkov et al. demonstrated that the uptake of morphine is affected by polymorphisms in 
the OCT1 gene. Loss-of-function phenotypes resulted in elevated plasma concentrations of morphine in affected patients, which improved analgesia but also increased the risk of accidental overdosing (Fukuda et al. 2013; Tzvetkov et al. 2013).

Another opioid whose plasma concentration is elevated in the presence of loss-of-function OCT1 genotypes is O-desmethyltramadol, the active metabolite of tramadol (Tzvetkov et al. 2011). The effect is so marked that, in a clinical study, patients with either one or two lossof-function OCT1 alleles consumed less tramadol after surgery than patients with two wild types OCT1 alleles (Stamer et al. 2016).

Thus, OCT1 has been shown to affect plasma concentrations of both a classic and a synthetic opioid to a clinically significant degree.

\subsection{Human organic cation transporter 1 (OCT1)}

Everything we ingest -food, fluid, pharmaceuticals- has to be transported across the barrier of the gastrointestinal tract into our bloodstream. Even when administered intravenously or epidurally, many compounds will only be effective once they arrive inside our cells.

These transitions -from outside the body to within, and from extracellular to intracellularare mediated by two mechanisms: diffusion and transport. While for a long time drugmetabolizing enzymes were the sole focus of pharmacogenomic research, attention has shifted over the past decade to membrane transporters (Yee et al. 2010). The role of membrane transporters on tissue and plasma concentrations of certain drugs is now widely recognized, and current and future research is expected to provide a better understanding of interactions between membrane transporters, drug-metabolizing enzymes, and their genes (Giacomini et al. 2010; Yee et al. 2010). The human organic cation transporter 1 (OCT1) is only one of the transporter in the spotlight of current research.

\subsubsection{OCT1 gene (SLC22A1)}

The human organic cation transporter 1 (OCT1, occasionally hOCT1 to better distinguish it from rat and mouse Oct1) is a transporter primarily expressed in the sinusoidal membranes of the liver, where it facilitates diffusion of polyspecific cations from the bloodstream into the liver cells (Grundemann et al. 1994; Zhang et al. 1997). It is a member of the solute carrier family of transport proteins, which belong to the major facilitator superfamily (Koepsell 2011; Pelis and Wright 2014). The gene encoding for OCT1, SLC22A1, is located on the long arm of chromosome 6 (6q25.3), and its corresponding mRNA comprises an 
open reading frame of $1662 \mathrm{bp}$, encoding a protein 554 amino acids in length (Gene: SLC22A1 ; Zhang et al. 1997). Apart from in the liver, OCT1 is weakly expressed in the kidneys and intestine, and OCT1 mRNA has been detected in the adrenal gland and lung (Nies et al. 2009; Tzvetkov et al. 2009). There is also some evidence that OCT1 expressed in the endothelial cells of brain vessels mediates the passage of drugs across the blood-brain barrier (Dickens et al. 2012).

\subsubsection{Structure of OCT1}

OCT1 is believed to be made up of twelve transmembrane helices (TMH) connected by intracellular and extracellular loops (Grundemann et al. 1994; Zhang et al. 1997; Keller et al. 2011). As the crystal structure of OCT1 has yet to be obtained, considerations as to OCT1's structure rely mostly on models fashioned after LacY (lactose permease), a bacterial transporter that also belongs to the major facilitator superfamily (Pelis and Wright 2014). Site-directed mutagenesis is another tool that has helped to elucidate the structure of the binding regions (Popp et al. 2005; Gorbunov et al. 2008). According to these models, OCT1 contains two large loops: one located between TMH 1 and 2 on the extracellular side, and one between TMH 6 and 7 on the intracellular side (Keller et al. 2011). The extracellular loop does not directly participate in substrate translocation, but mutations within the loop of rOct1 lead to a decrease in plasma membrane translocation of rOct1 (Keller et al. 2011). This observation is supported by findings from Seitz et al, who showed that six polymorphisms of OCT1, two of which were located in the extracellular loop, led to a retention of transporter within the endoplasmic reticulum (Seitz et al. 2015). The intracellular loop contains four potential phosphorylation sites; a fifth is at the C-terminal domain, which, like the $\mathrm{N}$ terminus, is located on the intracellular side (Zhang et al. 1997). A study by Ciarimboli et al proposes that OCT1 activity is inhibited by PKA-mediated phosphorylation and stimulated by $\mathrm{Ca} 2+/$ Calmodulin, Ca2+/Calmodulin-dependent CamKII, and p56lck tyrosine kinase (Ciarimboli et al. 2004).

Binding of a substrate to OCT1 induces a conformational change that displaces the bound substrate from extracellular to intracellular (or vice versa). rOct1 has three putative binding sites: one with a high, the other two with a low substrate affinity (Koepsell 2011). It has been hypothesized that substrate binding to the high affinity site may allosterically impact the low affinity sites and alter their transport capacities (Gorbunov et al. 2008). The proposed mechanism is one of many that would explain why some molecules act as inhibitors of OCT1 
without being transported, and why $\mathrm{IC}_{50}$ values vary depending on the concentration of the inhibited agent (Gorbunov et al. 2008).

In order to shuttle a substrate from one side of the cell to the other, be it by passive or active transport, the transport protein has to undergo a number of conformational changes: open outward-facing, occluded, and open inward-facing (Gouaux 2009). This model applies to OCT1, where conformational changes are induced by substrate binding, in contrast e.g. to voltage-gated Na-channels, where conformation is determined by membrane potential (Egenberger et al. 2012). Due to its penchant for (positively) charged molecules, the transport processes mediated by OCT1 are electrogenic, and it has been proposed that membrane potential influences the equilibrium between the open outward-facing and the open inwardfacing conformation (Busch et al. 1996b; Koepsell 2011).

\subsubsection{Substrates and inhibitors of OCT1}

To date, a number of compounds with diverse chemical structures have been identified as substrates of OCT1 (see Figure 1), among them morphine, O-desmethyltramadol, odansetron, sumatriptan, amisulpride, tiatropium, and amiloride (Tzvetkov et al. 2011; Tzvetkov et al. 2012; Hendrickx et al. 2013; Matthaei et al. 2016; Chen et al. 2017). Putative endogenous substrates include monoamines, such as the neurotransmitters serotonin, norepinephrine, dopamine, acetylcholine, and histamine, as well as thiamine (vitamin B1) (Busch et al. 1996a; Boxberger et al. 2014; Chen et al. 2014). MPP (1-methyl-4phenylpyridinium), TEA (tetraethylammonium), and $\mathrm{ASP}^{+}$(4-(4-(dimethylamino)styryl)-Nmethylpyridinium iodide) are established model substrates for OCT1 in research (Busch et al. 1996b; Gorboulev et al. 1997; Schlatter et al. 2002; Ahlin et al. 2008). 
<smiles>CN(C)CC1CCCCC1(O)c1cccc(O)c1</smiles>

O-desmethyltramadol<smiles>CCN1CCCC1CNC(=O)c1cc(S(=O)(=O)CC)c(N)cc1OC</smiles>

Amisulpride<smiles>NCCc1c[nH]c2ccc(O)cc12</smiles>

Serotonin

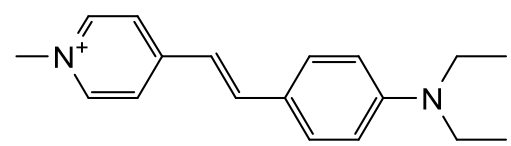

$\mathrm{ASP}^{+}$<smiles>N=C(N)NC(=O)c1nc(Cl)c(N)nc1N</smiles>

Amiloride

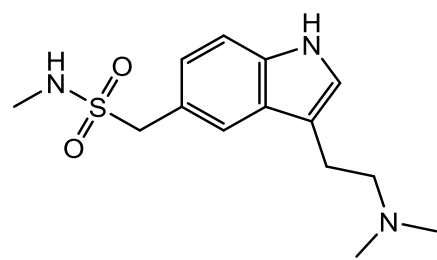

Sumatriptan

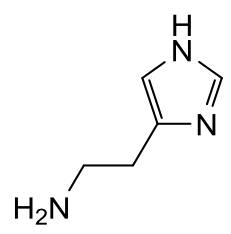

Histamine

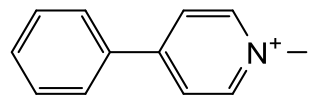

MPP

Figure 1: Chemical structures of selected substrates of OCT1

Despite their diversity, the substances intersect in at least four respects, as demonstrated by the example of morphine (see Figure 2). The first is charge. Although OCT1 does not exclusively transport molecules that are positively charged, most of its substrates do have a basic nature. The second is that they contain nitrogen, which may be quaternary at physiological $\mathrm{pH}$; methylation can further stabilize the resulting positive charge at the nitrogen atom (as in $\mathrm{N}$-methylated tilidine and unmethylated nortilidine). A third property is a cyclic structure or aromatic ring, which is integral to the substrate's structure. Finally, OCT1 substrates tend to exhibit low lipophilicity. Low lipophilicity in a compound, e.g. in the form 
of hydroxyl groups, increase the likelihood that it cannot diffuse through cell membranes, thus having to rely on transporter proteins to ferry it across. However, data suggest that a certain degree of lipophilicity is necessary to enable substrate-transporter interaction, which is enhanced in the absence of hydrogen-bond donors (Ahlin et al. 2008). In addition, a study by Hendrickx et al. concluded that molecular volume was an important characteristic of OCT1 substrates, with increased volumes diminishing the likelihood that a given substances is a substrate of OCT1 (Hendrickx et al. 2013).

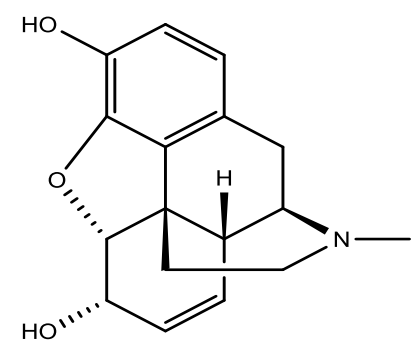

Figure 2: Chemical structure of morphine.

Morphine illustrates some of the features typical of an OCT1 substrate: a methylated nitrogen atom, which, at physiological $\mathrm{pH}$, will carry a positive charge; five cyclic rings that enhance lipophilicity, one of which is aromatic; and two polar hydroxyl groups.

On the other hand, various compounds inhibit OCT1 without being transported by it. Ahlin et al. concluded that the four most important features for an OCT1 inhibitor are hydrophobicity, lipophilicity, positive charge, and an absence of hydrogen -bonding moieties (Ahlin et al. 2008). While it is not entirely possible to predict what substance will act upon OCT1 as substrate or inhibitor -or at all- there is some evidence that lipophilic substances tend to be inhibitors rather than substrates (Ahlin et al. 2008).

\subsubsection{Genetic variability of OCT1}

The OCT1 gene is highly genetically polymorphic. Seitz et al. reported 85 variants within the 2770bp long SLC22A1 gene locus; of those, 44 lay within the coding region, and 29 caused amino acid substitutions (Seitz et al. 2015). OCT1 polymorphisms leading to incorrect compartmentalization of the transporter resulted in a global loss of activity, indiscriminate of substrate, whereas loss-of-function variants inserted into the plasma membrane displayed substrate specific loss-of-function (Seitz et al. 2015).

Loss-of-function OCT1 polymorphisms in the general population vary globally among regions and ethnic groups. While the frequency of reduced or loss-of-function alleles is 
below $2 \%$ in Chinese and Japanese populations, $40 \%$ of Caucasians carry one allele and $9 \%$ carry two alleles with the most common loss-of-function polymorphisms (Chen et al. 2010; Seitz et al. 2015).

\subsubsection{OCT1 and pharmacogenetics research}

Given the plethora of transporters so far identified (more than 15,000 transport protein sequences in over 1,200 families as of December 2017 (Transporter Classification Database)), what distinguishes OCT1 and makes it an especially interesting target for medical research?

First of all, OCT1 is mainly located in the sinusoidal membrane of hepatocytes (Gorboulev et al. 1997; Zhang et al. 1997). The liver is the body's powerhouse of metabolism; detoxification and elimination of both endogenous and exogenous compounds occur primarily here. This process, dubbed biotransformation, ultimately leads to the deactivation and elimination of xenobiotics. As gatekeeper to the intracellular metabolic machinery of the hepatocytes, OCT1 is part of phase 0 biotransformation. However, in some cases, instead of rendering xenobiotics ineffective, CYP-mediated modifications can also lead to their activation, as is the case with prodrugs tilidine and codeine, whose metabolites nortilidine and morphine, respectively, elicit the clinical effects associated with their parent compounds. Occasionally, activation also results in toxification, as with pethidine or acetaminophen, causing a potentially harmful accumulation of toxic metabolites in vulnerable patient groups, such as patients suffering from impaired renal clearance (Ramirez et al. 2004; Laine et al. 2009). Slightly overstated, it can be said that transport of many drugs into the liver cells, where they are deactivated (their effects on the body thus being terminated) or activated (thus becoming effective) would be diminished without OCT1.

Secondly, OCT1's high genetic variability has been shown to impact OCT1's transport capacities to a degree that is clinically significant. Diminished uptake in loss-of-function OCT1 polymorphisms has been shown for morphine, tramadol, and sumatriptan, effectively causing an increase in their bioavailability and half-life (Tzvetkov et al. 2012; Tzvetkov et al. 2013; Matthaei et al. 2016). Considering that a great number of drugs fulfill the formal criteria for OCT1 substrates and inhibitors, it would be of both use and interest for clinicians to know which drugs interact with OCT1, and whether their pharmacokinetic properties are altered in other-than wild type OCT1 variants.

Thirdly, the current list of substrates and inhibitors of OCT1 comprises substances that are staple drugs in clinical practice. Xenobiotics transported by OCT1 include morphine, O- 
desmethyltramadol, odansetron, tropisertron, and sumatriptan, to name only a few (Tzvetkov et al. 2011; Tzvetkov et al. 2012). Endogenous substrates of OCT1, on the other hand, remain elusive; so far only monoamines and vitamin B1 have been identified (Busch et al. 1996a; Chen et al. 2014). It seems, therefore, as if OCT1's primary role is to shuttle exogenous substrates into the liver for deactivation and detoxification.

For these reasons, OCT1 is a variable in drug metabolism worthy of attention. Knowing which opioids are impacted by OCT1 polymorphisms -and which opioids in turn impact its transport capacities- could help clinicians make better informed choices concerning the administration of opioids, their dosage, and co-medication.

\subsection{Aim}

The aim of this work was to perform a systematic screening of opioids in order to identify substrates and inhibitors of OCT1 beyond the previously identified morphine and Odesmethyltramadol. Screening for individual compounds as substrates and inhibitors of OCT1 was performed in four steps:

- in silicio predictions of the compounds' basic properties and lipophilicity

- experimental determination of their passive membrane permeability using parallel artificial membrane permeability assays (PAMPAs)

- determination of their inhibitory potential on OCT1

- determination of their uptake by OCT1

The in silicio predictions helped us in the initial selection process by identifying opioids with low or even negative $\log \mathrm{D}_{(7.4)}$ values, which indicate limited lipophilicity. The premise was that substances with low membrane permeability are more likely to require transporters to penetrate biological membranes than lipophilic substances. The PAMPAs that followed experimentally validated the substances' membrane permeability in an artificial, well-defined but cell-free model. The degree to which substances did or did not interact with OCT1 was evaluated with the help of the inhibition experiments, while the direct transport measurements identified those substances that interacted with OCT1 as substrates (as opposed to mere inhibitors). 


\section{$2 \quad$ Materials and Methods}

\section{$2.1 \quad$ Materials}

\subsubsection{Chemicals}

\begin{tabular}{l|l} 
Chemicals & Manufacturer \\
\hline ASP $^{+}$ & Invitrogen, Darmstadt, Germany \\
\hline Bicinchoninic Acid Solution & Sigma-Aldrich, Steinheim, Germany \\
\hline Copper sulfate solution & Sigma-Aldrich, Steinheim, Germany \\
\hline EDTA 0.5 M solution & AppliChem, Darmstadt, Germany \\
\hline Fecal Calf Serum (FCS) & Gibco Life Technologies, Darmstadt, Germany \\
\hline Formic acid & Merck-Schuchard, Hohenbrunn, Germany \\
\hline HBSS $^{+}$ & Gibco Life Technologies, Darmstadt, Germany \\
\hline Helipur ${ }^{\circledR}$ H plus N & B.Braun Medical AG, Sempach, Switzerland \\
\hline Medium & Gibco Life Technologies, Darmstadt, Germany \\
\hline Methanol LCMS grade & LCG Standards GmbH, Wesel, Germany \\
\hline MPP & Sigma-Aldrich, Steinheim, Germany \\
\hline NaCl & Merck, Darmstadt, Germany \\
\hline Na-deoxycholate & Sigma-Aldrich, Steinheim, Germany \\
\hline Nonidet®P40 Substitute & \\
(Nonylphenylethylenglycol) & Fluka (Sigma), Germany \\
\hline PBS buffer & AppliChem, Darmstadt, Germany \\
\hline Penicillin and Streptomycin (P/S) & Gibco Life Technologies, Darmstadt, Germany \\
\hline Poly-D-lysine bromide & Sigma-Aldrich, Steinheim, Germany \\
\hline PromoChem Acetonitrile Optigrade & LCG Standards GmbH, Wesel, Germany \\
\hline Sodium dodecyl sulfate (SDS) & BioRad, Hercules, USA \\
\hline Tris-HCl & Roth, Karlsruhe, Germany \\
\hline TrypLE & Gibco Life Technologies, Darmstadt, Germany \\
\hline Tryptane Blue & Sigma-Aldrich, Steinheim, Germany \\
\hline Water LCMS grade & LCG Standards GmbH, Wesel, Germany \\
\hline
\end{tabular}

\subsubsection{Drugs}

\begin{tabular}{l|l}
\hline Drugs & Manufacturer \\
\hline 3-Methoxymorphinan hydrochloride & Sigma-Aldrich, Steinheim, Germany \\
\hline 3-Hydroxymorphinan hydrobromide & Sigma-Aldrich, Steinheim, Germany \\
\hline Codeine & Sigma-Aldrich, Steinheim, Germany \\
\hline Dextromethorphan solution & Sigma-Aldrich, Steinheim, Germany \\
\hline Dextrorphan tartrate & Sigma-Aldrich, Steinheim, Germany \\
\hline Fentanyl solution & Sigma-Aldrich, Steinheim, Germany \\
\hline Hydrocodone bitartrate & Sigma-Aldrich, Steinheim, Germany \\
\hline Hydromorphone & Sigma-Aldrich, Steinheim, Germany \\
\hline Meptazinol hydrochloride & Sigma-Aldrich, Steinheim, Germany \\
\hline Methylnaltrexone bromide & Sigma-Aldrich, Steinheim, Germany \\
\hline
\end{tabular}




\begin{tabular}{l|l}
\hline Morphine & Sigma-Aldrich, Steinheim, Germany \\
\hline Naltrexone solution & Sigma-Aldrich, Steinheim, Germany \\
\hline $\begin{array}{l}\text { N-Desmethyl-cis-tramadol } \\
\text { hydrochloride solution }\end{array}$ & Sigma-Aldrich, Steinheim, Germany \\
\hline Norfentanyl oxalate solution & Sigma-Aldrich, Steinheim, Germany \\
\hline Noroxycodone hydrochloride solution & Sigma-Aldrich, Steinheim, Germany \\
\hline Nortilidine hydrochloride solution & Sigma-Aldrich, Steinheim, Germany \\
\hline Oxycodone & Sigma-Aldrich, Steinheim, Germany \\
\hline Oxymorphone (solution) & Sigma-Aldrich, Steinheim, Germany \\
\hline Pethidine (Meperidine) hydrochloride & Sigma-Aldrich, Steinheim, Germany \\
\hline Piritramide & Janssen-Cilag GmbH, Neuss, Germany \\
\hline Sufentanil citrate & LGS Standards, Wesel, Germany \\
\hline Tapentadol & Sigma-Aldrich, Steinheim, Germany \\
\hline Tilidine hydrochloride & Sigma-Aldrich, Steinheim, Germany
\end{tabular}

\subsubsection{Cell lines}

\begin{tabular}{l|l} 
Cell lines & Generated by \\
\hline HEK 293 hOCT1 & Ali Reeza Saadatmand \\
\hline HEK 293 pcDNA5 & Ali Reeza Saadatmand
\end{tabular}

\subsubsection{Consumables}

\section{Equipment}

96-well plate, clear

96-well PCR plate

Adhesive Sealing Sheets

Cakes and cookies

Cell culture flasks, $75 \mathrm{~cm}^{2}$

Centrifuge tubes, $15 \mathrm{ml}$

Centrifuge tubes, $50 \mathrm{ml}$

Discardit II ${ }^{\mathrm{TM}} 20 \mathrm{ml}$ syringe

Disposable gloves

Flat cap strips, 8

Ethanol $99 \%$ (methylated), diluted

with ddH2O to $70 \%$

Filtered tips, $200 \mu \mathrm{l}$

Glass pasteur pipet, $230 \mathrm{mM}$

Glass Vial Micro-Insert $0.05 \mathrm{ml}$

Minisart ${ }^{\circledR}$ plus Syringe Filters

Narrow tips, $100 \mu \mathrm{l}$

NunclonTM Delta Surface, 12-well plates

Parafilm ${ }^{\circledR}$

Pre-coated PAMPA Plate System

\section{Manufacturer}

Sigma-Aldrich, Nümbrecht, Germany

Thermo Scientific, Loughborough, UK

Thermo Fisher Scientific, Darmstadt, Germany

Tina, Marleen, Mladen, Karo, Ellen, Helen, Jiayin

Sarstedt, Nümbrecht, Germany

Sarstedt, Nümbrecht, Germany

Sarstedt, Nümbrecht, Germany

BD Biosciences, Heidelberg, Germany

Rösner-Mautby Meditrade Holding GmbH, Kiefersfelden, Germany

Thermo Fisher Scientific, Darmstadt, Germany

Walter CMP GmbH, Ratingen, Germany

Kisker, Steinfurt, Germany

Brand, Wertheim, Germany

Th. Geyer, Renningen, Germany

Sartorius, Göttingen, Germany

Sarstedt, Nümbrecht, Germany

ThermoScientific, Roskilde, Denmark

Brand, Wertheim, Germany

Corning, Bedford, MA, USA 


\begin{tabular}{l|l}
\hline Septum $8 \mathrm{mM}$ PTFE virginal & VWR International GmbH, Darmstadt, Germany \\
\hline Serological pipet, $5 \mathrm{ml}$ & Sarstedt, Nümbrecht, Germany \\
\hline Serological pipet, $10 \mathrm{ml}$ & Sarstedt, Nümbrecht, Germany \\
\hline Serological pipet, $25 \mathrm{ml}$ & Sarsted, Nümbrecht, Germany \\
\hline Test tubes, $1.5 \mathrm{ml}$ & Sarsted, Nümbrecht, Germany \\
\hline Test tubes, $2.0 \mathrm{ml}$ & Sarstedt, Nümbrecht, Germany \\
\hline Test tubes, $5.0 \mathrm{ml}$ & Sarstedt, Nümbrecht, Germany \\
\hline Tips, $10 \mu \mathrm{l}$ & Sarstedt, Nümbrecht, Germany \\
\hline Tips, $1000 \mu \mathrm{l}$ & Sarsted, Nümbrecht, Germany \\
\hline Tips, $200 \mu \mathrm{l}$ & Sarstedt, Nümbrecht, Germany
\end{tabular}

\subsubsection{Reusable equipment}

\begin{tabular}{l|l} 
Equipment & Manufacturer \\
\hline 96-well plate, black with clear bottom & Corning Incorporated, Corning, USA \\
\hline Cover slip & Schütt, Göttingen, Germany \\
\hline Neubauer Cell Counting Chamber & Schütt, Göttingen, Germany \\
\hline Screw neck vials for autosampler & VWR International GmbH, Darmstadt, Germany \\
\hline Screw tops without septa for vials & VWR International GmbH, Darmstadt, Germany \\
\hline Spring for Micro Insert $0.05 \mathrm{ml}$ & VWR International GmbH, Darmstadt, Germany \\
\hline
\end{tabular}

\subsubsection{Instruments}

\begin{tabular}{l|l}
\hline Instruments & Manufacturer \\
\hline Analytical balance & Sartorius, Göttingen, Germany \\
\hline API4000 LC-MS/MS system & AB Sciex, Darmstadt, Germany \\
\hline $\begin{array}{l}\text { Arium }{ }^{\circledR} \text { pro VF Ultrapure Water } \\
\text { System }\end{array}$ & Sartorius, Göttingen, Germany \\
\hline Axiovert 40 CFL microscope & Carl Zeiss Microscopy GmbH, Göttingen, Germany \\
\hline Centrifuge 5810R & Eppendorf, Hamburg, Germany \\
\hline CO $_{2}$ Incubator BBD 6220 & ThermoFischer Scientific, Osterode, Germany \\
\hline Ecovac safety vacuum system & Schuett-biotec GmbH, Göttingen, Germany \\
\hline Fridges and freezers & Liebherr, Biberach an der Riß, Germany \\
\hline Heraeus Biofuge Pico & ThermoFischer Scientific, Osterode, Germany \\
\hline Heraeus Multifuge X3R & ThermoFischer Scientific, Osterode, Germany \\
\hline Magnetic stirrer & 2mag, Munich, Germany \\
\hline MS2 Minishaker & W.Krannich GmbH, Göttingen, Germany \\
\hline Polymax 1040 Platform Shaker & Heidolph Instruments GmbH, Schwabach, Germany \\
\hline Sample Concentrator & Techne, Stone, UK \\
\hline $\begin{array}{l}\text { Stretching Table OTS40,150 x } 400 \mathrm{x} \\
80 \text { mm (W/D/H) }\end{array}$ & Medite, Burgdorf, Germany \\
\hline Tecan Ultra microplate reader & Tecan, Crailsheim, Germany \\
\hline Thermomixer 5436 & Eppendorf, Hamburg, Germany \\
\hline Waterbath GFL 1083 & Schuett-biotec GmbH, Göttingen, Germany \\
\hline
\end{tabular}




\subsubsection{Software}

\section{Software Manufacturer}

\begin{tabular}{l|l}
\hline ADMET Predictor & Simulations Plus Inc., Lancaster, USA \\
\hline Analyst ${ }^{\circledR}$ Version 1.4.2 & Applied Biosystems, Darmstadt, Germany \\
\hline ChemBioDraw Ultra 14.0.0.117 & PerkinElmer Inc. \\
\hline EndNote X7.3.1 & Thomson Reuters, Philadelphia PA, USA \\
\hline $\begin{array}{l}\text { GIMP Image Editor 2.8 (GNU } \\
\text { Image Manipulation Program) }\end{array}$ & $\begin{array}{l}\text { Spencer Kimball, Peter Mattis and the GIMP } \\
\text { Development Team }\end{array}$ \\
\hline GraphPad Prism 5 & GraphPad Software Inc. \\
\hline Microsoft Excel 2013 & Microsoft Corporation, Redmond, WA, USA \\
\hline Microsoft Word 2013 & Microsoft Corporation, Redmond, WA, USA \\
\hline SigmaPlot 12.0 & Systat Software Inc., Erkrath, Germany \\
\hline XFluor4 Software & Tecan, Crailsheim, Germnay
\end{tabular}




\subsection{Methods}

\subsubsection{Cell culture}

The cells were kept in $75 \mathrm{~cm}^{2}$ cell culture flasks with Dulbecco's Modified Eagle Medium (DMEM), which was supplemented with $10 \%$ fecal calf serum (FCS) and $1 \%$ penicillin/streptomycin mix (P/S) (hereafter referred to as "medium"). The flasks were cultivated in an incubator at $37{ }^{\circ} \mathrm{C}$ and $5 \% \mathrm{CO}_{2}$. Depending on cell growth and plating frequency, the cells were split every 2-5 days. Passages between 4 and 31 were used for plating.

\subsubsection{Plating}

The cells were grown on 12-well plates. To enhance cell adhesion, the wells were coated with poly-D-lysine by adding $0.5 \mu \mathrm{l}$ of poly-D-lysine solution to each well and incubating the plate in a cell culture incubator at $37^{\circ} \mathrm{C}$ for $15 \mathrm{~min}$. The superfluous poly-D-lysine was then removed from the wells and stored at $4{ }^{\circ} \mathrm{C}$ for reuse.

Poly-D-lysine solution was prepared by mixing $100 \mathrm{mg}$ of D-lysine with $50 \mathrm{ml}$ of $\mathrm{ddH}_{2} \mathrm{O}$. This solution was filtered through a syringe with a filter tip before use.

For plating, the medium was removed from the cell culture flask and $3.5 \mathrm{ml}$ of trypsine added to the flask. The flask was then incubated in the cell culture incubator at $37^{\circ} \mathrm{C}$ for $4 \mathrm{~min}$. during which time the trypsine dissolved the extracellular matrix that bonded the cells together into a biofilm. As soon as the time was up, the flask was removed from the incubator and $10 \mathrm{ml}$ of medium were added to terminate the trypsine reaction. The cells were then ablated from the bottom of the flask, transferred into a falcon tube, and the tube centrifuged for $3 \mathrm{~min}$. at $700 \mathrm{xg}$. The medium was then removed from the tube and the cell pellet at the bottom of the tube resuspended in $10 \mathrm{ml}$ of fresh medium. Of this cell suspension, $20 \mu \mathrm{l}$ was added to a test tube and mixed with $20 \mu \mathrm{l}$ of trypthane blue. A sample of the dyed cell solution was pipetted onto a cell counting chamber and the cells counted under a light microscope. The sum of the cells from the four fields of the counting chamber was divided by two and multiplied with $10^{4}$ to yield the total number of cells per milliliter. The cell solution was then diluted with medium to meet the concentration of cells required, i.e. $6 \times 10^{5}$ cells per well. Of this final cell solution, $1 \mathrm{ml}$ was added to each well.

For the inhibition experiments, three wells of a 12 -well plate were plated with pcDNA5 cells and nine wells with OCT1-overexpressing cells. For the transport experiment four wells of 
a 12-well plate were plated with pcDNA5 cells and eight wells with OCT1-overexpressing cells.

\subsubsection{In silicio predictions}

Initially, we compiled a list of 60 opioids and opioid congeners by reviewing pharmacological and medical textbooks, and by browsing PubMed and Wikipedia. Especially those opioids and their congeners were considered of interest that are either well established in clinical practice and widely used, or else belong to newer, emerging classes of opioids, whose pharmacological interactions have yet to be elucidated.

On the basis of the substances' chemical structure, which were obtained from PubChem (The PubChem Project), three values were predicted with ADMET Predictor Software: the dissociation constant $\mathrm{pKa}$; the partition coefficient $\log \mathrm{P}$ (the $\log$ of the ratio of unionized compounds in a lipophilic and a hydrophilic phase); and the distribution coefficient $\log \mathrm{D}_{(7.4)}$ (log of the ration of the sum of both unionized and ionized compound in a lipophilic and a hydrophilic phase). The $\log \mathrm{D}_{(7.4)}$ values were of greatest interest to us as they best reflect lipophilicity under physiological conditions, which were also the conditions emulated in the inhibition and transport experiments.

\subsubsection{Parallel artificial membrane permeability assays (PAMPAs)}

Drug solutions of the 23 substances selected to undergo this experiment were prepared at three different concentrations each. They were prepared in phosphate buffered solution (PBS) to yield aliquots of $400 \mu \mathrm{l}$ with concentrations of $20 \mu \mathrm{M}, 100 \mu \mathrm{M}$, and $500 \mu \mathrm{M}$, except for codeine, fentanyl, and morphine, which were prepared at $10 \mu \mathrm{M}, 20 \mu \mathrm{M}$, and $50 \mu \mathrm{M}$.

Of these drug solutions, $300 \mu \mathrm{l}$ was added to the donor wells (lower plate) of the PAMPA plate. The remaining $100 \mu \mathrm{l}$ was set aside as C0 samples and their exact concentration determined via mass spectrography (MS) in order to adjust for inaccuracies that might have occurred during pipetting.

Once the donor wells had been prepared, $200 \mu \mathrm{l}$ of PBS was added to each well of the acceptor wells (upper plate). The upper plate was then carefully placed into the lower, trapping as little air between the membranes as possible, since bubbles impede diffusion between the two plates. The PAMPA plates were then set aside at room temperature $\left(21^{\circ} \mathrm{C}\right)$ and not disturbed for $5 \mathrm{~h}$.

After incubating for $5 \mathrm{~h}$, the PAMPA plates were separated and the lower plate set aside. Starting with the acceptor plate, $180 \mu$ l of solution from each well was transferred into a 
corresponding well on a standard 96-well PCR plate. Analogously, $180 \mu$ l of solution from the donor wells was transferred into corresponding wells on a second standard 96-well PCR plate. The samples from the acceptor plate were designated C5A (concentration after $5 \mathrm{~h}$, acceptor plate), those of the donor plate C5D (concentration after $5 \mathrm{~h}$, donor plate).

Before MS measurements, the samples from C0 and C5D were diluted 1:10,000 in $0.1 \%$ formic acid. The samples from C5A were initially measured undiluted, but as their concentrations exceeded the detection capacities of the mass spectrometer, the samples were likewise diluted in $0.1 \%$ formic acid, either 1:100 or 1:10,000 depending on how strong the initial signal detected by the mass spectrometer was. The different dilution ratios were later taken into account when the results of the MS measurements for C0, C5A, and C5D were converted into $\mathrm{mM}$ (millimolar) for calculation.

Permeability and mass retention were calculated according to the formula provided by the producer of the PAMPA plates.

$\underline{\text { Recommended formula for data analysis provided by the producer }}$

$$
P e=\frac{-\ln \left(1-\frac{C A(t)}{C \text { equilibrium }}\right)}{A \times\left(\frac{1}{V D}+\frac{1}{V A}\right) \times t}
$$

$\mathrm{C}_{0} \quad=$ initial compound concentration in donor well in $[\mathrm{mM}]$

$\mathrm{C}_{\mathrm{D}}(\mathrm{t}) \quad=$ compound concentration in donor well at time $\mathrm{t}$ in $[\mathrm{mM}]$

$\mathrm{C}_{\mathrm{A}}(\mathrm{t})=$ compound concentration in acceptor well at time $\mathrm{t}$ in $[\mathrm{mM}]$

$\mathrm{V}_{\mathrm{D}} \quad=$ donor well volume

$\mathrm{V}_{\mathrm{A}} \quad=$ acceptor well volume

$\mathrm{C}_{\text {equilibrium }}=\frac{(C D(t) \times V D+C A(t) \times V A)}{(V D+V A)}$

A $\quad=$ filter area $\left(0.3 \mathrm{~cm}^{2}\right)$

$\mathrm{t} \quad=$ incubation time in $\mathrm{s}(5 \mathrm{~h}=18,000 \mathrm{~s})$

\subsubsection{Inhibition experiments}

The $\mathrm{IC}_{50} \mathrm{~S}$ of the substrates were determined with 4-(4-(dimethylamino)styryl)-Nmethylpyridinium iodine $\left(\mathrm{ASP}^{+}\right)$. A fluorescent molecule that can be easily quantified by photometer measurements, $\mathrm{ASP}^{+}$is also an established substrate of OCT1. As such, its uptake depends on OCT1's transport capacities, which will be diminished in the presence of an inhibitor or that of a competing substrate. The competing substances (hereafter referred to as "test drug") were the 23 opioids selected for testing. 
$\mathrm{ASP}^{+}$uptake was measured at eight different concentrations of test drug, including a concentration of zero, which served as the baseline of $\mathrm{ASP}^{+}$uptake by OCT1 and pcDNA5 cells. Drug concentrations of 1, 5,10,50,100, 500, and $1000 \mu$ l were obtained through serial dilution of a stock solution with high molar mass. Oxycodone was measured at higher concentrations of $0,10,50,100,500,1000,2000,5000 \mu \mathrm{l}$ after initial measurements at lower concentrations yielded inconclusive results. All samples were diluted with Hank's Balanced Salt Solution $\left(\mathrm{HBSS}^{+}\right.$) and prepared at twice the target concentration, so that when the test drug solution was mixed with an equal amount of $\mathrm{ASP}^{+}$solution shortly before the experiment the final solution yielded the concentrations desired for testing.

$\mathrm{ASP}^{+}$solution was prepared from a $10 \mathrm{mM}$ stock solution with $\mathrm{HBSS}^{+}$as diluent. As with the inhibitor solutions, the solution was prepared at a concentration of $1 \mu \mathrm{M}$ and the target concentration of $0.5 \mu \mathrm{M}$ obtained when equal volumes of $1 \mu \mathrm{M} \mathrm{ASP}{ }^{+}$and test drug solution were mixed prior to the experiment.

The uptake measurements were performed under (human) physiological conditions. These conditions were met by adjusting the $\mathrm{HBSS}^{+}$buffer to fall within a $\mathrm{pH}$ range of 7.3- 7.5 and by warming it up to $37^{\circ} \mathrm{C}$ in a water bath prior to the experiments. Eppendorf tubes containing the $\mathrm{ASP}^{+}$-test drug solutions were also kept on a heating block at $37{ }^{\circ} \mathrm{C}$ until the solutions were added to the cells.

The cells were prepared for the experiment by discarding the old medium within the wells and washing them once with $2 \mathrm{ml}$ of pre-warmed $\mathrm{HBSS}^{+}$per well. This, too, was completely removed.

The experiment began with the addition of the $\mathrm{ASP}^{+}$-test drug solution to the wells. $400 \mu \mathrm{l}$ of $\mathrm{ASP}^{+}$-test drug solutions were added to the OCT1-containing wells, with $\mathrm{ASP}^{+}$at a concentration of $0.5 \mu \mathrm{M}$ and test drug at the aforementioned concentrations. Additionally, pure $0.5 \mu \mathrm{M} \mathrm{ASP}{ }^{+}$solution without test drug was added to two of the OCT1 wells and both of the pcDNA5 wells (see pipetting scheme, Figure 3). 


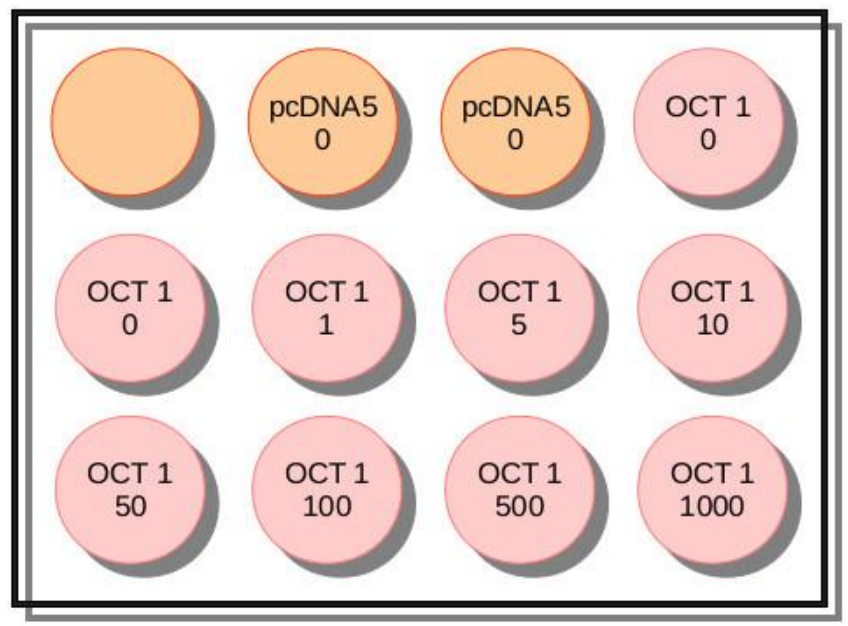

Figure 3: Plating and pipetting scheme for inhibition experiments, concentrations in $\mu \mathrm{M}$

The plates were kept at $37^{\circ} \mathrm{C}$ on a hot plate during the entire course of the experiment to allow for optimal uptake of $\mathrm{ASP}^{+}$and test drug under physiological conditions. After an incubation period of $2 \mathrm{~min}$, the reaction was stopped by adding $2 \mathrm{ml}$ of ice-cold $\mathrm{HBSS}^{+}$to each well. This was discarded, and the cells were washed two more times with ice-cold $\mathrm{HBSS}^{+}$.

The cell lysate required for fluorescence measurement was won by removing all vestiges of $\mathrm{HBSS}^{+}$buffer and lysing the cells with $0.5 \mu$ l of RIPA buffer per well.

\begin{tabular}{lr}
\multicolumn{2}{c}{ RIPA buffer } \\
\hline Tris-HCl & $50 \mathrm{mM}$ \\
\hline SDS & $0.1 \%$ \\
\hline NP-40 & $1 \%$ \\
\hline Na-deoxycholate & $0.25 \%$ \\
\hline $\mathrm{NaCl}$ & $150 \mathrm{mM}$ \\
\hline EDTA & $1 \mathrm{mM}$ \\
\hline
\end{tabular}

The plates were then placed on the Shaker for 10 min. to ensure complete lysis had taken place, followed by $10 \mathrm{~min}$. of centrifugation at $700 \mathrm{x}$. Centrifugation was not mandatory, but performed nonetheless because it helped to isolate the DNA and thereby facilitated pipetting. Cell lysate from each well, $200 \mu \mathrm{l}$ and $10 \mu \mathrm{l}$, were transferred to a 96-well black bottom for fluorescence measurements and to a standard 96-well plate for protein measurements, respectively. A standard of bovine serum albumin (BSA) of $0,1,3,5,10$, and $15 \mu \mathrm{l}$ was added in duplicate to the standard 96-well plate. $200 \mu \mathrm{l}$ of a bicinchoninic acid mastermix prepared from $200 \mu \mathrm{l}$ of bicinchoninic acid and $4 \mu \mathrm{l}$ of cupric sulfate solution was then added to each of the protein samples and the plate incubated at $37^{\circ} \mathrm{C}$ for $30 \mathrm{~min}$. 
Fluorescence of the cell lysate in the 96-well black bottom plate was measured by a Tecan Ultra Plate Photometer using XFluor4 Software.

\begin{tabular}{ll}
\multicolumn{2}{c}{ Measurement Parameters } \\
\hline Mode & Fluorescence \\
\hline Excitation wavelength & 486nm \\
\hline Emission wavelength & $615 \mathrm{~nm}$ \\
\hline Gain (Manual) & 50 \\
\hline Number of flashes & 10 \\
\hline Lag time & 0 \\
\hline Integration time & 40 \\
\hline Mirror selection & Dichronic 2 \\
\hline Z-position & Adjust manually \\
\hline
\end{tabular}

Protein measurements were performed analogously, with measurement mode "Absorbance" and an absorption wavelength of $570 \mathrm{~nm}$.

The relative fluorescent measurement unit ( $\mathrm{rfu}$ ) per milligram served as a relative scale that helped to quantify the amount of $\mathrm{ASP}^{+}$taken up in the presence of inhibitor at different concentrations. It was determined by calculating the average rfu from the two measurements performed for each sample and extrapolated to $500 \mu$ l, the initial amount of cell lysate. The amount of protein per well was calculated from the degree of absorption of the samples within the 96-well plate. These values were corrected through the BSA standard and converted to milligrams. The quotient of $\mathrm{rfu}$ and protein in milligram $(\mathrm{rfu} / \mathrm{mg})$ represented $\mathrm{ASP}^{+}$uptake and yielded absolute values, which were subsequently converted into relative values. The $\mathrm{IC}_{50}$ was calculated by equating the average amount of $\mathrm{ASP}^{+}$uptake by OCT1overexpressing cells in the wells without any inhibitor (i.e. non-inhibited $\mathrm{ASP}^{+}$uptake) minus the uptake by the pcDNA5 cells (i.e. the baseline uptake) with 1,0. The amount of $\mathrm{ASP}^{+}$ uptake at all other concentrations was set in relation to this baseline. Their values were expressed in percent of non-inhibited $\mathrm{ASP}^{+}$uptake and the percentages plotted as functions of their respective inhibitor concentration in a graph with SigmaPlot. The $\mathrm{IC}_{50} \mathrm{~s}$ of the tested substances were also calculated with SigmaPlot by plotting the percentages as functions of their respective inhibitor concentrations and fitting a nonlinear regression curve through the graph.

The $\mathrm{ASP}^{+}$uptake inhibition experiments were conducted at least thrice in independent experiments for each of the test drugs. 


\subsubsection{Transport experiments}

The transport experiments were performed with OCT1-overexpressing HEK293 cell and two negative controls: pcDNA5 cells and OCT1-overexpressing cells supplemented with $\mathrm{MPP}^{+}$, an inhibitor of OCT1.

Drug uptake was measured at three concentrations: $0.05,0.1$, and $0.5 \mu \mathrm{M}$. This was done once for pcDNA5 and twice for OCT1, one batch of which was supplemented with $2 \mathrm{mM}$ $\mathrm{MPP}^{+}$, a potent inhibitor of OCT1, and served as an additional negative control. The three remaining wells -one with pcDNA5 and two with OCT1- were reserved for protein measurements (see Figure 4).

Drug solutions were prepared at twice the desired concentration (i.e. 0.1, 0.2, and $1.0 \mu \mathrm{M}$ ) and the final concentrations obtained by adding an equal amount of either pure $\mathrm{HBSS}^{+}$or $\mathrm{HBSS}^{+}$spiked with $4 \mathrm{mM}$ of $\mathrm{MPP}^{+}$(which would be diluted to the desired concentration of $2 \mathrm{mM}$, analogously to the $\mathrm{ASP}^{+}$in the inhibition experiments). For a single experiment, $0.75 \mathrm{ml}$ of drug solution at double concentration was prepared for each drug. The stock solutions of $0.1,0.2$, and $1.0 \mu \mathrm{M}$ were each split into 0.5 and $0.25 \mathrm{ml}$ aliquots. $0.5 \mathrm{ml}$ of pure $\mathrm{HBSS}^{+}$was added to the $0.5 \mathrm{ml}$ aliquots, yielding $1 \mathrm{ml}$ of $0.05,0.1$, and $0.5 \mu \mathrm{M}$ drug solutions, the volume sufficient for testing one pcDNA5 and one OCT1 well. $0.25 \mathrm{ml}$ of $\mathrm{HBSS}^{+}$ containing $4 \mathrm{mM}$ of $\mathrm{MPP}^{+}$was added to the $0.25 \mathrm{ml}$ aliquots, tallying up to $0.5 \mathrm{ml}$ of 0.05 , 0.1 , and $0.5 \mu \mathrm{M}$ drug solutions with $2 \mathrm{mM} \mathrm{MPP}^{+}$each that were added to the negative control OCT1 wells.

In addition to the tested concentrations, a standard curve was prepared for each drug at concentrations of $0.1,1,10$, and $100 \mathrm{nM}$. It was prepared in $80 \% \mathrm{LC} / \mathrm{MS}$-grade acetonitrile containing $10 \mathrm{ng} / \mathrm{ml}$ of an internal standard (IS), which varied depending on the substances tested (see 2.2.7, LC-MS). They underwent the same treatment as the samples did subsequent to cell lysis. The $80 \%$ acetonitrile/IS solution also served as lysis buffer for the cells. 


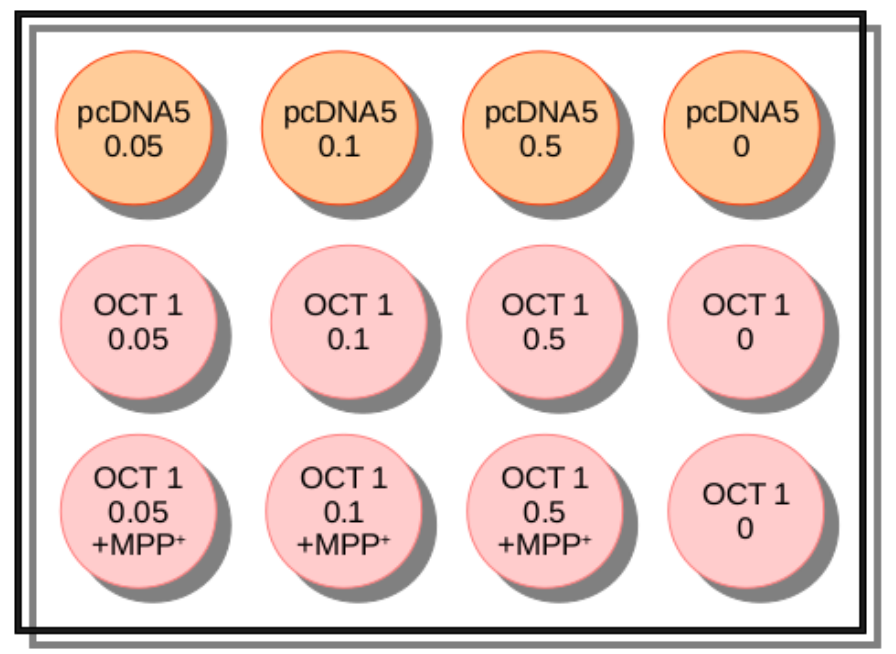

Figure 4: Plating and pipetting scheme for transport experiments, concentrations in $\mu \mathrm{M}$

Treatment before, during, and after drug uptake was the same as in the inhibition experiments. The solutions were warmed up to $37^{\circ} \mathrm{C}$ and $400 \mu \mathrm{l}$ added to the wells every ten seconds, while the wells for protein measurement (the zero concentration wells, see Figure 4) remained in pure $\mathrm{HBSS}^{+}$. After incubating for two minutes, the cells were doused in $2 \mathrm{ml}$ of ice-cold $\mathrm{HBSS}^{+}$per well and all transport processes thus terminated. The wells were then washed two more times before the buffers were added to the cells. Analogously to the inhibition experiments, $500 \mu \mathrm{l}$ of RIPA buffer was added to the zero concentration wells destined for protein measurement, whereas the cells incubated in drug solution were treated with $500 \mu \mathrm{l}$ of acetonitrile/IS buffer.

After placing the plates on the shaker for ten minutes, approx. $450 \mu \mathrm{l}$ of the lysate (more if possible) were transferred from the wells on the plate and into test tubes. The samples, as well as the standards, were then centrifuged in a tabletop centrifuge at $13 \mathrm{x} g$ for $10 \mathrm{~min}$. $350 \mu \mathrm{l}$ of the supernatant was subsequently transferred into new, carefully labeled (!) test tubes. These tubes were either stored at $-20{ }^{\circ} \mathrm{C}$ until testing or immediately processed further. For further processing, the tubes containing the samples were placed in a heating block and the samples evaporated with molecular nitrogen. Once the fluid had completely evaporated, the samples were resuspended in $350 \mu \mathrm{l}$ of formic acid, vortexed, and centrifuged at $10 \mathrm{x} g$ for $5 \mathrm{~min}$. Finally, $100 \mu \mathrm{l}$ of the centrifuged samples were transferred to LC-MS bottles and stored at $8{ }^{\circ} \mathrm{C}$ until measurement in the mass spectrometer

Protein measurements were performed analogously to those in the inhibition experiments (see 2.2.5). 
The results of the LC-MS/MS measurement were given by the program in ng of detected drug per $\mathrm{ml}$ of eluent. These concentrations were converted into $\mathrm{pmol} / \mu \mathrm{l}$ and extrapolated via the total volume of lysis buffer per well (500 $\mu \mathrm{l} /$ well) to pmol/well. The concentration of pmol/well was then divided by the amount of protein in mg per well and the incubation time of $2 \mathrm{~min}$, resulting in the uptake of measured drug in $\mathrm{pmol} / \mathrm{min} / \mathrm{mg}$ protein.

\subsubsection{LC-MS/MS}

Direct transport measurements were performed via mass spectrometry using an API4000 LC-MS/MS system with the Analyst ${ }^{\circledR}$ Version 1.4 .2 software. The samples were processed as described above and then subjected to measurements following the measurement protocols listed in Table 1. The mass-to-charge ratio of precursor and product ions were mostly obtained from the literature, but frequently supplemented with data from our own tuning process since we preferred to measure the mass-to-ratio values of at least two product ions when possible. The remaining parameters -retention time, mobile phase, flow- are also the results of priming and testing conducted during the course of the experiments. 
Table 1: Parameters for LC-MS/MS

\begin{tabular}{|c|c|c|c|c|c|c|c|c|}
\hline Analyte & $\begin{array}{c}\text { Qualifier } \\
\text { Precursor } \\
\text { Ion to Product } \\
\text { Ion }(\mathrm{m} / \mathrm{z})\end{array}$ & $\begin{array}{c}\text { Quantifier } \\
\text { Precursor } \\
\text { Ion to Product } \\
\text { Ion }(\mathrm{m} / \mathrm{z})\end{array}$ & $\begin{array}{l}\text { Retention } \\
\text { time } \\
\text { (min) }\end{array}$ & Internal Standard & $\begin{array}{c}\text { Internal } \\
\text { Standard } \\
\text { Precursor } \\
\text { Ion to } \\
\text { Product Ion } \\
(\mathrm{m} / \mathrm{z})\end{array}$ & $\begin{array}{l}\text { Retention time } \\
\text { Internal } \\
\text { Standard (min) }\end{array}$ & $\begin{array}{l}\text { Mobile } \\
\text { phase } \\
(\% \text { aceto- } \\
\text { nitrile })\end{array}$ & $\begin{array}{c}\text { Flow } \\
(\mu \mathrm{l} / \mathrm{min})\end{array}$ \\
\hline 3-Hydroxymorphinan & $244.1 / 157.0$ & $244.1 / 132.9$ & $7.3^{\prime}$ & Nortilidine & $260.3 / 155.1$ & $8.3^{\prime}$ & 15 & 300 \\
\hline 3-Methoxymorphinan & $258.4 / 215.1$ & $258.4 / 171.2$ & $8.4^{\prime}$ & Nortilidine & $260.3 / 155.1$ & $5.0^{\prime}$ & 20 & 500 \\
\hline Codeine & $300.3 / 215.1$ & $300.3 / 165.1$ & $4.8^{\prime}$ & Morphine & $286.2 / 201.1$ & $3.2^{\prime}$ & 8 & 300 \\
\hline Dextromethorphan & $272.2 / 171.1$ & $272.2 / 215.2$ & $8.1^{\prime}$ & Nortilidine & $260.3 / 155.1$ & $5.0^{\prime}$ & 20 & 500 \\
\hline Dextrorphan & $258.4 / 157.1$ & 258.4/199.1 & $4.7^{\prime}$ & Nortilidine & $260.3 / 155.1$ & $5.0^{\prime}$ & 20 & 500 \\
\hline Fentanyl & $337.4 / 104.9$ & $337.35 / 188.2$ & $5.0^{\prime}$ & 3-Methoxymorphinan & $258.4 / 215$ & $5.4^{\prime}$ & 20 & 700 \\
\hline Hydrocodone & $300.5 / 199.1$ & $300.5 / 128.1$ & $6.8^{\prime}$ & Codeine & $300.3 / 215.1$ & $5.0^{\prime}$ & 8 & 300 \\
\hline Hydromorphone & $286.2 / 185.2$ & $286.2 / 157.1$ & $4.0^{\prime}$ & Codeine & $300.3 / 215.1$ & $5.0^{\prime}$ & 8 & 300 \\
\hline Levorphanol & $258.1 / 157.1$ & $258.1 / 133.0$ & $7.2^{\prime}$ & Nortilidine & $260.3 / 155.1$ & $8.3^{\prime}$ & 15 & 300 \\
\hline Meptazinol & $234.5 / 107.0$ & $234.5 / 76.9$ & $6.3^{\prime}$ & Nortilidine & $260.3 / 155.1$ & $7.9^{\prime}$ & 15 & 300 \\
\hline \multirow[t]{2}{*}{ Methylnaltrexone } & $356.2 / 338.2$ & $356.2 / 284.1$ & $5.6^{\prime}$ & Morphine & $286.2 / 201.1$ & $3.2^{\prime}$ & 8 & 300 \\
\hline & $356.2 / 338.2$ & $356.2 / 284.1$ & $3.6^{\prime}$ & Nortilidine & $260.3 / 155.1$ & $8.1^{\prime}$ & 15 & 300 \\
\hline Morphine & $286.2 / 201.1$ & $286.2 / 165.1$ & $3.2^{\prime}$ & Codeine & $300.3 / 215.1$ & $4.8^{\prime}$ & 8 & 300 \\
\hline Naltrexone & $342.3 / 324.2$ & $342.3 / 270.1$ & $6.3^{\prime}$ & Codeine & $300.3 / 215.1$ & $4.8^{\prime}$ & 8 & 300 \\
\hline N-Desmethyltramadol & $250.2 / 232.3$ & $250.2 / 44.1$ & $6.5^{\prime}$ & $\begin{array}{l}\text { Norfentanyl } \\
\text { N- }\end{array}$ & $233.2 / 84.1$ & $4.8^{\prime}$ & 15 & 300 \\
\hline Norfentanyl & $233.2 / 84.1$ & $233.2 / 150.1$ & $4.7^{\prime}$ & Desmethyltramadol & $250.2 / 232.3$ & $6.4^{\prime}$ & 15 & 300 \\
\hline Noroxycodone & $302.4 / 284.1$ & $302.4 / 187.0$ & $5.8^{\prime}$ & Codeine & $300.3 / 215.1$ & $4.9^{\prime}$ & 8 & 300 \\
\hline
\end{tabular}




\begin{tabular}{|c|c|c|c|c|c|c|c|c|}
\hline Analyte & $\begin{array}{c}\text { Qualifier } \\
\text { Precursor } \\
\text { Ion Analyte to } \\
\text { Product Ion }(\mathrm{m} / \mathrm{z})\end{array}$ & $\begin{array}{c}\text { Quantifier } \\
\text { Precursor } \\
\text { Ion to Product } \\
\text { Ion }(\mathrm{m} / \mathrm{z})\end{array}$ & $\begin{array}{l}\text { Retention } \\
\text { time } \\
\text { (min) }\end{array}$ & Internal Standard & $\begin{array}{c}\text { Internal } \\
\text { Standard } \\
\text { Precursor } \\
\text { Ion to } \\
\text { Product Ion } \\
\text { (m/z) }\end{array}$ & $\begin{array}{l}\text { Retention time } \\
\text { Internal } \\
\text { Standard (min) }\end{array}$ & $\begin{array}{l}\text { Mobile } \\
\text { phase } \\
(\% \text { aceto- } \\
\text { nitrile) }\end{array}$ & $\begin{array}{c}\text { Flow } \\
(\mu \mathrm{l} / \mathrm{min})\end{array}$ \\
\hline Nortilidine & $260.3 / 155.1$ & $260.3 / 229.1$ & $8.0^{\prime}$ & $\begin{array}{l}\text { N- } \\
\text { Desmethyltramadol }\end{array}$ & $250.2 / 232.3$ & $6.5^{\prime}$ & 15 & 300 \\
\hline Oxycodone & $316.3 / 298.2$ & $316.3 / 256.2$ & $5.7^{\prime}$ & Codeine & $300.3 / 215.1$ & $4.8^{\prime}$ & 8 & 300 \\
\hline Oxymorphone & $302.3 / 284.1$ & $302.3 / 277.1$ & $3.7^{\prime}$ & Codeine & $300.3 / 215.1$ & $4.8^{\prime}$ & 8 & 300 \\
\hline Pethidine (Meperidine) & $248.4 / 174.1$ & $248.4 / 91.0$ & $8.0^{\prime}$ & Nortilidine & $260.3 / 155.1$ & $7.9^{\prime}$ & 15 & 300 \\
\hline Sufentanil & $387.2 / 238.1$ & $387.15 / 110.9$ & $10.5^{\prime}$ & 3-Methoxymorphinan & $258.4 / 215$ & $5.4^{\prime}$ & 20 & 700 \\
\hline Tapentadol & $222.1 / 107.1$ & $222.1 /-$ & $7.5^{\prime}$ & Nortilidine & $260.3 / 155.1$ & $7.9^{\prime}$ & 15 & 300 \\
\hline
\end{tabular}

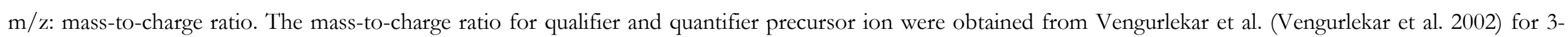

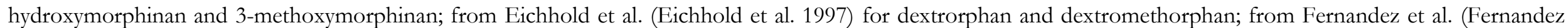

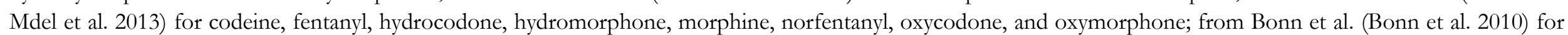

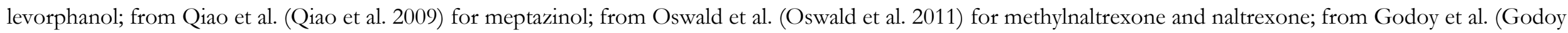

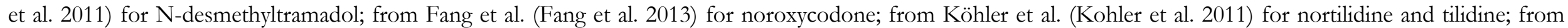

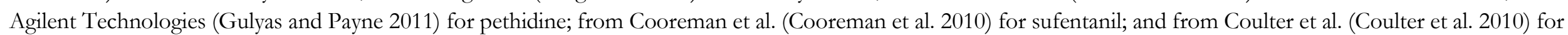
tapentadol. 


\section{$3 \quad$ Results}

\subsection{In silicio predictions}

We utilized in silico methods to narrow down the spectrum of possible OCT1 substrates by evaluating the $\mathrm{pK}_{\mathrm{a}}, \log \mathrm{P}$, and $\log \mathrm{D}_{(7.4)}$ values of 60 opioids and excluding drugs with very high hydrophobicity. The average $\mathrm{pK}_{\mathrm{a}}, \log \mathrm{P}$, and $\log \mathrm{D}_{(7.4)}$ of the complete set of opioids were $8.52,2.55$, and 1.51, respectively (Table 2). The predicted $\mathrm{pK}_{\mathrm{a}}$ values lay between 6.71 and 10.02, and only three substances (alfentanil, remifentanil, and naloxone) had $\mathrm{pK}_{\mathrm{a}}$ values below 7.4, indicating that overall the analyzed substances are moderate to strong bases and that, at a physiological $\mathrm{pH}$ in the range of 7.3-7.5, the equilibrium of 57 of the 60 substrates will favor an ionized state. $\log \mathrm{P}$ values ranged from -1.34 to 5.71 , and $\log \mathrm{D}_{(7.4)}$ values from -1.57 to 4.66 .

Based on this data, we initially selected compounds with $\operatorname{low} \log \mathrm{D}_{(7.4)}$ values for further analyses and then expanded the list of candidate substances to include commonly used opioids (e.g. fentanyl, $\log \mathrm{D}_{(7.4)}$ value of 3.47), opioid/metabolite pairs (e.g. oxycodone/noroxycodone), and opioids that, despite yielding high $\log \mathrm{D}_{(7.4)}$ values, bore a promising structural resemblance to established OCT1 substrates (e.g. similarity of meptazinol to O-desmethyltramadol).

In this way, we selected a total of 23 opioid to undergo further experiments(Table 2). Their average $\mathrm{pK}_{\mathrm{a}}, \log \mathrm{P}$, and $\log \mathrm{D}_{(7.4)}$ values were $8.68,2.25$, and 1.00 , respectively. The average $\mathrm{pK}_{\mathrm{a}}$ and $\log \mathrm{P}$ values of the complete set containing the original 60 substances and those of the experiment subset barely differ ( +1.8 and $-1.6 \%$, respectively). In contrast, the average $\log \mathrm{D}_{(7.4)}$ value of the experiment subset was $33.8 \%$ lower than the average of the complete set (Table 2). This was in keeping with our strategy of testing substances with probable low lipophilicity. 
Table 2: Opioids and their predicted $\mathrm{pK}_{a}, \log \mathrm{P}$ and $\log \mathrm{D}_{(7.4)}$ values, in alphabetical order

\begin{tabular}{|c|c|c|c|c|c|}
\hline Opioid & $\mathrm{pKa}$ & $\log \mathrm{P}$ & $\log \mathrm{D}(7.4)$ & $\begin{array}{l}\text { Included } \\
\text { in } \\
\text { further } \\
\text { analysis }\end{array}$ & Reasons for inclusion \\
\hline 3-Hydroxymorphinan & 9.39 & 3 & 1.03 & Yes & $\begin{array}{c}\text { Metabolite of } \\
\text { dextromethorphan }\end{array}$ \\
\hline 3-Methoxymorphinan & 9.72 & 3.65 & 1.36 & Yes & $\begin{array}{c}\text { Metabolite of } \\
\text { dextromethorphan }\end{array}$ \\
\hline 3-Monoacetylmorphine & 8.23 & 1.13 & 0.21 & & \\
\hline 6-Monoacetylcodeine & 8.24 & 1.84 & 0.94 & & \\
\hline 6-Monoacetylmorphine & 8.1 & 1.39 & 0.62 & & \\
\hline Alfentanil & 6.71 & 2.26 & 2.18 & & \\
\hline alpha-L-Acetylmethadol & 9.01 & 4.83 & 3.21 & & \\
\hline Alvimopan & 7.9 & 0.73 & 0.61 & & \\
\hline Buprenorphine & 7.94 & 4.72 & 4.07 & & \\
\hline Butorphanol & 7.87 & 3.71 & 3.11 & & \\
\hline Codeine & 8.43 & 1.5 & 0.44 & Yes & $\begin{array}{l}\text { Opioid used in clinical } \\
\text { practice (cough syrups, } \\
\text { analgesia), precursor of } \\
\text { morphine }\end{array}$ \\
\hline Dextromethorphan & 8.92 & 4.04 & 2.51 & Yes & $\begin{array}{l}\text { Opioid used in clinical } \\
\text { practice (cough syrups) }\end{array}$ \\
\hline Dextrorphan & 8.81 & 3.34 & 1.92 & Yes & $\begin{array}{c}\text { Metabolite of } \\
\text { dextromethorphan }\end{array}$ \\
\hline Dezocine & 8.99 & 3.36 & 1.77 & & \\
\hline Dihydrocodeine & 8.69 & 1.78 & 0.47 & & \\
\hline Dihydromorphine & 8.54 & 1.14 & -0.02 & & \\
\hline Dipipanone & 9.08 & 4.78 & 3.1 & & \\
\hline Diprenorphine & 7.97 & 3.33 & 2.66 & & \\
\hline D-Propoxyphene & 8.77 & 4.74 & 3.35 & & \\
\hline EDDP & 8.77 & 4.98 & 3.59 & & \\
\hline Ethorphine & 8.04 & 3.09 & 2.36 & & \\
\hline Fentanyl & 8.23 & 4.36 & 3.47 & Yes & $\begin{array}{l}\text { Opioid used in clinical } \\
\text { practice (analgesia) }\end{array}$ \\
\hline Heronie (Diamorphine) & 8.07 & 1.55 & 0.79 & & \\
\hline Hydrocodone & 8.59 & 1.54 & 0.32 & Yes & $\begin{array}{l}\text { Opioid used in clinical } \\
\text { practice (analgesia) }\end{array}$ \\
\hline Hydromorphone & 8.43 & 1.09 & 0.04 & Yes & $\begin{array}{l}\text { Opioid used in clinical } \\
\text { practice (analgesia) }\end{array}$ \\
\hline Levorphanol & 8.81 & 3.34 & 1.92 & Yes & $\begin{array}{l}\text { Opioid used in clinical } \\
\text { practice (analgesia), } \\
\text { enantiomer of dextrorphan }\end{array}$ \\
\hline L-Methadone & 9.1 & 3.92 & 2.21 & & \\
\hline Lofentanil & 7.64 & 4.46 & 4.02 & & \\
\hline Loperamide & 7.74 & 5.17 & 4.66 & & \\
\hline
\end{tabular}




\begin{tabular}{|c|c|c|c|c|c|}
\hline Opioid & $\mathrm{pKa}$ & $\log \mathrm{P}$ & $\log \mathrm{D}(7.4)$ & $\begin{array}{l}\text { Included } \\
\text { in } \\
\text { further } \\
\text { analysis }\end{array}$ & Reasons for inclusion \\
\hline Meptazinol & 8.9 & 3.36 & 1.85 & Yes & $\begin{array}{l}\text { Opioid used in clinical } \\
\text { practice (analgesia), } \\
\text { chemical structure }\end{array}$ \\
\hline Methylnaltrexone & 9.15 & -1.27 & -1.59 & Yes & $\begin{array}{l}\text { Opioid used in clinical } \\
\text { practice (OIBD), negative } \\
\log \mathrm{D}_{(7.4)} \text { (lowest of all) }\end{array}$ \\
\hline Morphine & 8.3 & 0.9 & -0.05 & Yes & $\begin{array}{c}\text { Opioid used in clinical } \\
\text { practice (analgesia), negative } \\
\log \mathrm{D}_{(7.4)}\end{array}$ \\
\hline Morphine-3-Glucuronide & 8.41 & -1.23 & -1.27 & & \\
\hline Morphine-6-Glucuronide & 8.19 & -1.34 & -1.4 & & \\
\hline Nalbuphine & 7.63 & 1.83 & 1.4 & & \\
\hline Nalmefene & 7.72 & 2.6 & 2.11 & & \\
\hline Nalorphine & 7.78 & 1.65 & 1.12 & & \\
\hline Naloxone & 7.26 & 1.09 & 0.85 & & \\
\hline Naltrexone & 7.63 & 1.24 & 0.81 & Yes & $\begin{array}{c}\text { Opioid used in clinical } \\
\text { practice (antidote to opioid } \\
\text { overdose) }\end{array}$ \\
\hline N-Desmethyltramadol & 10.02 & 2.5 & 0.08 & Yes & Metabolite of tramadol \\
\hline Norbuprenorphine & 9.1 & 3.34 & 1.64 & & \\
\hline Norfentanyl & 9.62 & 1.86 & -0.33 & Yes & $\begin{array}{l}\text { Metabolite of fentanyl, } \\
\text { negative } \log \mathrm{D}_{(7.4)}\end{array}$ \\
\hline Noroxycodone & 8.82 & 0.41 & -0.93 & Yes & $\begin{array}{c}\text { Metabolite of oxycodone, } \\
\text { negative } \log \mathrm{D}_{(7.4)}\end{array}$ \\
\hline Norpethidine & 9.69 & 2.16 & 0.16 & & \\
\hline Norpropoxyphene & 9.73 & 4.26 & 2.01 & & \\
\hline Nortilidine & 8.43 & 2.76 & 1.71 & Yes & $\begin{array}{l}\text { Metabolite of tilidine (and } \\
\text { active compound) }\end{array}$ \\
\hline O-Desmethyltramadol & 8.98 & 2.19 & 0.6 & & \\
\hline Oripavine & 7.79 & 2.01 & 1.47 & & \\
\hline Oxycodone & 8 & 0.81 & 0.11 & Yes & $\begin{array}{l}\text { Opioid used in clinical } \\
\text { practice (analgesia) }\end{array}$ \\
\hline Oxymorphone & 7.89 & 0.33 & -0.28 & Yes & $\begin{array}{c}\text { Opioid used in clinical } \\
\text { practice (analgesia), negative } \\
\log \mathrm{D}_{(7.4)}\end{array}$ \\
\hline Pentazocine & 8.23 & 4.25 & 3.36 & & \\
\hline Pethidine (Meperidine) & 8.91 & 2.45 & 0.93 & Yes & $\begin{array}{c}\text { Opioid used in clinical } \\
\text { practice (analgesia, to } \\
\text { counter shivering), chemical } \\
\text { structure }\end{array}$ \\
\hline Phenazocin & 8.33 & 4.7 & 3.73 & & \\
\hline Piritramide & 7.57 & 3.48 & 3.08 & & \\
\hline Remifentanil & 7.25 & 1.96 & 1.73 & & \\
\hline Sufentanil & 7.78 & 3.91 & 3.38 & Yes & $\begin{array}{l}\text { Opioid used in clinical } \\
\text { practice (analgesia, esp. } \\
\text { during general anesthesia) }\end{array}$ \\
\hline Tapentadol & 9.29 & 3.27 & 1.39 & Yes & $\begin{array}{l}\text { Opioid used in clinical } \\
\text { practice (analgesia) }\end{array}$ \\
\hline
\end{tabular}




\begin{tabular}{|l|r|r|r|r|r|}
\hline Thebaine & 7.92 & 2.63 & 1.99 & & \\
\hline Opioid & $\mathrm{pKa}$ & $\log \mathrm{P}$ & $\log (7.4)$ & $\begin{array}{c}\text { Included } \\
\text { in } \\
\text { further } \\
\text { analysis }\end{array}$ & Reasons for inclusion \\
\hline Tilidine & $\mathbf{7 . 6 4}$ & $\mathbf{3 . 3 3}$ & $\mathbf{2 . 8 9}$ & Yes & $\begin{array}{c}\text { Opioid used in clinical } \\
\text { practice (analgesia, prodrug) }\end{array}$ \\
\hline Tramadol & 9.04 & 2.83 & 1.18 & & \\
\hline
\end{tabular}

\begin{tabular}{|l|r|r|r|}
\hline AVERAGE $(\mathrm{n}=60)$ & 8.43 & 2.55 & 1.51 \\
\hline SEM & \pm 0.09 & \pm 0.20 & \pm 0.19 \\
\hline AVERAGE $\mathbf{( n = 2 3 )}$ & $\mathbf{8 . 6 8}$ & $\mathbf{2 . 5 1}$ & $\mathbf{1 . 0 0}$ \\
\hline SEM & $\pm \mathbf{0 . 1 4}$ & $\pm \mathbf{0 . 3 0}$ & $\pm \mathbf{0 . 2 8}$ \\
\hline $\begin{array}{l}\text { Difference AVERAGES } \\
\text { in \% }\end{array}$ & +1.8 & -1.6 & -33.8 \\
\hline
\end{tabular}

SEM: standard error of the mean. The 23 opioids that were selected to undergo further experiments are marked in bold. Averages and SEMs of all 60 analyzed opioids are at the bottom of the table, along with the averages of the 23 opioids of the experiment subset. The difference between the average $\mathrm{pK}_{\mathrm{a}}, \log \mathrm{P}$, and $\log \mathrm{D}_{(7.4)}$ of the 23 opioid subset as compared to all 60 opioids is given in percent. 


\subsection{Parallel artificial membrane assays (PAMPAs)}

We conducted the PAMPAs in order to establish in how far the in silicio $\log \mathrm{D}_{(7.4)}$ values corresponded to actual membrane permeability in an in vitro cell membrane model.

The membrane permeabilities $\left(\mathrm{P}_{\mathrm{e}}\right)$ of the 23 substances tested in the PAMPAs ranged across three potencies, from $0.002 \times 10^{-5}$ (methylnaltrexone) to $6.4 \times 10^{-5}$ (dextromethorphan). Despite the wide distribution, only six substances had values greater than $2 \times 10^{-5}$. Seven substances had values smaller $0.5 \times 10^{-5}$ (Table 3 ).

All substances were tested in duplicate at three concentrations, except for morphine and codeine, which were only tested once at three concentrations. However, since their $\mathrm{P}_{\mathrm{e}}$ 's correspond to those published previously by Tzvetkov et al. $\left(5 \pm 0.5 \times 10^{-7}\right.$ versus our $1.58 \pm$ $0.1 \times 10^{-7}$ for morphine, and $8.2 \pm 0.4 \times 10^{-6}$ versus our $8.01 \pm 1.3 \times 10^{-6}$ for codeine (Tzvetkov et al. 2013)), we can assume that three measurements are sufficient to provide reliable $P_{e}$ values.

Determining the exact $\mathrm{P}_{\mathrm{e}}$ values of the substances with the highest membrane permeability caused some difficulty. Because their $\mathrm{P}_{\mathrm{e}}$ 's lie close to equilibrium, even slight imprecisions in MS measurements led to $\mathrm{C}_{\mathrm{A}}$ becoming nominally larger than $\mathrm{C}_{\text {equil. }}$ In those cases, the formula used for calculating the $\mathrm{P}_{\mathrm{e}}$ became invalid, so that the amount of data for the affected substances is not as large as we would have liked it to be. However, there was enough data to ensure that at least three individual $\mathrm{P}_{\mathrm{e}}$ values contributed to the mean $\mathrm{P}_{\mathrm{e}}$ of each substance presented. In addition, the high $\mathrm{P}_{\mathrm{e}}$ 's determined for dextromethorphan, fentanyl, pethidine, sufentanil, tilidine, and nortilidine are in line with established knowledge regarding their lipophilicity.

Overall, the $\mathrm{P}_{\mathrm{e}}$ values correspond to the predicted $\log \mathrm{D}_{(7.4)}$; however in the cases of 3hydroxymorphinan, dextrorphan, and levorphanol the experimentally determined $\mathrm{P}_{\mathrm{e}}$ values are lower than the $\log \mathrm{D}_{(7.4)}$ values would originally have led us to expect. Conversely, oxycodone and pethidine yielded relatively high $\mathrm{P}_{\mathrm{e}}$ values considering their $\log \mathrm{D}_{(7.4)}$ values. It follows that, while the $\log \mathrm{D}_{(7.4)}$ values are indicators of a substance's lipophilicity, actual membrane permeability should be assessed with cell-free membrane models such as PAMPA. 
Table 3: $\mathrm{P}_{\mathrm{e}}\left(\right.$ mean) and $\mathrm{SEM}($ mean $)$ in comparison to $\log \mathrm{D}_{(7.4)}$ values

\begin{tabular}{|l|c|c|c|}
\multicolumn{1}{|c|}{ Opioid } & $\begin{array}{c}\text { Pe(mean) } \\
\mathbf{1 0}^{-5}\end{array}$ & $\begin{array}{c}\text { SEM } \\
\mathbf{1 0}^{-5}\end{array}$ & $\log _{(7.4)}$ \\
\hline Methylnaltrexone & 0.002 & 0.001 & -1.59 \\
\hline Morphine & 0.016 & 0.001 & -0.05 \\
\hline 3-Hydroxymorphinan & 0.073 & 0.009 & 1.03 \\
\hline Noroxycodone & 0.094 & 0.016 & -0.93 \\
\hline Hydromorphone & 0.17 & 0.04 & 0.04 \\
\hline Norfentanyl & 0.26 & 0.07 & -0.33 \\
\hline Oxymorphone & 0.32 & 0.16 & -0.28 \\
\hline Dextrorphan & 0.54 & 0.16 & 1.92 \\
\hline Codeine & 0.80 & 0.13 & 0.44 \\
\hline Hydrocodone & 0.91 & 0.21 & 0.32 \\
\hline Levorphanol & 0.92 & 0.18 & 1.92 \\
\hline N-Desmethyltramadol & 1.3 & 0.32 & 0.08 \\
\hline Tapentadol & 1.4 & 0.26 & 1.39 \\
\hline Meptazinol & 1.4 & 0.35 & 1.85 \\
\hline Naltrexone & 1.5 & 0.22 & 0.81 \\
\hline 3-Methoxymorphinan & 1.7 & 0.29 & 1.36 \\
\hline Oxycodone & 1.8 & 0.42 & 0.11 \\
\hline Nortilidine & 2.7 & 0.88 & 1.71 \\
\hline Tilidine & 3.2 & 1.2 & 2.89 \\
\hline Sufentanil & 3.8 & 0.59 & 3.38 \\
\hline Pethidine (Meperidine) & 4.0 & 0.72 & 0.93 \\
\hline Fentanyl & 5.7 & 0.10 & 3.47 \\
\hline Dextromethorphan & 6.4 & 0.71 & 2.51 \\
\hline
\end{tabular}

The PAMP assay simulated diffusion across a cell membrane under nearly physiological conditions (pH 7.4, ambient temperature of approx. $21^{\circ} \mathrm{C}$ ). The substances are ranked from the substance with the smallest $\mathrm{P}_{\mathrm{e}}$ down to the one with the largest. Opioids that emerged as substrates of OCT1 are printed in bold, opioids that emerged as inhibitors of OCT1 are highlighted in pale red. The smaller the partition coefficient $\mathrm{P}_{e}$, the lower membrane permeability. The $\log \mathrm{D}_{(7.4)}$ values are the same as those discussed in section 3.1 and are listed here to facilitate the direct comparison of the values. 


\subsection{Inhibition experiments}

Twenty-three opioids were tested for their potency to inhibit OCT1. To this end, OCT1overexpressing cells were incubated with the model substrate $\mathrm{ASP}^{+}$in the presence of increasing concentrations of opioids. An inhibitor was defined as a substance with an $\mathrm{IC}_{50}$ of $100 \mu \mathrm{M}$ or less, i.e. $\mathrm{ASP}^{+}$uptake had to be reduced by $50 \%$ or more at inhibitor concentrations of $100 \mu \mathrm{M}$ or less. Fourteen inhibitors of OCT1 were identified in this manner (Table 4).

Table 4: Tested substances sorted by $\mathrm{IC}_{50}$ from lowest to highest

\begin{tabular}{|l|r|r|}
\hline \multicolumn{1}{|c|}{ Opioids } & \multicolumn{1}{|c|}{$\begin{array}{c}\text { IC } \\
{[\boldsymbol{\mu M}]}\end{array}$} & \multicolumn{1}{c|}{$\begin{array}{c}\text { SEM } \\
{[\boldsymbol{\mu M}]}\end{array}$} \\
\hline Dextrorphan & 6.40 & 1.63 \\
\hline Levorphanol & 8.48 & 0.60 \\
\hline 3-Methoxymorphinan & 10.29 & 2.14 \\
\hline Dextromethorphan & 15.15 & 2.52 \\
\hline Meptazinol & 18.96 & 3.06 \\
\hline Sufentanil & 19.36 & 0.19 \\
\hline Tapentadol & 21.89 & 1.24 \\
\hline Pethidine (Meperidine) & 22.25 & 3.66 \\
\hline 3-Hydroxymorphinan & 24.93 & 5.13 \\
\hline Tilidine & 38.71 & 13.95 \\
\hline Fentanyl & 46.17 & 6.81 \\
\hline N-Desmethyltramadol & 55.75 & 9.41 \\
\hline Morphine & 71.79 & 6.74 \\
\hline Nortilidine & 88.76 & 18.81 \\
\hline Norfentanyl & 117.74 & 16.56 \\
\hline Hydromorphone & 137.97 & 19.22 \\
\hline Naltrexone & 157.51 & 7.54 \\
\hline Noroxycodone & 199.82 & 22.27 \\
\hline Methylnaltrexone & 234.39 & 29.97 \\
\hline Codeine & 235.50 & 29.42 \\
\hline Oxymorphone & 250.33 & 35.24 \\
\hline Hydrocodone & 536.96 & 87.58 \\
\hline Oxycodone & 2003.78 & 172.90 \\
\hline
\end{tabular}

OCT1 substrates are marked in bold. The dashed line indicates the cut-off between $\mathrm{IC}_{50}$ s lower and larger than $100 \mu \mathrm{M}$. 
The inhibition curves of the tested substances are shown in Figure 5. The previously reported OCT1 substrate morphine had an $\mathrm{IC}_{50}$ of $71.8 \pm 6.7 \mu \mathrm{M}$. Dextromethorphan and its derivatives were more potent OCT1-inhibitors than morphine and other morphinans with a more "morphine-like" structure (Fig. 8A and B). The group of synthetic opioids is mixed (Figs. C and D), but overall their $\mathrm{IC}_{50}$ values tend to lie below that of morphine, as do the $\mathrm{IC}_{50}$ values of the opioid receptor antagonists naltrexone and methylnaltrexone (Fig. E).

The nine most potent inhibitors had $\mathrm{IC}_{50}$ values below $25 \mu \mathrm{M}$, ranging from dextrorphan $\left(\mathrm{IC}_{50}\right.$ of $\left.6.4 \mu \mathrm{M}\right)$ to 3-hydroyxmorphinan $\left(\mathrm{IC}_{50}\right.$ of $\left.34.9 \mu \mathrm{M}\right)$. Tilidine, fentanyl, $\mathrm{N}$ desmethyltramadol, morphine, and nortilidine also qualified as inhibitors.

In contrast, the substances with the highest $\mathrm{IC}_{50}$ values -methylnaltrexone, codeine, oxymorphone, hydromorphone and especially oxycodone- spanned a range from $234 \mu \mathrm{M}$ to above $2 \mathrm{mM}$. 


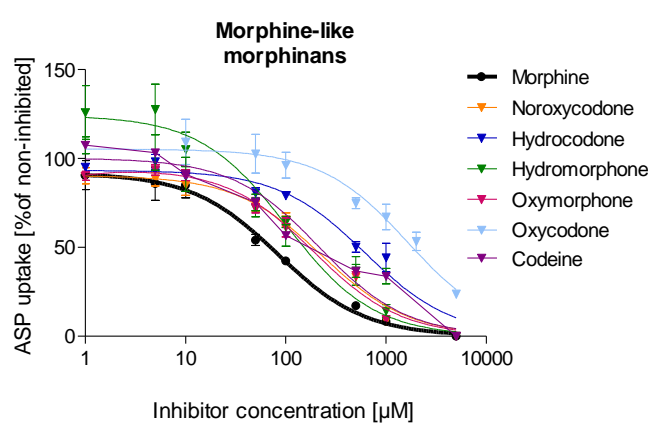

(A)

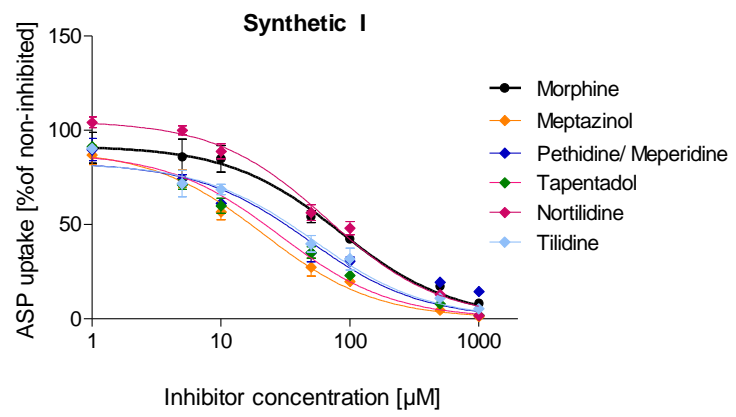

(C)

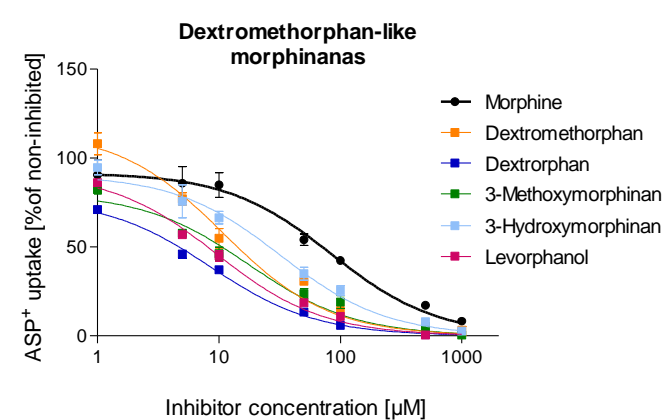

(B)

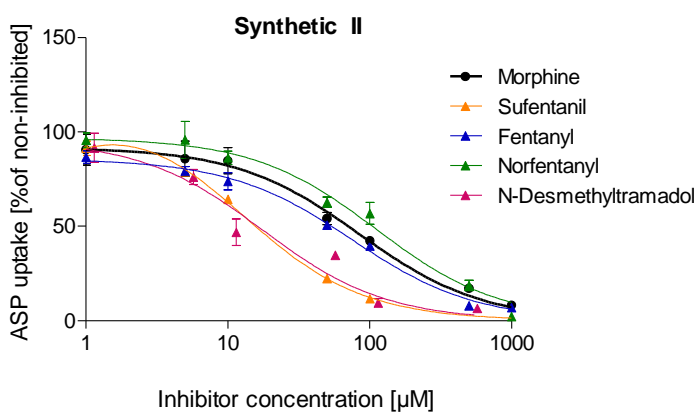

(D)

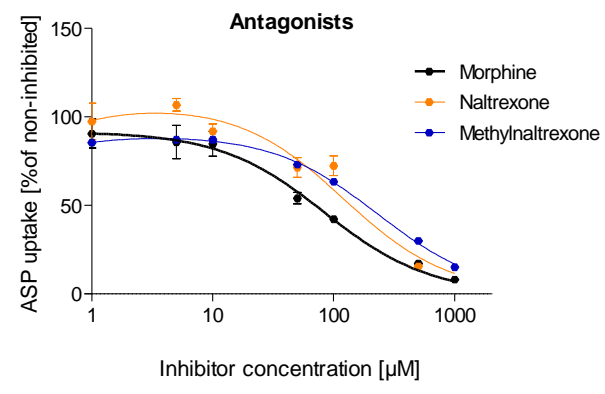

(E)

Figure 5: Comparative analyses of opioids as inhibitors of OCT1

For better comparability, the substances were assigned to one of five different groups based on their structure and inhibitory potency. The first group (A) comprises those morphinans with a structure similar to morphine. The second group (B) is made up of dextromethorphan and its metabolites, plus levorphanol, the enantiomer of dextromethorphan-metabolite dextrorphan. Although they, too, are morphinans, they differ from morphine and the antagonists structurally in that they contain only four rings instead of five. The synthetic opioids (C and D) are structurally more heterogeneous than the morphinans and were distributed across two graphs to provide a better overview over the curves. The final group (E), the antagonists, are also morphine-like morphinans, but in contrast to the other opioids they act antagonistically upon opioid receptors. The morphine curve was added in black to all graphs to allow for better comparability of the curves between graphs. 


\subsection{Transport experiments}

\subsubsection{Relative transport}

The main objective of this work was to determine which opioids may profit from OCT1 for their cellular uptake, i.e. which opioids are OCT1 substrates. To this end, we performed direct uptake measurements of the different opioids into OCT1-overexpressing cells via mass spectrometry. A substance was arbitrarily defined as a substrate if uptake of the substance into OCT1-overexpressing cells was at least 2.0 times as high as that into pcDNA5 cells at two or more of the three concentrations tested. In addition to the negative control pcDNA5 cells, we also measured uptake in $\mathrm{MPP}^{+}$-inhibited OCT1-overexpressing cells to confirm that the values obtained from the pcDNA5 cells were the result of diffusion and not of some fault in the cell line.

Overall, we assigned the tested substances to one of three groups: strong transport, moderate transport, and no transport. Out of 23 tested substances the transport experiment yielded next to the previously known morphine- seven further OCT1 substrates; three with strong transport and four with moderate transport.

\section{Strong transport}

Strong transport was defined as an at least five-fold increase of uptake of tested substance into OCT1-overexpressing cells compared to the negative control. In total, three substances strongly transported by OCT1 were identified: methylnaltrexone, 3-hydroxymorphinan, and norfentanyl (Table 5). The strongest increase in uptake was seen in methylnaltrexone, with a 32-, 67-, and 85-fold increase in uptake at concentrations of $0.05,0.1$, and $0.5 \mu \mathrm{M}$, respectively. 3-Hydroxymorphinan experienced a 14 to 17-fold increase in uptake across the concentration range, while norfentanyl showed an approximately 7 -fold increase in uptake at all three concentrations. 


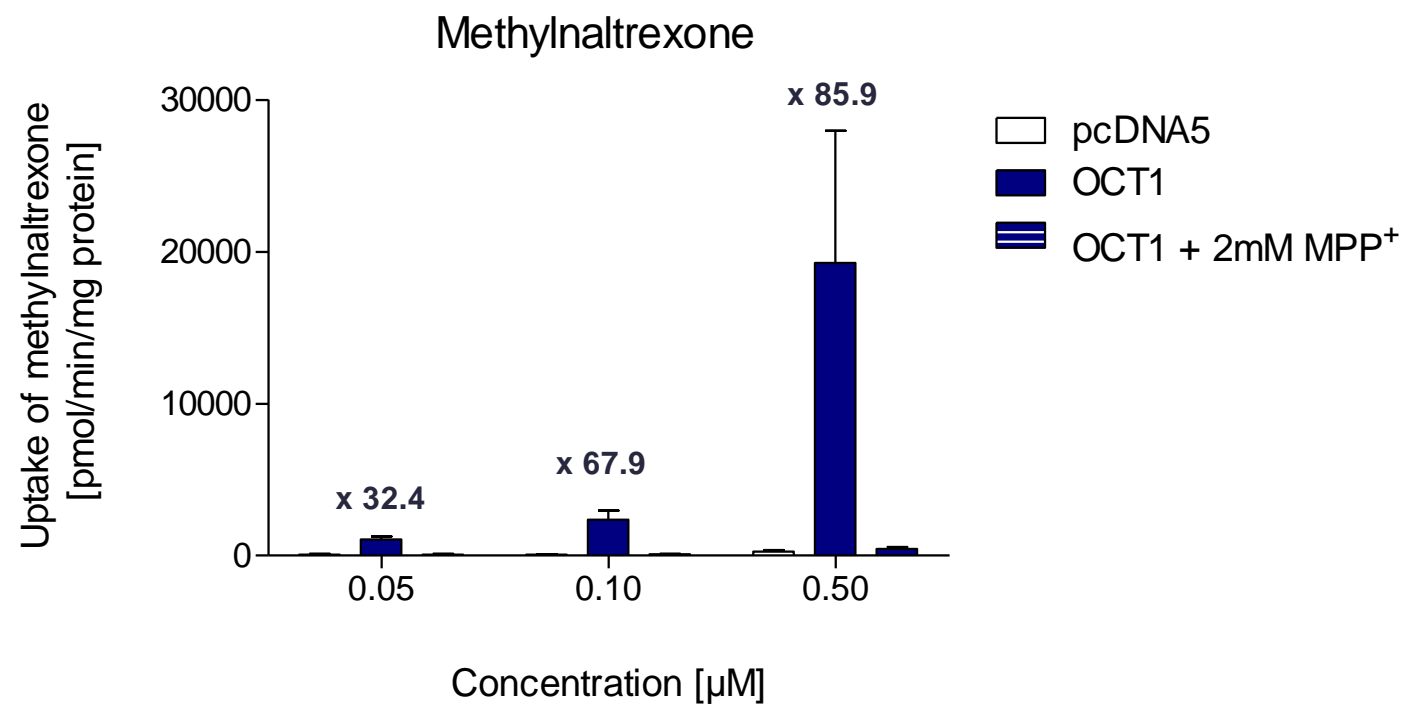

Figure 6: Relative increase in uptake of methylnaltrexone

Negative control pcDNA5 cells, OCT1 cells, and OCT1 cells inhibited with $1 \mathrm{mM} \mathrm{MPP}+$ were incubated with opioid solutions at concentrations of $0.05 \mu \mathrm{M}, 0.1 \mu \mathrm{M}$, and $0.5 \mu \mathrm{M}$ for two minutes and uptake of the opioid into the cells determined via LC-MS/MS. On the scale presented, the bars of the pcDNA5 cells and the OCT1 $+2 \mathrm{mM} \mathrm{MPP}^{+}$cells are barely visible compared to the bars of the OCT1 cells.

\section{Moderate transport}

Moderate transport was defined as an at least two-fold, but less than five-fold increase in uptake of tested substance into OCT1-overexpressing cells compared to the negative control cells. Next to morphine, which has already been established as a substrate, four other substances were identified to be transported by OCT1 (Table 5). In descending order of uptake, these substances were morphine (maximally 5.1-fold increase), noroxycodone (maximally 4-fold increase), 3-methoxymorphinan (maximally 2.5-fold increase), meptazinol (maximally 2.3-fold increase, and hydromorphone (maximally 2-fold increase).

\section{No transport}

Transport activity was deemed non-existent when the uptake of substance into OCT1overexpressing cell was less than two times high as that into the negative controls. Codeine, dextromethorphan, dextrorphan, fentanyl, hydrocodone, levorphanol, naltrexone, oxycodone, oxymorphone, pethidine, sufentanil, tapentadol, and tilidine were allocated to this group. 
Data on $\mathrm{N}$-desmethyltramadol (the inactive M2 metabolite of tramadol) and nortilidine was inconclusive; whether or not and to what extent $\mathrm{N}$-desmethyltramadol and nortilidine are transported by OCT1 could therefore not be determined.

Table 5: Relative increase in uptake of tested substances

\begin{tabular}{|l|c|c|c|c|c|c|}
\cline { 2 - 7 } \multicolumn{1}{c|}{} & \multicolumn{2}{c|}{$0.05 \mu \mathrm{M}$} & \multicolumn{2}{c|}{$0.1 \mu \mathrm{M}$} & \multicolumn{2}{c|}{$0.5 \mu \mathrm{M}$} \\
\hline Substance & Mean & SEM & Mean & SEM & Mean & SEM \\
\hline 3-Hydroxymorphinan & 14.0 & \pm 1.7 & 14.9 & \pm 1.2 & 17.4 & \pm 4.8 \\
\hline 3-Methoxymorphinan & 2.5 & \pm 0.7 & 2.2 & \pm 0.4 & 2.0 & 0.1 \\
\hline Codeine & 0.7 & \pm 0.2 & 1.0 & \pm 0.3 & 0.8 & \pm 0.0 \\
\hline Dextromethorphan & 1.1 & \pm 0.2 & 1.3 & \pm 0.4 & 0.8 & \pm 0.2 \\
\hline Dextrorphan & 2.1 & \pm 0.2 & 1.9 & \pm 0.8 & 1.5 & \pm 0.1 \\
\hline Fentanyl & 1.0 & \pm 0.1 & 1.0 & \pm 0.1 & 1.0 & \pm 0.1 \\
\hline Hydrocodone & 0.9 & \pm 0.1 & 1.6 & \pm 0.3 & 1.2 & \pm 0.1 \\
\hline Hydromorphone & 2.0 & \pm 0.1 & 1.9 & \pm 0.1 & 2.0 & \pm 0.1 \\
\hline Levorphanol & 1.5 & \pm 0.2 & 1.7 & \pm 0.1 & 1.3 & \pm 0.0 \\
\hline Meptazinol & 0.8 & \pm 0.2 & 2.2 & \pm 0.5 & 3.2 & \pm 1.4 \\
\hline Methylnaltrexone & 32.4 & \pm 20.4 & 67.9 & \pm 39.8 & 85.9 & \pm 24.7 \\
\hline Morphine & 4.6 & \pm 0.5 & 5.1 & \pm 0.7 & 4.3 & \pm 0.7 \\
\hline Naltrexone & 0.8 & \pm 0.2 & 0.8 & \pm 0.2 & 1.0 & \pm 0.2 \\
\hline N-desmethyltramadol & N.A. & N.A. & N.A. & N.A. & N.A. & N.A. \\
\hline Norfentanyl & 7.0 & \pm 0.5 & 6.6 & \pm 0.6 & 7.2 & \pm 0.6 \\
\hline Noroxycodone & 4.0 & \pm 1.4 & 3.9 & \pm 0.3 & 3.6 & \pm 0.1 \\
\hline Nortilidine & N.A. & N.A. & N.A. & N.A. & N.A. & N.A. \\
\hline Oxycodone & 0.9 & \pm 0.0 & 0.8 & \pm 0.1 & 0.9 & \pm 0.0 \\
\hline Oxymorphone & 2.4 & \pm 1.6 & 1.3 & \pm 0.4 & 0.9 & \pm 0.2 \\
\hline Pethidine (Meperidine) & 1.1 & \pm 0.1 & 1.2 & \pm 0.1 & 1.2 & \pm 0.1 \\
\hline Sufentanil & 1.1 & \pm 0.0 & 1.0 & \pm 0.1 & 1.1 & \pm 0.1 \\
\hline Tapentadol & 0.9 & \pm 0.2 & 1.6 & \pm 0.3 & 1.5 & \pm 0.2 \\
\hline Tilidine & 1.3 & \pm 0.2 & 1.3 & \pm 0.3 & 1.3 & \pm 0.1 \\
\hline
\end{tabular}

The relative increase of substrate into OCT1-overexpressing cells was calculated in relation to the negative control cells at concentrations of $0.05,0.1$, and $0.5 \mu \mathrm{M}$. Substances identified as substrates of OCT1 are highlighted in pale green.

\subsubsection{Absolute transport}

The absolute transport of the different opioids into the different cells lines is of less interest than the relative uptake; nevertheless, the data are included in Table 6 in order to supplement the relative values and help with their interpretation. 
Table 6: Absolute uptake of the tested substance

\begin{tabular}{|c|c|c|c|c|c|c|c|c|c|}
\hline & \multicolumn{9}{|c|}{ Uptake in $\mathrm{pmol} / \mathrm{min} / \mathrm{mg}$ protein } \\
\hline & pcDNA 0.05 & pcDNA 0.1 & pcDNA 0.5 & ОСТ 10.05 & ОСТ 10.1 & OCT1 0.5 & $\begin{array}{c}\text { OCT1 } 0.05+ \\
\text { MPP }^{+}\end{array}$ & $\begin{array}{l}\text { OCT1 } 0.1+ \\
\text { MPP }^{+}\end{array}$ & $\begin{array}{l}\text { OCT1 } 0.5+ \\
\text { MPP }^{+}\end{array}$ \\
\hline \multirow{2}{*}{ 3-Hydroxymorphinan } & 168.5 & 333.7 & 1852.3 & 2324.2 & 4857.0 & 30594.4 & 209.1 & 418.0 & 2601.9 \\
\hline & \pm 16.5 & \pm 50.8 & \pm 168.1 & \pm 198.2 & \pm 376.6 & \pm 5098.1 & \pm 14.4 & \pm 21.3 & \pm 78.8 \\
\hline \multirow{2}{*}{ 3-Methoxymorphinan } & 3950.1 & 2706.4 & 18262.3 & 6903.9 & 6246.3 & 37657.1 & 3849.1 & 4581.9 & 30503.0 \\
\hline & \pm 2169.5 & \pm 746.1 & \pm 4635.4 & \pm 1343.8 & \pm 1942.0 & \pm 10295.7 & \pm 1057.1 & \pm 1358.3 & \pm 11154.5 \\
\hline \multirow{2}{*}{ Codeine } & 434.0 & 909.5 & 4281.8 & 322.7 & 749.9 & 3499.0 & 567.9 & 734.7 & 4389.3 \\
\hline & \pm 82.3 & \pm 270.8 & \pm 1027.8 & \pm 131.5 & \pm 100.5 & \pm 774.9 & \pm 318.2 & \pm 114.3 & \pm 1227.4 \\
\hline \multirow[t]{2}{*}{ Dextromethorphan } & 2417.9 & 6314.6 & 30502.3 & 2692.5 & 9233.4 & 21134.0 & 2539.8 & 4375.0 & 24182.7 \\
\hline & \pm 622.4 & \pm 2575.9 & \pm 9044.0 & \pm 1055.3 & \pm 5900.6 & \pm 4605.1 & \pm 940.2 & \pm 1382.9 & \pm 6976.0 \\
\hline \multirow{2}{*}{ Dextrorphan } & 897.5 & 2613.0 & 11808.0 & 2357.3 & 5897.5 & 17326.3 & 1284.3 & 2037.2 & 11235.1 \\
\hline & \pm 151.7 & \pm 919.7 & \pm 4056.5 & \pm 479.4 & \pm 1663.0 & \pm 5610.3 & \pm 179.8 & \pm 588.0 & \pm 2397.8 \\
\hline \multirow[t]{2}{*}{ Fentanyl } & 591.1 & 1153.6 & 5488.4 & 604.3 & 1127.8 & 5402.9 & 497.4 & 872.1 & 5009.9 \\
\hline & \pm 177.6 & \pm 199.3 & \pm 727.0 & \pm 155.5 & \pm 198.5 & \pm 746.6 & \pm 145.8 & \pm 165.5 & \pm 760.2 \\
\hline \multirow[t]{2}{*}{ Hydrocodone } & 80.8 & 176.4 & 1751.0 & 77.9 & 265.0 & 2175.8 & 85.0 & 223.9 & 1761.6 \\
\hline & \pm 18.8 & \pm 25.7 & \pm 153.0 & \pm 27.9 & \pm 40.9 & \pm 308.7 & \pm 18.9 & \pm 32.6 & \pm 271.6 \\
\hline \multirow[t]{2}{*}{ Hydromorphone } & 95.5 & 196.5 & 1089.8 & 193.3 & 371.6 & 2158.1 & 95.0 & 175.3 & 991.6 \\
\hline & \pm 2.2 & \pm 9.2 & \pm 86.6 & \pm 13.6 & \pm 22.3 & \pm 102.2 & \pm 1.2 & \pm 2.3 & \pm 83.4 \\
\hline \multirow[t]{2}{*}{ Levorphanol } & 1215.3 & 1457.6 & 8104.7 & 1339.6 & 2427.6 & 10654.0 & 795.7 & 2146.2 & 8098.2 \\
\hline & \pm 503.5 & \pm 137.9 & \pm 777.7 & \pm 190.7 & \pm 213.1 & \pm 1297.4 & \pm 85.5 & \pm 728.8 & \pm 587.1 \\
\hline \multirow[t]{2}{*}{ Meptazinol } & 599.0 & 806.1 & 3930.5 & 415.2 & 1645.5 & 13038.5 & 356.6 & 884.2 & 3353.4 \\
\hline & \pm 170.0 & \pm 148.1 & \pm 874.2 & \pm 50.7 & \pm 373.9 & \pm 5564.5 & \pm 98.0 & \pm 167.1 & \pm 355.3 \\
\hline \multirow[t]{2}{*}{ Methylnaltrexone } & 71.2 & 54.3 & 261.0 & 1061.2 & 2374.6 & 19269.2 & 61.6 & 86.6 & 427.1 \\
\hline & \pm 42.6 & \pm 21.5 & \pm 106.7 & \pm 200.7 & \pm 588.8 & \pm 8701.0 & \pm 40.5 & \pm 34.6 & \pm 144.4 \\
\hline
\end{tabular}




\begin{tabular}{|c|c|c|c|c|c|c|c|c|c|}
\hline Morphine & $\begin{array}{r}141.8 \\
\pm 7.9\end{array}$ & $\begin{array}{r}257.5 \\
\pm 8.7\end{array}$ & $\begin{array}{r}1367.0 \\
\pm 146.0\end{array}$ & $\begin{array}{r}654.0 \\
\pm 52.4\end{array}$ & $\begin{array}{r}1324.8 \\
\pm 180.1\end{array}$ & $\begin{array}{r}5803.9 \\
\pm 620.1\end{array}$ & $\begin{array}{r}102.4 \\
\pm 3.2\end{array}$ & $\begin{array}{r}440.9 \\
\pm 249.9\end{array}$ & $\begin{array}{r}872.0 \\
\pm 104.4\end{array}$ \\
\hline \multirow[t]{2}{*}{ Naltrexone } & 380.5 & 788.9 & 3949.2 & 274.9 & 596.1 & 4133.9 & 301.1 & 720.9 & 4452.6 \\
\hline & \pm 113.7 & \pm 31.6 & \pm 87.8 & \pm 11.4 & \pm 107.6 & \pm 908.1 & \pm 70.1 & \pm 130.5 & \pm 1093.3 \\
\hline \multirow[t]{2}{*}{ N-desmethyltramadol } & N.A. & N.A. & N.A. & N.A. & N.A. & N.A. & N.A. & N.A. & N.A. \\
\hline & N.A. & N.A. & N.A. & N.A. & N.A. & N.A. & N.A. & N.A. & N.A. \\
\hline \multirow[t]{2}{*}{ Norfentanyl } & 109.9 & 232.1 & 1189.6 & 757.4 & 1503.8 & 8554.4 & 105.0 & 185.8 & 875.3 \\
\hline & \pm 12.8 & \pm 17.8 & \pm 56.3 & \pm 50.9 & \pm 21.8 & \pm 621.9 & \pm 16.5 & \pm 7.3 & \pm 21.3 \\
\hline \multirow[t]{2}{*}{ Noroxycodone } & 94.0 & 163.8 & 979.2 & 320.5 & 623.9 & 3496.0 & 45.4 & 120.1 & 755.1 \\
\hline & \pm 20.1 & \pm 24.4 & \pm 29.5 & \pm 58.5 & \pm 39.7 & \pm 45.5 & \pm 21.8 & \pm 20.9 & \pm 31.6 \\
\hline \multirow{2}{*}{ Nortilidine } & N.A. & N.A. & N.A. & N.A. & N.A. & N.A. & N.A. & N.A. & N.A. \\
\hline & N.A. & N.A. & N.A. & N.A. & N.A. & N.A. & N.A. & N.A. & N.A. \\
\hline \multirow[t]{2}{*}{ Oxycodone } & 227.0 & 463.1 & 2402.4 & 212.1 & 370.3 & 2212.5 & 56.6 & 183.9 & 1083.6 \\
\hline & \pm 28.3 & \pm 25.5 & \pm 247.6 & \pm 22.3 & \pm 40.7 & \pm 272.1 & \pm 28.5 & \pm 41.6 & \pm 158.2 \\
\hline \multirow{2}{*}{ Oxymorphone } & 114.2 & 857.0 & 1849.4 & 189.0 & 761.2 & 1568.0 & 470.9 & 605.7 & 2021.8 \\
\hline & \pm 98.1 & \pm 408.9 & \pm 87.1 & \pm 17.6 & \pm 295.1 & \pm 366.4 & \pm 272.3 & \pm 365.3 & \pm 283.5 \\
\hline \multirow[t]{2}{*}{ Pethidine } & 458.1 & 806.5 & 5177.4 & 503.5 & 959.0 & 5728.5 & 579.7 & 1120.8 & 5502.8 \\
\hline & \pm 154.5 & \pm 231.3 & \pm 1777.5 & \pm 149.8 & \pm 188.9 & \pm 1162.8 & \pm 181.5 & \pm 289.3 & \pm 1299.8 \\
\hline \multirow[t]{2}{*}{ Sufenanil } & 849.2 & 2040.3 & 11525.7 & 931.8 & 2105.2 & 12482.4 & 718.7 & 1895.6 & 11161.1 \\
\hline & \pm 77.2 & \pm 99.3 & \pm 776.0 & \pm 107.9 & \pm 217.6 & \pm 2033.8 & \pm 138.1 & \pm 303.0 & \pm 1853.8 \\
\hline \multirow[t]{2}{*}{ Tapentadol } & 1070.0 & 1886.5 & 10534.1 & 944.1 & 2921.7 & 15453.2 & 963.3 & 1553.6 & 8182.0 \\
\hline & \pm 89.1 & \pm 572.3 & \pm 1581.6 & \pm 244.2 & \pm 854.4 & \pm 2753.6 & \pm 276.1 & \pm 343.7 & \pm 1888.1 \\
\hline \multirow{2}{*}{ Tilidine } & 171.0 & 312.7 & 1704.4 & 229.8 & 437.2 & 2158.1 & 215.5 & 350.3 & 2041.6 \\
\hline & \pm 19.3 & \pm 30.5 & \pm 319.9 & \pm 56.8 & \pm 132.4 & \pm 496.7 & \pm 47.9 & \pm 118.4 & \pm 687.1 \\
\hline
\end{tabular}

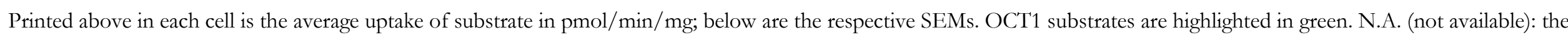
measurements performed with these substances were inconclusive and not further pursued due to unavailability of the required amounts of test substance. 


\section{Discussion}

We will discuss the results of our experiments under four aspects: pharmaco-clinical properties, structural aspects, aspects of metabolism, and clinical aspects.

\subsection{Pharmaco-chemical properties}

In order to better evaluate our findings regarding $\mathrm{pK}_{a}, \log \mathrm{D}_{(7.4)}$, and $\mathrm{P}_{\mathrm{e}}$, we are going to explore these parameters under the aspects of OCT1 transport (OCT1 substrates vs. nonsubstrates), OCT1 inhibition (OCT inhibitors vs. non-inhibitors), and pharmacologic class (morphinans vs. synthetic opioids).

\section{$\underline{\text { Substrates vs. non-substrates }}$}

A histogram of the $\mathrm{pK}_{\mathrm{a}}$ values of OCT1 substrates compared to those of non-substrates yielded no marked difference between the two groups (Figure 7), though the substrates' average $\mathrm{pK}_{a}$ lay slightly above that of the non-substrates, with 9.04 and 8.49 , respectively (Table 7).

With respect to $\log \mathrm{D}_{(7.4)}$, substrates of OCT1 displayed lower values than non-substrates, with substrates yielding an average $\log \mathrm{D}_{(7.4)}$ of 0.17 and non-substrates of $1.44(\mathrm{p}=0.026$, Table 7). This was to be expected since only substances with low lipophilicity and presumed low membrane permeability would require a transporter to enable their uptake into cells. This finding was further bolstered by the results of the substrates' and non-substrates' $\mathrm{P}_{\mathrm{e}}$ values. With a value of $0.47 \times 10^{-5}$, the average $P_{\mathrm{e}}$ 's of the substrates is considerably lower than that of the non-substrates, which lies at $2.35 \times 10^{-5}(p=0.013$, Table 7$)$. Of the seven substances with $\mathrm{P}_{\mathrm{e}}$ values below $5 \times 10^{-6}$, six are substrates of OCT1. The two substrates of OCT1 with larger $\mathrm{P}_{\mathrm{e}}$ values, meptazinol and 3-methoxymorphinan, lay between 1.4 and $1.7 \times 10^{-5}$ (see Table 3, section 3.2). The $\mathrm{P}_{\mathrm{e}}$ values of non-substrates were evenly spread across the spectrum (Figure 9).

These results nicely illustrate that substances with low membrane permeability are more likely to be substrates of OCT1 than those with high $\log \mathrm{D}_{(7.4)}$ and $\mathrm{P}_{\mathrm{e}}$ values.

\section{Inhibitors vs. non-inhibitors}

At 8.80 and 8.51 , the average $\mathrm{pK}_{\mathrm{a}}$ 's of inhibitors and non-inhibitors happen to be very similar. Their average $\log \mathrm{D}_{(7.4)}$ and $\mathrm{P}_{\mathrm{e}}$ values, however, differ markedly. While the average $\log \mathrm{D}_{(7.4)}$ 
and $\mathrm{P}_{\mathrm{e}}$ values of the inhibitors were 3.16 and 1.74, respectively, those of the non-inhibitors lay far below that, with a $\log \mathrm{D}_{(7.4)}$ of 0.83 and a $\mathrm{P}_{\mathrm{e}}$ value of $-0.16(\mathrm{p}=0.00014$ and $\mathrm{p}=0.023$, respectively, Table 7). The histogram in Figure 9 especially illustrates that non-inhibitors have low $\mathrm{P}_{\mathrm{e}}$ values, whereas inhibitors span the entire spectrum.

It appears that, while $\operatorname{low} \log \mathrm{D}_{(7.4)}$ and $\mathrm{P}_{\mathrm{e}}$ values are common in substrates of OCT1, they also correlate with a low probability for inhibitory potential.

Morphinans vs. synthetic opioids

Following fourteen substances are morphinans: morphine, codeine, oxycodone, oxymorphone, hydrocodone, hydromorphone, noroxycodone, naltrexone, and methlynaltrexone as well as dextromethorphan, dextrorphan, levorphanol, 3methoxymorphinan, and 3-hydroxymorphinan. Opposed to the morphinans are the synthetic opioids and their metabolites, whose chemical structure bears no resemblance to the polycyclic structure of the morphinans. The group of synthetic opioids was made up by nine substances: fentanyl, meptazinol, N-desmethyltramadol, norfentanyl, nortilidine, pethidine, sufentanil, tapentadol, and tilidine.

While there is little difference in the $\mathrm{pK}_{\mathrm{a}}$ values of morphinans and synthetic opioids (8.64 and 8.74 , respectively; $\mathrm{p}=0.675)$, the average $\log \mathrm{D}_{(7.4)}$ of the synthetic opioids lay above that of the morphinans, with values of 1.94 and 0.54 , respectively ( $\mathrm{p}=0.038$, Table 7 , Figure 7 , and Figure 8). These values indicate that synthetic opioids are more lipophilic than the classic morphinans, which is indeed their purpose. Synthetic opioids were designed to be more potent than classic opioid, and higher lipophilicity means these opioids can cross the bloodbrain barrier more easily and have a more powerful effect on the central nervous system. In comparison, the difference between the $\mathrm{P}_{\mathrm{e}}$ values of morphinans and synthetic opioids seems less marked (1.09 and 2.64, respectively; $\mathrm{p}=0.042)$; however, the discrepancy in the distribution of their $\mathrm{P}_{\mathrm{e}}$ values becomes visible in Figure 9, with the morphinans clearly clustered around low $\mathrm{P}_{\mathrm{e}}$ values. Dextromethorphan, on the far right of the $\mathrm{x}$-achsis, is the only morphinan with a $\mathrm{P}_{\mathrm{e}}$ value larger $2 \times 10^{-5}$ (Figure 9). In contrast, the $\mathrm{P}_{\mathrm{e}}$ values of the synthetic opioids did not fall below $1 \times 10^{-5}$.

Methylnaltrexone yielded the lowest $\mathrm{P}_{\mathrm{e}}\left(0.002 \pm 0.001 \times 10^{-5}\right)$ by far, indicating very poor membrane permeability. It was followed by morphine, 3-hydroxymorphinan, noroxycodone, hydromorphone, and norfentanyl, all of which are substrates of OCT1, and all of which, except for norfentanyl, are morphinans. 
Overall, OCT1 substrates, non-inhibitors, and morphinans have significantly lower $\log \mathrm{D}_{(7.4)}$ and $\mathrm{P}_{\mathrm{e}}$ values than their respective counterparts. Opioids with low lipophilicity are therefore more likely to be a substrate of OCT1, a non-inhibitor, or a morphinan (or a combination thereof) while more lipophilic opioids are more likely to be non-substrates, inhibitors, and synthetic opioids. 
Table 7: $\mathrm{pKa}, \log \mathrm{D}_{(7.4)}$, and $\mathrm{P}_{\mathrm{e}}$ values and their significance

\begin{tabular}{|c|c|c|c|}
\hline Opioid & $\mathrm{pKa}$ & $\log \mathrm{D}_{(7.4)}$ & $P_{e} \times 10^{-5}$ \\
\hline 3-Hydroxymorphinan & 9.39 & 1.03 & 0.073 \\
\hline 3-Methoxymorphinan & 9.72 & 1.36 & 1.7 \\
\hline Codeine & 8.43 & 0.44 & 0.80 \\
\hline Dextromethorphan & 8.92 & 2.51 & 6.4 \\
\hline Dextrorphan & 8.81 & 1.92 & 0.54 \\
\hline Fentanyl & 8.23 & 3.47 & 5.7 \\
\hline Hydrocodone & 8.59 & 0.32 & 0.91 \\
\hline Hydromorphone & 8.43 & 0.04 & 0.17 \\
\hline Levorphanol & 8.81 & 1.92 & 0.92 \\
\hline Meptazinol & 8.90 & 1.85 & 1.4 \\
\hline Methylnaltrexone & 9.15 & -1.59 & 0.002 \\
\hline Morphine & 8.30 & -0.05 & 0.016 \\
\hline Naltrexone & 7.63 & 0.81 & 1.5 \\
\hline N-Desmethyltramadol & 10.02 & 0.08 & 1.3 \\
\hline Norfentanyl & 9.62 & -0.33 & 0.26 \\
\hline Noroxycodone & 8.82 & -0.93 & 0.094 \\
\hline Nortilidine & 8.43 & 1.71 & 2.7 \\
\hline Oxycodone & 8.00 & 0.11 & 1.8 \\
\hline Oxymorphone & 7.89 & -0.28 & 0.32 \\
\hline Pethidine (Meperidine) & 8.91 & 0.93 & 4.0 \\
\hline Sufentanil & 7.78 & 3.38 & 3.8 \\
\hline Tapentadol & 9.29 & 1.39 & 1.4 \\
\hline Tilidine & 7.64 & 2.89 & 3.2 \\
\hline Average Total & 8.68 & 1.00 & 1.70 \\
\hline Average substrates & 9.04 & 0.17 & 0.47 \\
\hline Average non-substrates & 8.49 & 1.44 & 2.35 \\
\hline Significance (p-value) & 0.057 & 0.026 & 0.013 \\
\hline Average inhibitors & 8.80 & 1.74 & 2.37 \\
\hline Average non-inhibitors & 8.51 & -0.16 & 0.65 \\
\hline Significance (p-value) & 0,318 & 0,00014 & 0,023 \\
\hline Average morphinans & 8.64 & 0.54 & 1.09 \\
\hline Average synthetic opioids & 8.76 & 1.71 & 2.64 \\
\hline Significance (p-value) & 0.675 & 0.038 & 0.042 \\
\hline
\end{tabular}

The averages are given in bold, along with the significance of the differences between the averages for substrates vs. non-substrates, inhibitors vs. non-inhibitors, and morphinans vs. synthetic opioids. 

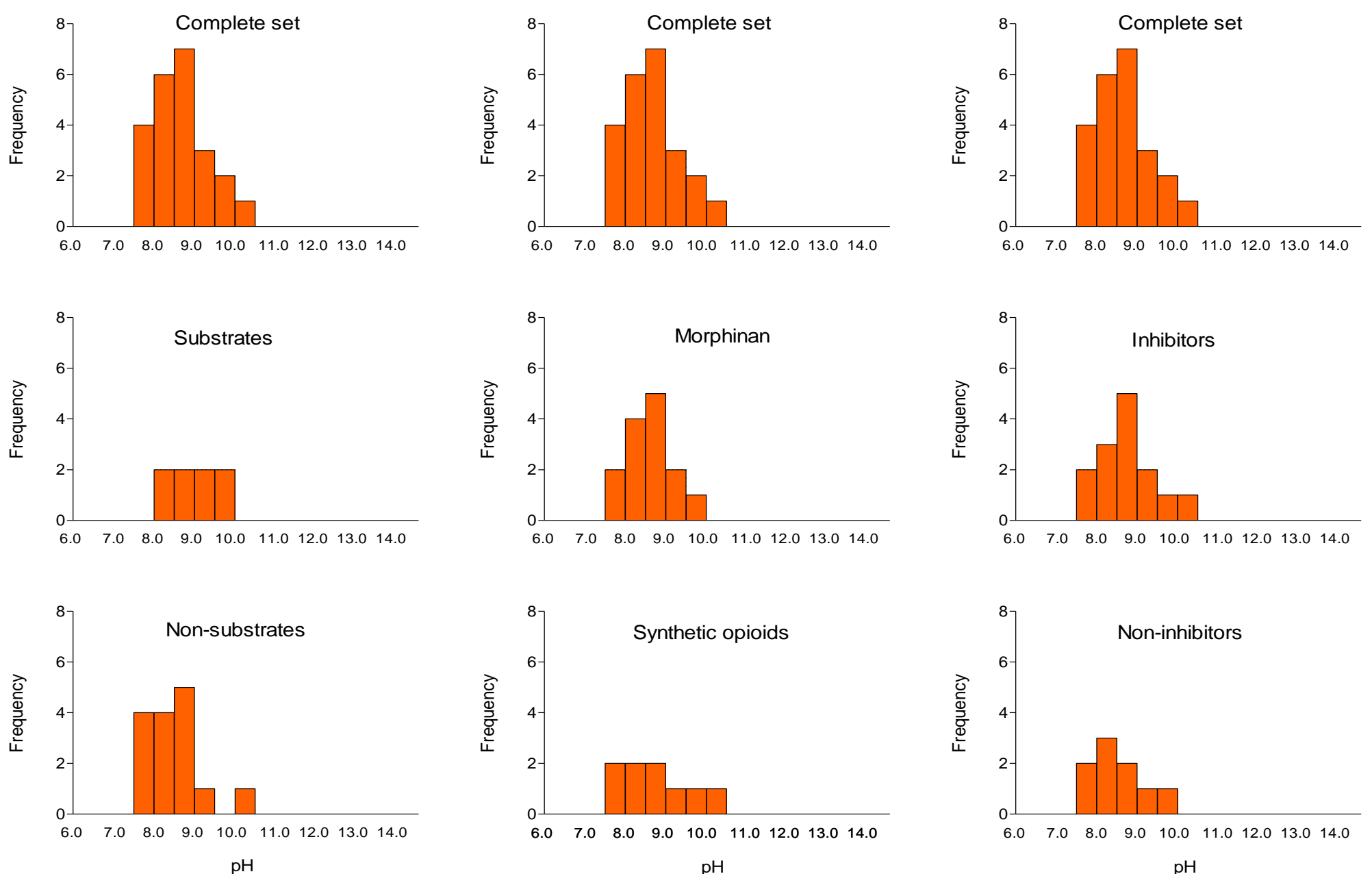

Figure 7: Histograms of pKa values for OCT1 substrates and non-substrates, morphinans and synthetic opioids, and OCT1 inhibitors and non-inhibitors 

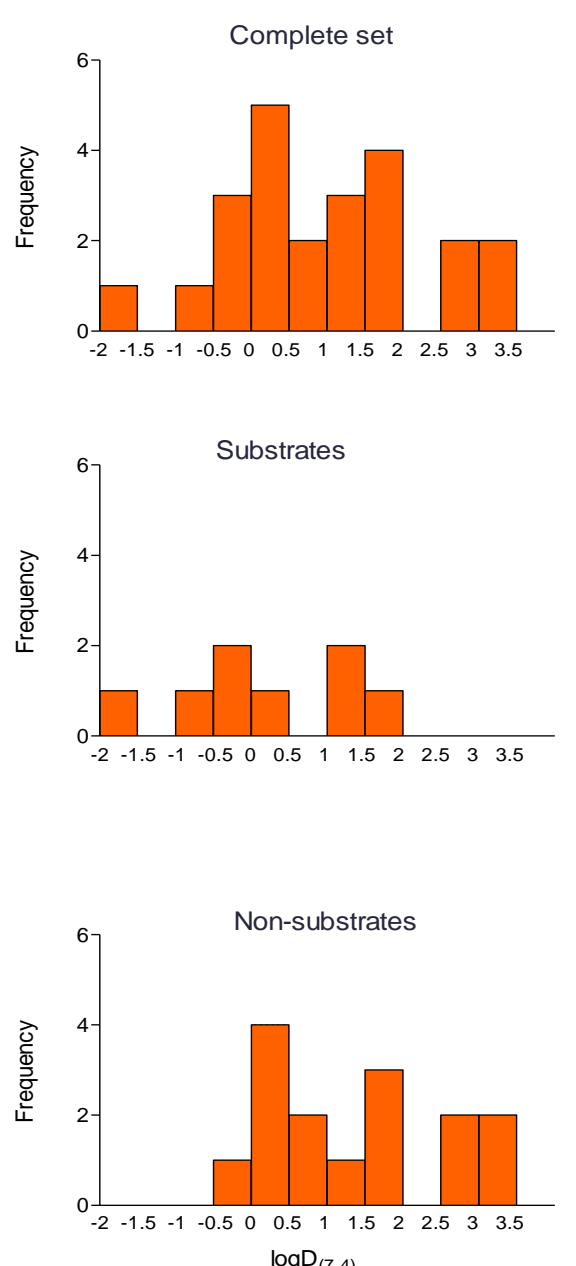
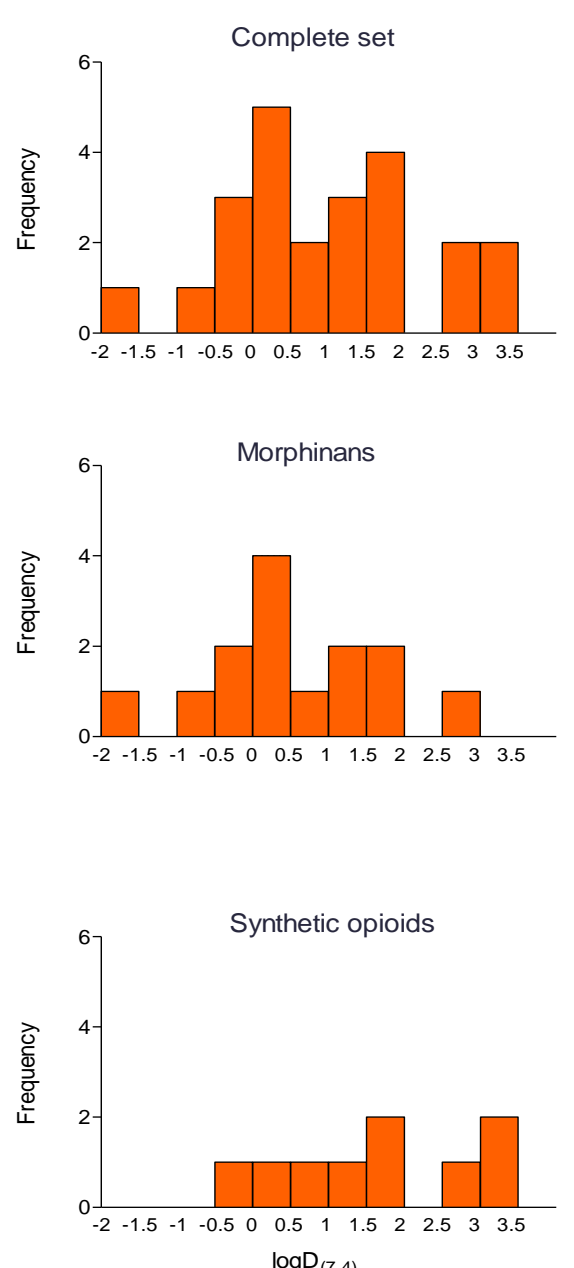
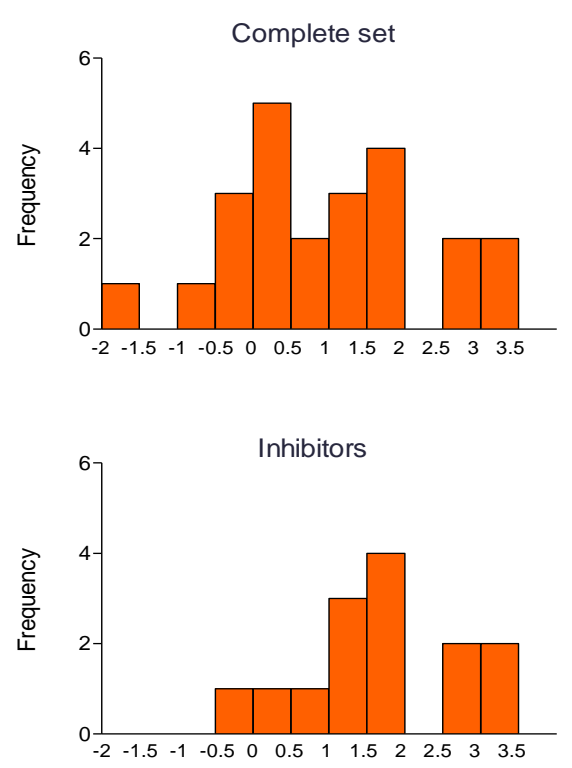

$B$

Figure 8: Histograms of $\log \mathrm{D}_{(7.4)}$ values for OCT1 substrates and non-substrates, morphinans and synthetic opioids, and OCT1 inhibitors and non-inhibitors 

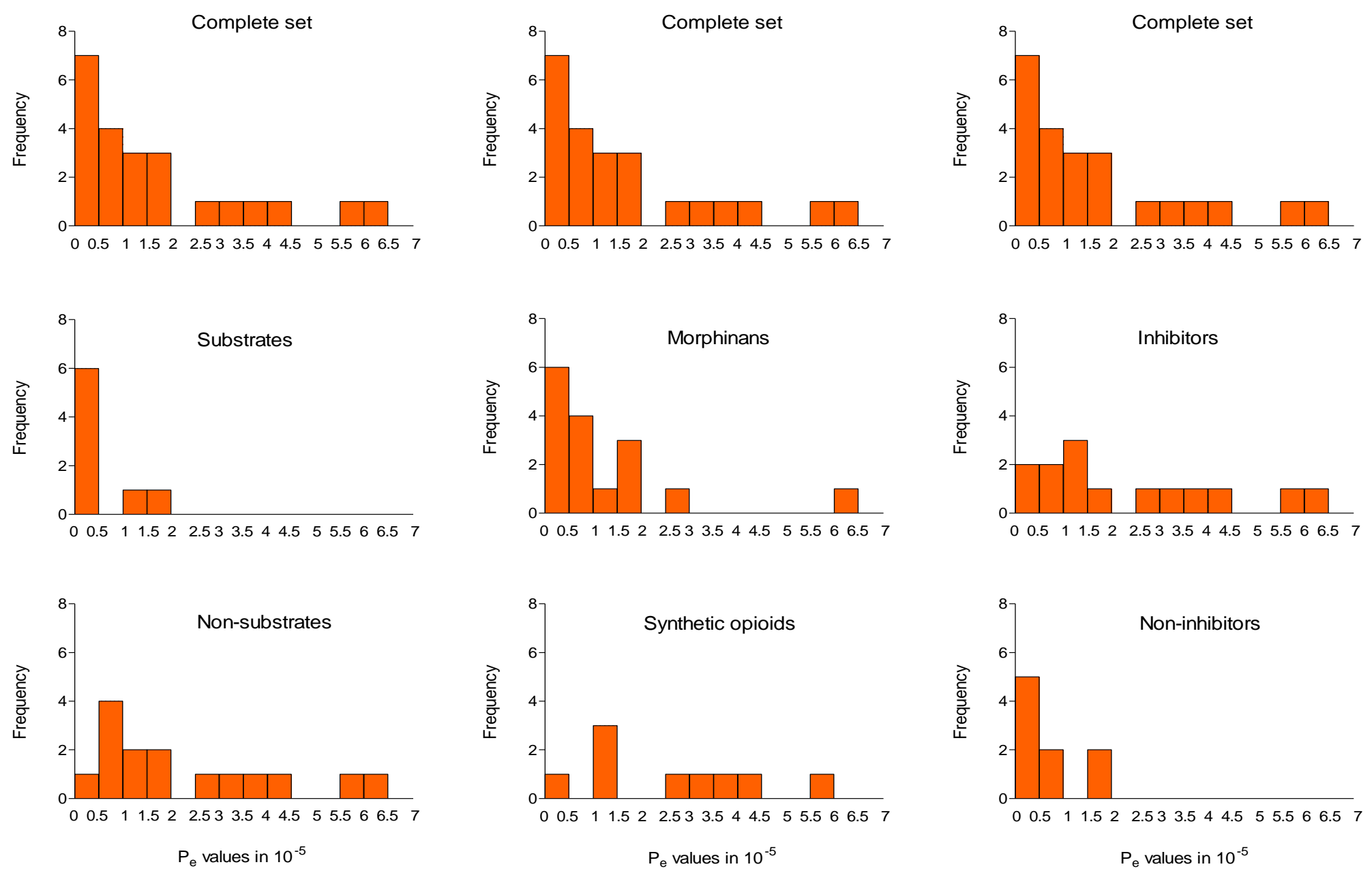

Figure 9: Histograms of $\mathrm{P}_{\mathrm{e}}$ values for OCT1 substrates and non-substrates, morphinans and synthetic opioids, and OCT1 inhibitors and non-inhibitors 

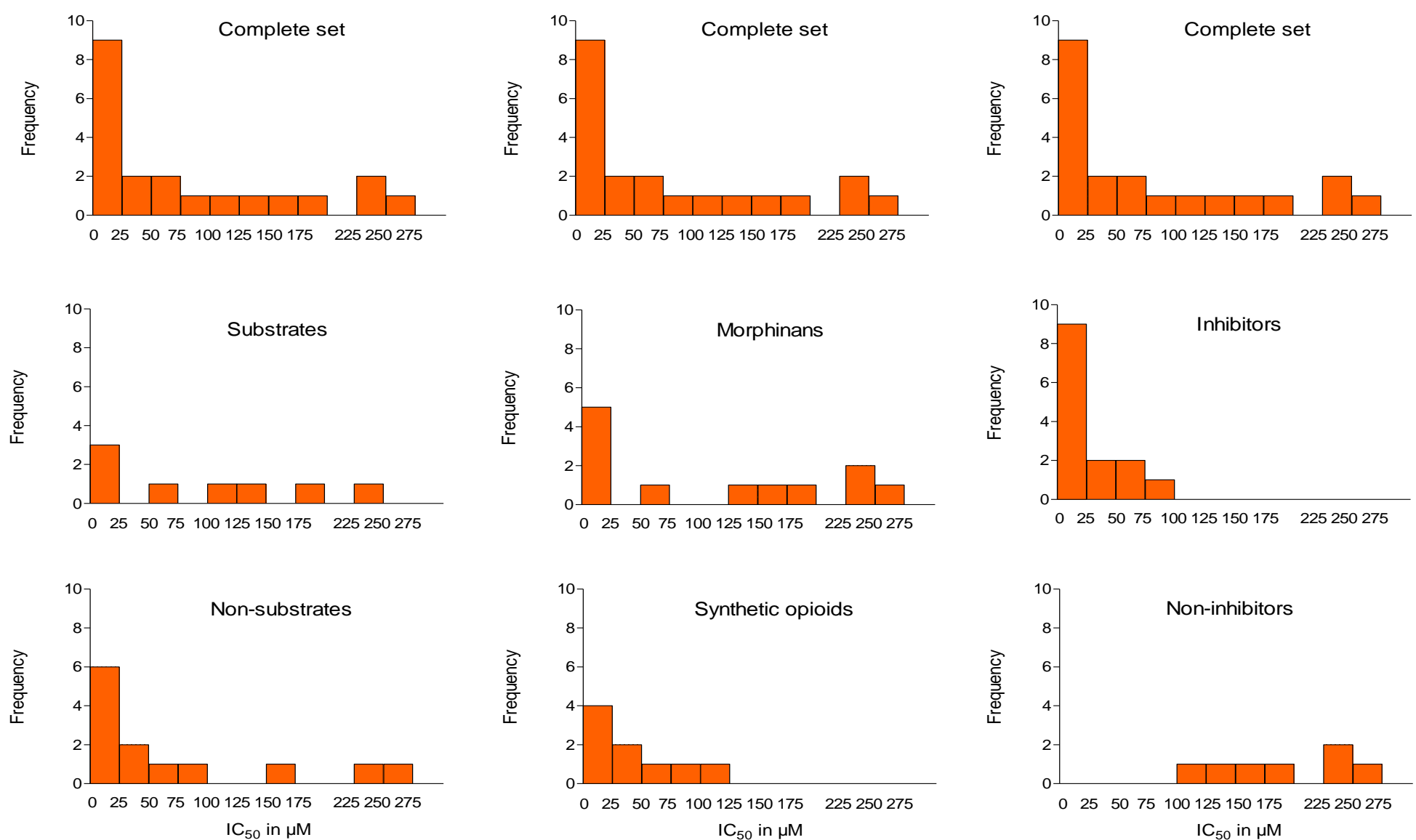

Figure 10: Histograms of IC $_{50}$ values for OCT1 substrates and non-substrates, morphinans and synthetic opioids, and OCT1 inhibitors and non-inhibitors In order to provide a better overview, outliers hydrocodone $\left(\mathrm{IC}_{50}=537 \mu \mathrm{M}\right)$ and oxycodone $\left(\mathrm{IC}_{50}=2004 \mu \mathrm{M}\right)$ have been omitted. 


\subsection{Structural aspects}

In the following we shall discuss which structural aspects might predispose a substance to be either a substrate of OCT1 or an inhibitor of OCT1, or to have no observed interaction with OCT1.

\section{$\underline{\text { Substrates }}$}

Six of eight substrates are opioids with a morphinan structure. The two exceptions are meptazinol, a synthetic opioid, and norfentanyl, metabolite of the synthetic opioid fentanyl. Norfentanyl, despite being a synthetic opioid, resembles the morphinans in its chemical properties more than it does the synthetic opioids (see Table 7, section 4.1).

Despite obvious shared characteristics (polycyclic structure, aromatic ring), a common denominator that singles out these opioids as substrates in contrast to, for example, dextrorphan or oxycodone, remains elusive.
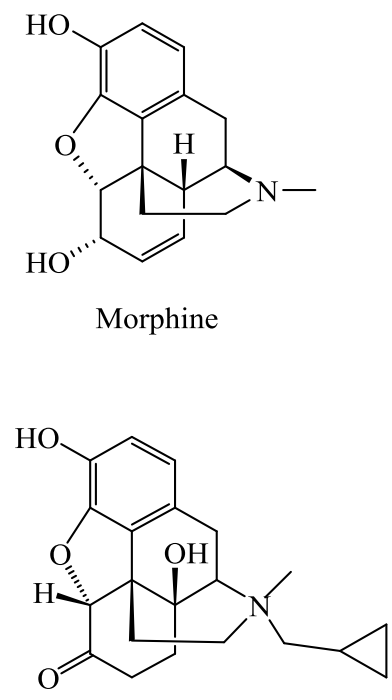

Methylnaltrexone
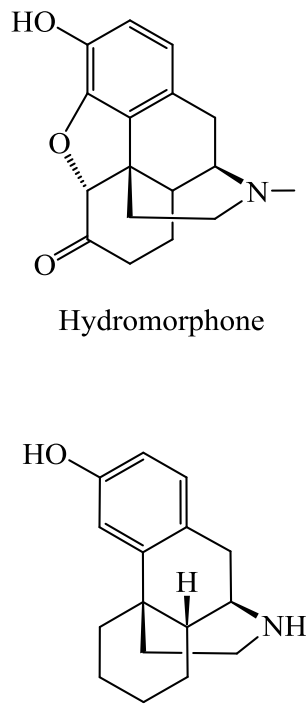

3-Hydroxymorphinan
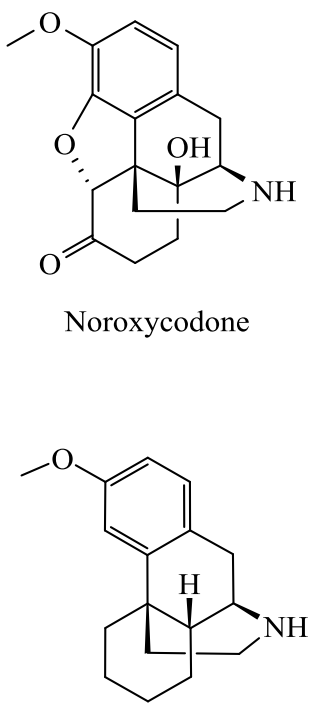

3-Methoxymorphinan<smiles>CCC(=O)N(c1ccccc1)C1CCNCC1</smiles>

Norfentanyl

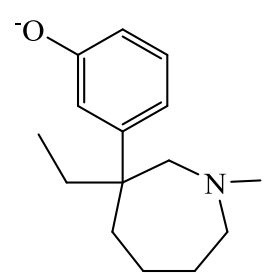

Meptazinol

Figure 11: Identified substrates of OCT1 


\section{$\underline{\text { Inhibitors }}$}

Synthetic opioids and their metabolites make up more than half the roster of inhibitors; of the fourteen inhibitors, eight are synthetic. Of the six inhibitors with a morphinan structure, morphine is the only "classic" morphinan; the other five inhibitors are dextromethorphan and its metabolites.

As mentioned in the introduction, substances with an inhibitory effect on OCT1 have different qualities in common. One of them is lipophilicity. The results from our PAMP assays confirm that the opioids identified by us as inhibitors are indeed more lipophilic than those that did not inhibit OCT1 (see Table 7). Additionally, all our inhibitors are at least partially charged at a physiological $\mathrm{pH}$ and have a relative dearth of hydrogen-bonding moieties (Figure 12). The properties intrinsic to our set of inhibitors are therefore in keeping with the model developed by Ahlin et al. (Ahlin et al. 2008).

As can be seen in Figure 13 and Figure 14, synthetic opioids and dextromethorphan-like morphinans interact strongly with OCT1. The dextromethrophans interact even more strongly than the synthetic opioids; of the five inhibitors with $\mathrm{IC}_{50}$ values below $20 \mu \mathrm{M}$, four are dextromethorphan-like morphinans. But again, we cannot name a specific moiety responsible for making an opioid an inhibitor of OCT1. 


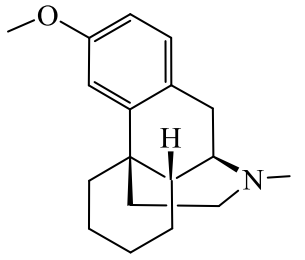

Dextromethorphan
$\mathrm{HO}$

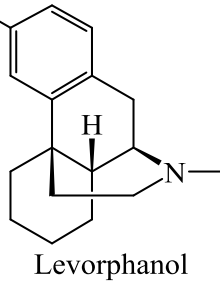

$\mathrm{HO}$

Morphine

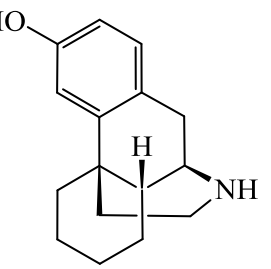

3-Hydroxymorphinan

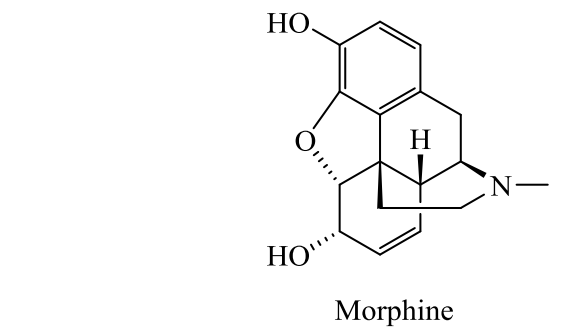

$\mathrm{HO}$

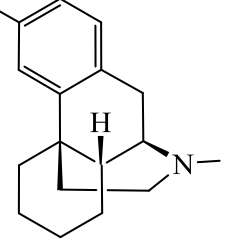

Dextrorphan

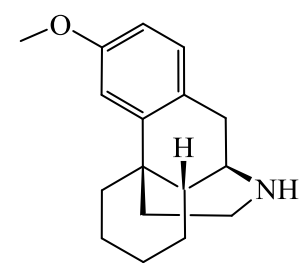

3-Methoxymorphinan<smiles>CCC(=O)N(c1ccccc1)C1CCN(CCc2ccccc2)CC1</smiles><smiles>CCC(=O)N(c1ccccc1)C1(COC)CCN(CCc2cccs2)CC1</smiles>

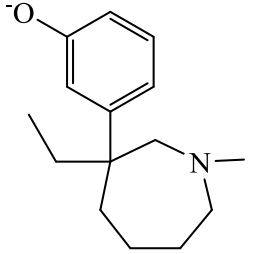

Meptazinol

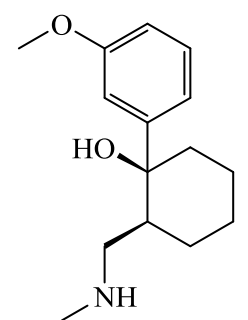

N-Desmethyltramadol<smiles>CCOC(=O)C1(c2ccccc2)CCC2CCC1C2(C(=O)O)N(C)C</smiles>

Tilidine

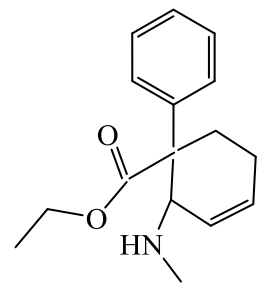

Nortilidine<smiles>CC[C@@H](c1cccc(O)c1)[C@H](C)CN(C)C</smiles>

Tapentadol<smiles>CCOC(=O)C1(c2ccccc2)CCN(C)CC1</smiles>

Pethidine

Figure 12: Identified inhibitors of OCT1 

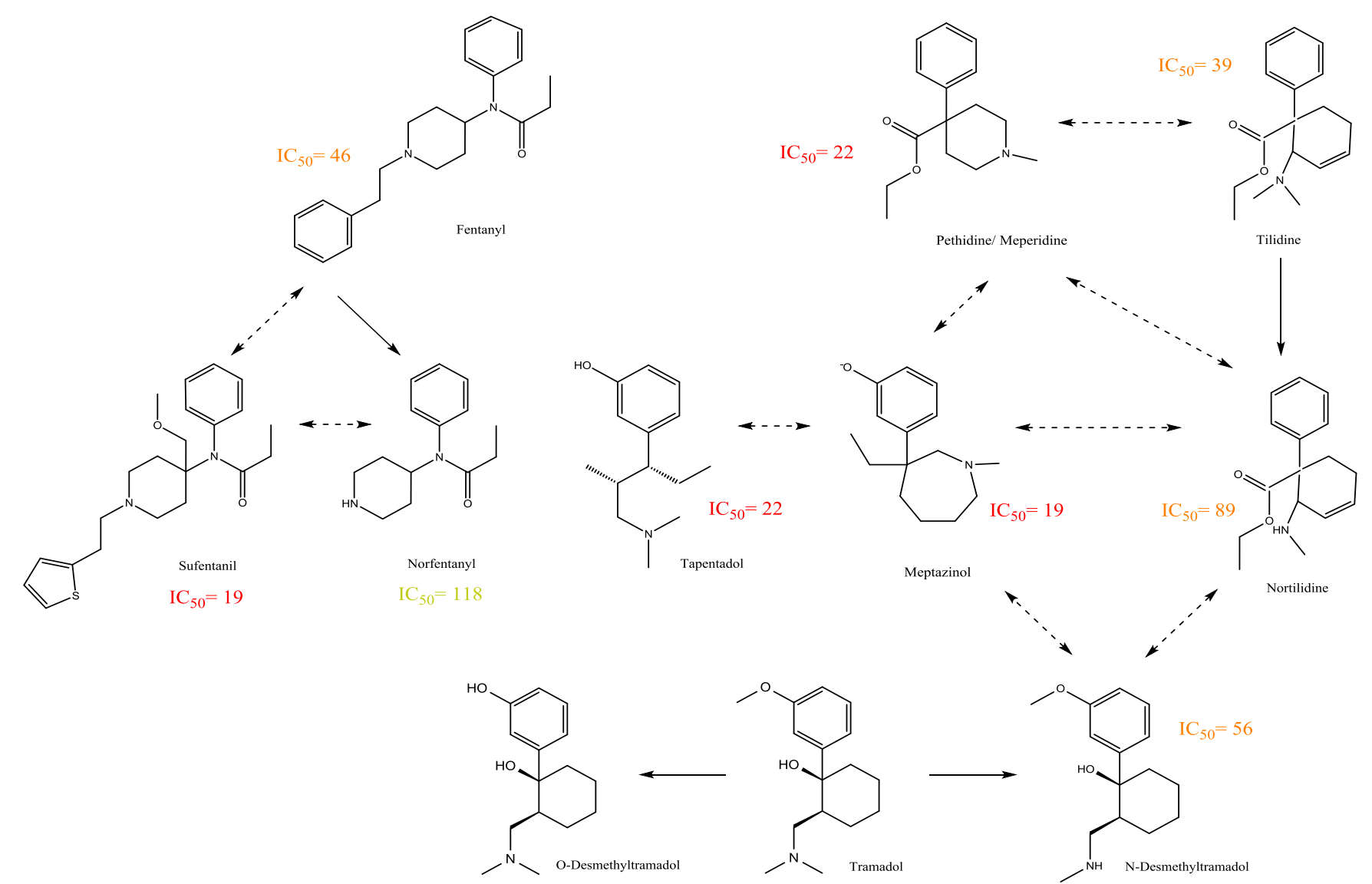

Figure 13: Synthetic opioids and their respective $\mathrm{IC}_{50}$ values

Normal arrows indicate a metabolic, dashed arrows a structural relationship. Tramadol und O-desmethyltramadol have been discussed elsewhere (Tzvetkov et al. 2011) and are merely included to provide a better overview. IC $\mathrm{C}_{50}$ values are given in $\mu \mathrm{M}$. 


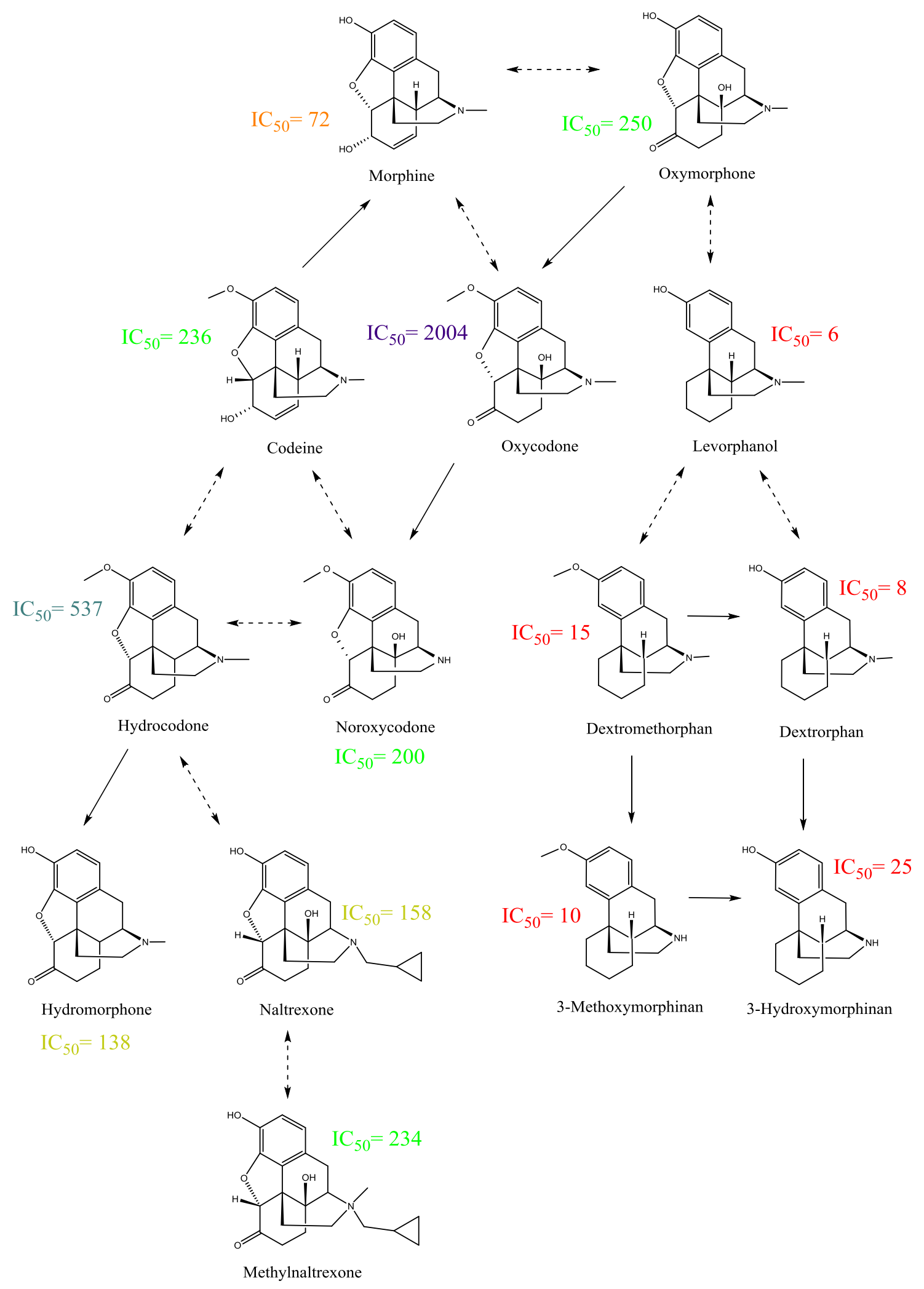

Figure 14: Morphinans and their respective $\mathrm{IC}_{50}$ values

Normal arrows indicate a metabolic, dashed arrows a close structural relationship. $\mathrm{IC}_{50}$ s are given in $\mu \mathrm{M}$. 


\section{$\underline{\text { No observed interaction }}$}

Five substances did not observably interact with OCT1 either in the way of substrates or in that of inhibitors: codeine, hydrocodone, naltrexone, oxycodone, and oxymorphone (Figure 15).

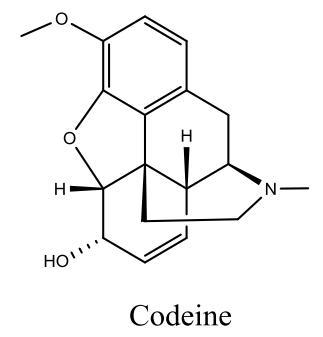

Codeine

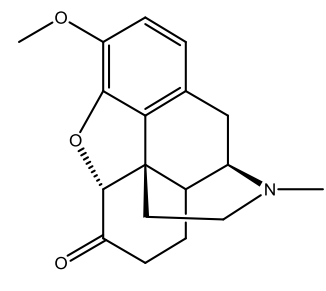

Hydrocodone

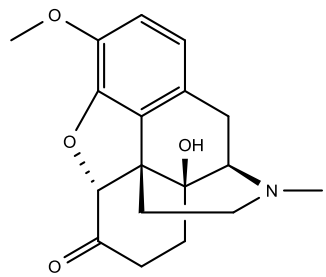

Oxycodone

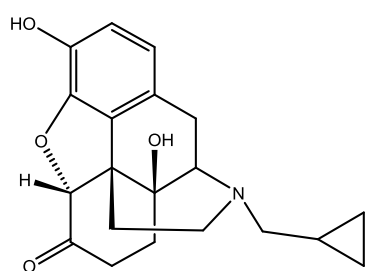

Naltrexone

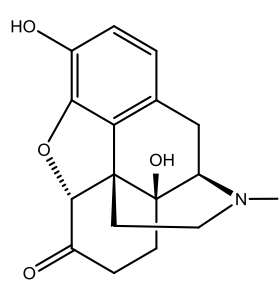

Oxymorphone

Figure 15: Opioids with no observed interaction with OCT1

The observation that naltrexone does not interact with OCT1 is surprising because only a methyl group at the nitrogen atom distinguishes it structurally from methylnaltrexone, which proved to depend heavily on OCT1-mediated transport. However, with a $\mathrm{P}_{\mathrm{e}}$ of $1.5 \times 10^{-5}$ naltrexone is a lot more lipophilic than methylnaltrexone $\left(\mathrm{P}_{\mathrm{e}}\right.$ of $\left.0.002 \times 10^{-5}\right)$. It remains similarly mystifying why hydromorphone should be a substrate of OCT1 while oxymorphone is not, or why noroxycodone relies on OCT1-mediated transport while oxycodone, quite overwhelmingly, does not interact with OCT1 at all. 


\subsection{Aspects of metabolism}

Six of the eight substances we identified as OCT1 substrates are metabolites of other opioids: 3-methoxymorphinan and 3-hydroxymorphinan are metabolites of dextromethorphan; hydromorphone is a metabolite of hydrocodone, morphine of codeine, noroxycodone of oxycodone, and norfentanyl of fentanyl. At the same time, four of the substances -3methoxymorphinan, morphine, meptazinol and hydromorphone- are amenable to further metabolization, i.e. they are parent compounds themselves. These four compounds are active until biotransformation, mainly hepatocytic glucuronidation, leads to their inactivation (see Appendix for more detail).

We observed that uptake of metabolite opioids by OCT1-overexpressing cells was elevated compared to that of their parent compounds, which were often not transported by OCT1 at all (Figure 16). A possible explanation for this observation is that biotransformation renders opioids more hydrophilic and thus more dependent on transporter-mediated uptake and release from hepatocytes, whereas the parent compounds are more lipophilic and thus capable of crossing cell membranes independently of OCT1 via diffusion.

The metabolic progression of dextromethorphan and its metabolites in Figure 16 nicely illustrates how OCT1-mediated transport progresses with each modification introduced by biotransformation. Unfortunately, we lack data on OCT1-mediated transport -if present- of the glucuronidated metabolites of hydromorphone, meptazinol, and morphine. It would be interesting to see if OCT1-mediated transport of their metabolites increases in the same fashion as observed with dextromethorphan. 

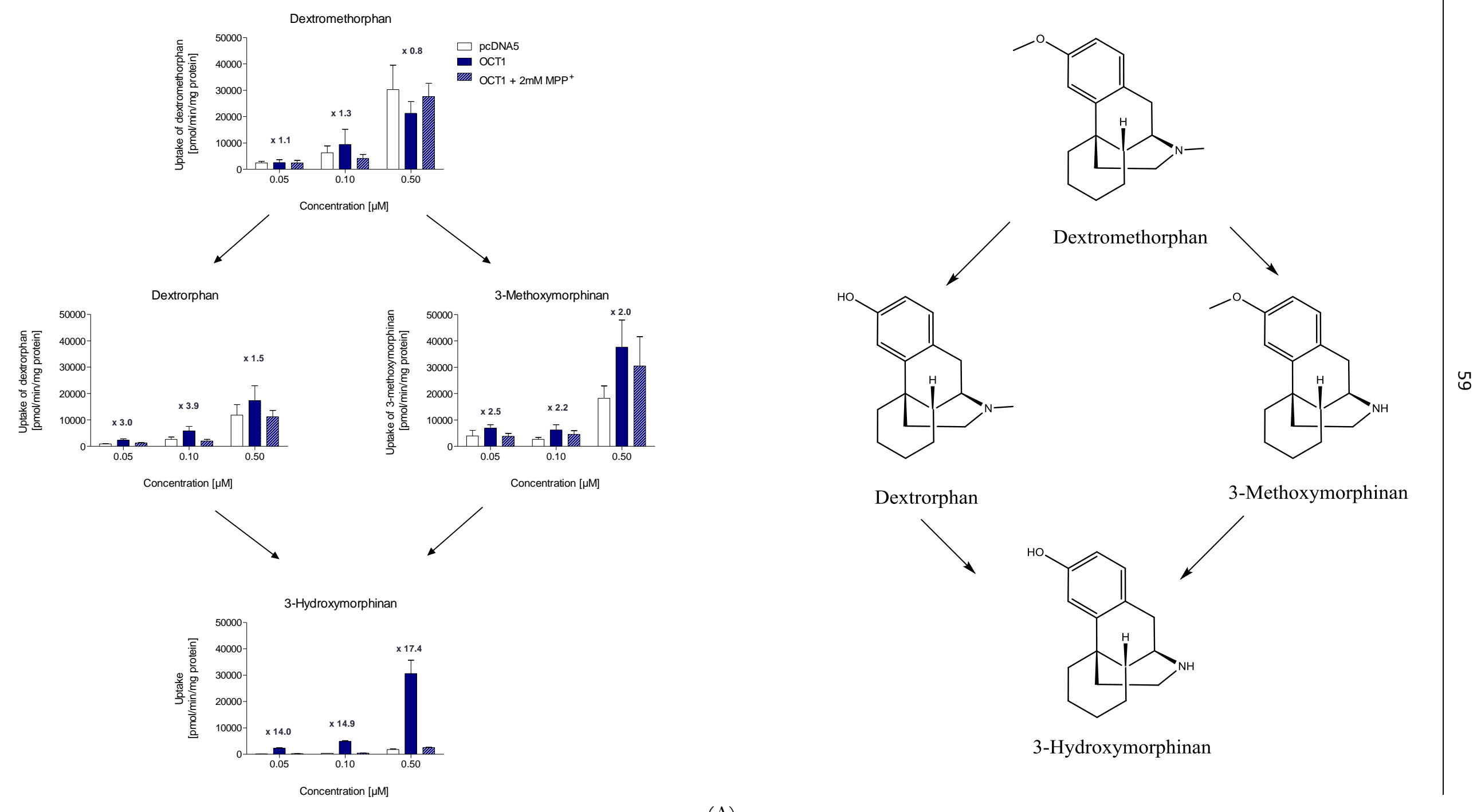

(A) 

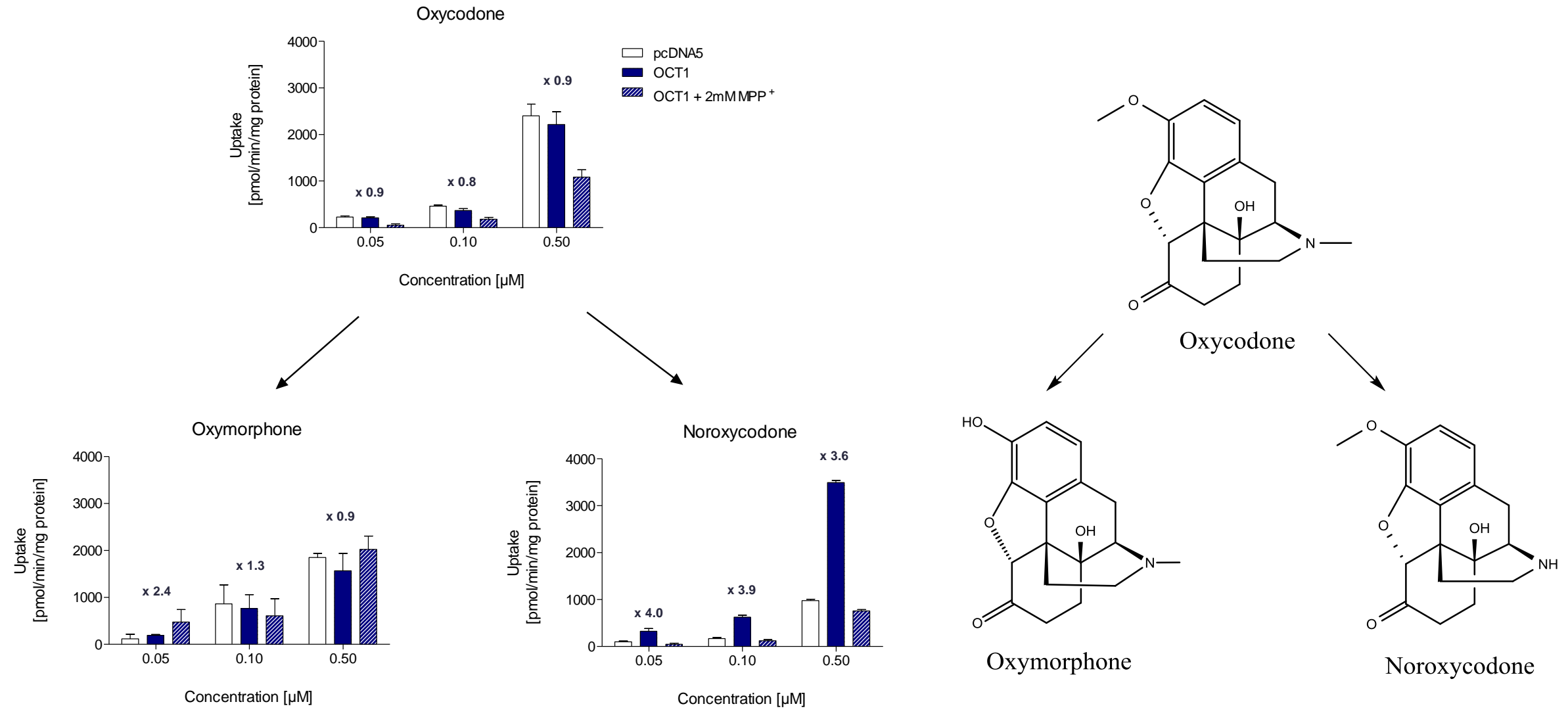

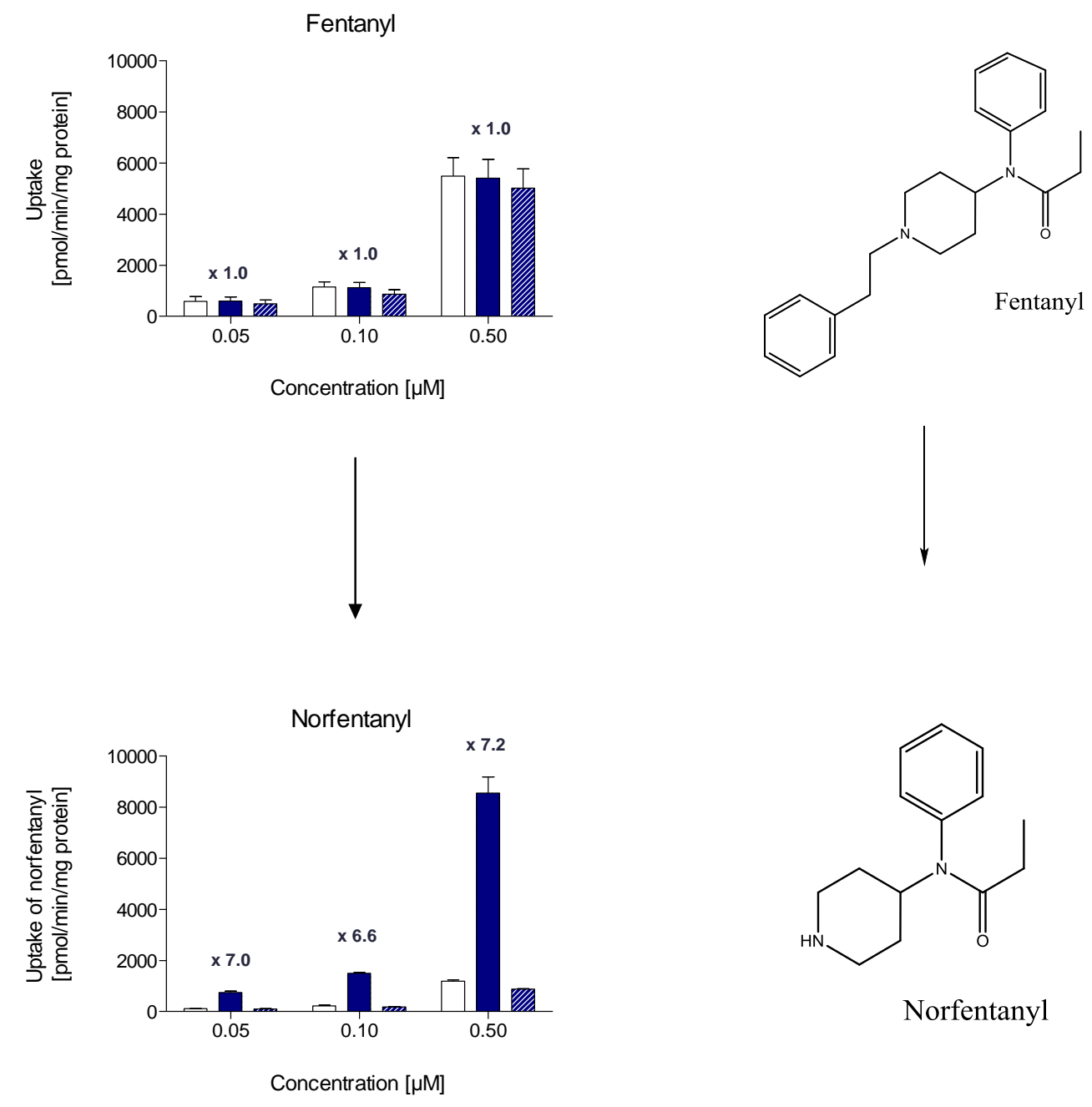

(C) 


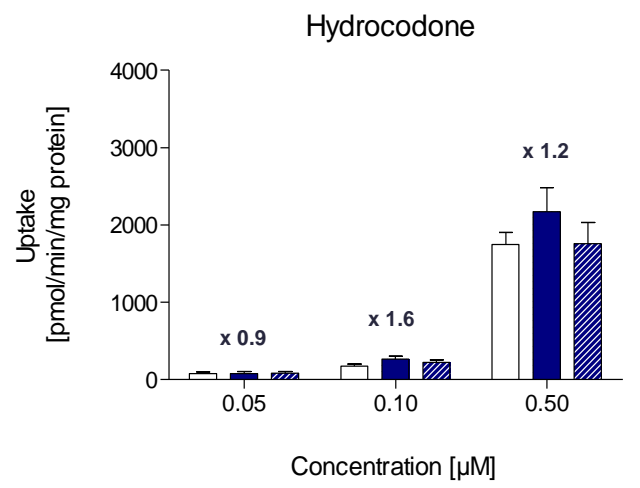

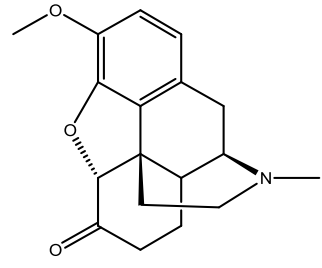

Hydrocodone

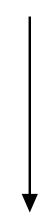

Hydromorphone

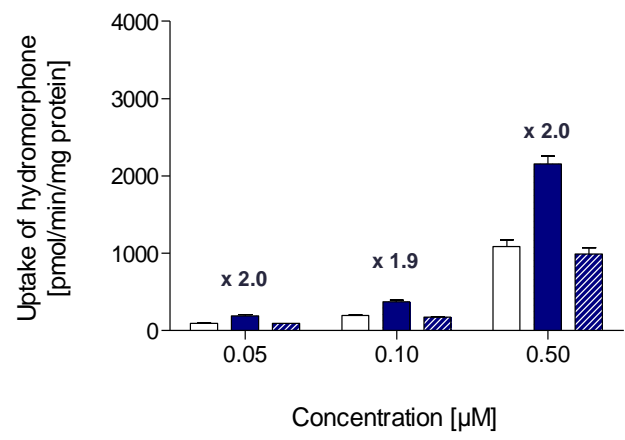

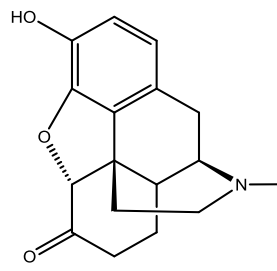

Hydromorphone

(D)

Figure 16: Uptake of parent compounds and their metabolites

(A) Progressive increase in OCT1-dependent uptake of dextromethorphan and its metabolites. (B) Uptake is only increased for oxycodone metabolite noroxycodone, not for its alternative metabolite oxymorphone. (C) Uptake of fentanyl is not altered in the presence of OCT1 but that of its metabolite norfentanyl is. (D) OCT1-dependent transport of hydromorphone is increased compared to that of its parent compound hydrocodone. 


\subsection{Clinical aspects}

Identifying opioids as either substrates or inhibitors of OCT1 is not merely an exercise born from academic interest; it is also an attempt to understand -and possibly predict- how opioids administered in a clinical setting may affect patients. We shall therefore now discuss the ramifications of our findings and attempt to put them into a practical context.

\section{$\underline{\text { Substrates }}$}

Morphine aside, we identified seven novel substrates, three of which act upon opioid receptors: hydromorphone, meptazinol, and methylnaltrexone. The other four -3hydroxymorphinan, 3-methoxymorphinan, norfentanyl, and noroxycodone- are considered inactive with respect to opioid receptor activity.

The relative increase in the uptake of hydromorphone was the lowest of all substrates. Taking into account that the absolute uptake of oxycodone -not a substrate of OCT1 - into OCT1overexpressing cells was equal to that of hydromorphone, it seems highly improbable that OCT1 polymorphisms would have a clinically noticeable impact on hydromorphone plasma concentrations. However, hydromorphone is a widely employed analgesic, and the impact of OCT1 polymorphisms on its metabolization, however marginal, should not be easily dismissed.

Meptazinol is the most lipophilic of the substrates, and the only active member of the class of synthetic opioids that qualifies as a substrate. It is also extensively metabolized by the liver, so that OCT1 might indeed play a role in its phase 0 biotransformation and elimination (Franklin et al. 1975). It would be worth investigating if and in how far plasma concentrations of meptazinol are affected by diminished OCT1 transport capacities.

Methylnaltrexone turned out to rely heavily on OCT1-mediated transport. Though methylnaltrexone interacted poorly with OCT1 in the presence of $\mathrm{ASP}^{+}$and failed to qualify as an inhibitor by a wide margin $\left(\mathrm{IC}_{50}\right.$ of $\left.234.39 \mu \mathrm{M}\right)$, its uptake via OCT1 skyrocketed in the absence of competing substrates. Assumedly, when in direct competition for the binding site that mediates transportation, $\mathrm{ASP}^{+}$binds more efficiently to OCT1 than methylnaltrexone. Otherwise the fact that methylnaltrexone is transported by OCT1 came not entirely surprising, considering that methylnaltrexone's quaternary nitrogen atom and low membrane permeability essentially render it unsuitable for diffusion. The relative increase in uptake $32 \mathrm{x}$, 68x, and 86x) was impressive nevertheless (see Figure 6, section 3.4.1). 
It also remains uncertain in how far OCT1-mediated transport of methylnaltrexone into the liver is clinically relevant, considering that $60 \%$ of methylnaltrexone are excreted unchanged and thus independently of hepatic biotransformation (see Appendix for more detail). Instead, methylnaltrexone might play a greater role in research as a new, highly sensitive model substrate for OCT1.

The other substrates do not currently have any confirmed clinical effects. Even if their plasma concentrations were affected by diminished OCT1 transport capacities, the consequences of such diminished transport would bear little or no clinical relevancy.

\section{$\underline{\text { Inhibitors }}$}

Though our main interest initially lay with the substrates of OCT1, our results gradually shifted our focus to the inhibitors. Since OCT1 is one of the transporters most involved in the metabolism of a wide range of drugs, the opioids identified by us as inhibitors of OCT1 have at least the potential to affect the transport of such drugs into OCT1-expressing cells. In order to assess which of the inhibitors might, at least in theory, affect OCT1-mediated uptake in vivo, we calculated the ratio of the opioids' maximal unbound plasma concentration in the portal vein and our experimentally determined $\mathrm{IC}_{50}$ values as described elsewhere (Ito et al. 2002; Ahlin et al. 2011). These calculations are of interest in so far as they attempt to translate our findings from an in vitro set up into an in vivo environment. However, they cannot level out the experimental nature of our findings entirely.

The $\mathrm{IC}_{50} \mathrm{~s}$ were determined by measuring how effectively they inhibited the uptake of a test substrate. In our case, this test substrate was $\mathrm{ASP}^{+}$, which yielded an $\mathrm{IC}_{50}$ of $72 \mu \mathrm{M}$ for morphine. This value is more than fifteen-times as high as the $4.2 \mu \mathrm{M}$ reported by Tzvetkov et al.; however, latter determined the $\mathrm{IC}_{50}$ of morphine using the model substrate $\mathrm{MPP}^{+}$and liquid scintillating counting (Tzvetkov et al. 2013). So while the calculations presented in Table 8 nudge us into promising directions in terms of future research, the opioids' $\mathrm{K}_{\mathrm{m}}$ and $\mathrm{V}_{\max }$ are needed in order to fully appreciate their effects on OCT1.

Of the fourteen in vitro inhibitors, dextromethorphan, levorphanol, and tapentadol emerged as candidates that may be potent enough at clinically realistic plasma concentrations to inhibit OCT1 in vivo. Tapentadol yielded especially high ratios in both the immediate and extended release formulation (0.86 and 0.88 , respectively) as did levorphanol (0.88) when administered repeatedly. Tapentadol and levorphanol are both opioids employed in chronic pain management, which means that they are likely to reach steady-state concentrations and that, due to the respective patient population, they are likely to be co-administered along with 
other drugs, which may well rely on OCT1-mediated uptake for metabolization (e.g. the antiemetic odansetron). Further studies would be needed to confirm or invalidate such interactions in actual patients, but given the broad spectrum of available opioids, our experimental data may invite clinicians to defer from administering tapentadol and levorphanol in favor of opioids such as oxycodone or hydrocodone (always provided the patients tolerate them).

Dextromethorphan -somewhat confusingly on first glance- only seems to have an effect in extensive metabolizers of CYP2D6. The CYP2D6 genotype should not affect the portal venous concentrations of dextromethorphan, since the drug has only just been absorbed from the gut and not yet been metabolized by the liver (and even if we assumed we had reached steady-state plasma concentrations after repeated dosing, we would expect the concentration of dextromethorphan to be higher in poor than in extensive metabolizer). However, in the studies from which we took the plasma concentrations for dextromethorphan, test subjects with a known PM CYP2D6 genotype were given lower doses of dextromethorphan than those with an EM CYP2D6 genotype (Thummel et al. 2005). It is fair to assume that, had the PMs been given the same dose of dextromethorphan as the EMs rather than just half of it, that their portal venous concentration of dextromethorphan would have equalled that of the EMs. We can only speculate that patients with a PM CYP2D6 genotype, since less effective at metabolizing dextromethorphan, will suffer prolonged inhibition of OCT1. But since patients have unchecked access to cough syrups with dextromethorphan and the PM CYP2D6 is relatively common in the Caucasian population, it would be well worth it to further explore the inhibitory effects of dextromethorphan on OCT1 in clinical studies. 
Table 8: Inhibition of OCT1-mediated uptake by opioids identified as inhibitors of OCT1 in vitro

\begin{tabular}{|c|c|c|c|c|c|c|}
\hline Inhibitor & $\mathrm{IC}_{50}, \mu \mathrm{M}$ & Dose p.o., mg & $\begin{array}{l}\text { Plasma conc. } \\
\max , \mu \mathrm{g} / 1\end{array}$ & $\begin{array}{c}\text { Plasma conc. } \\
\max , \mu \mathrm{M}\end{array}$ & Cmax portal unb., $\mu \mathrm{M}$ & Cmax portal unb/ $\mathrm{IC}_{50}$ \\
\hline Dextromethorphan EM & 15.1 & 60 & 5.2 & 0.019 & 4.813 & 0.318 \\
\hline Dextromethorphan PM & 15.1 & 30 & 33 & 0.122 & 2.446 & 0.161 \\
\hline Levorphanol, repeated dose & 8.5 & 50 & 10 & 0.039 & 7.473 & 0.881 \\
\hline Levorphanol, single dose & 8.5 & 2 & 100 & 0.389 & 0.313 & 0.037 \\
\hline Morphine IR, single dose & 71.8 & 10 & 10 & 0.035 & 1.438 & 0.020 \\
\hline Morphine ER, single dose & 71.8 & 50 & 7.4 & 0.026 & 7.091 & 0.099 \\
\hline Tapentadol IR & 21.9 & 86 & 22.5 & 0.102 & 19.539 & 0.892 \\
\hline Tapentadol ER & 21.9 & 86 & 64.2 & 0.290 & 19.388 & 0.886 \\
\hline Tilidine & 38.7 & 50 & 30 & 0.110 & 8.029 & 0.207 \\
\hline
\end{tabular}

\section{Parenteral administration}

\begin{tabular}{|c|c|c|c|c|c|c|}
\hline Inhibitor & $\mathrm{IC}_{50}, \mu \mathrm{M}$ & Dose, $\mathrm{mg}$ & $\begin{array}{l}\text { Plasma conc. } \\
\max , \mu g / 1\end{array}$ & $\begin{array}{c}\text { Plasma conc. } \\
\max , \mu \mathrm{M}\end{array}$ & Cmax portal unb., $\mu \mathrm{M}$ & Cmax portal unb/ $\mathrm{IC}_{50}$ \\
\hline Fentanyl & 46.2 & $0,4 \mathrm{mg}$ t.m. & 0.8 & 0.002 & $<0.000$ & $<0.000$ \\
\hline Meptazinol & 19.0 & $25 \mathrm{mg}$ i.v. & 90 & 0.386 & 0.104 & 0.005 \\
\hline Morphine & 71.8 & $10 \mathrm{mg}$ i.v. & 400 & 1.402 & 0.911 & 0.013 \\
\hline Pethidine (Meperidine) & 22.3 & $\begin{array}{l}24 \mathrm{mg} / \mathrm{hr} \text { i.v. to } \\
\text { steady state }\end{array}$ & 670 & 2.709 & 1.138 & 0.051 \\
\hline Sufentanil & 19.4 & i.v. & 10 & 0.026 & 0.002 & 0.000 \\
\hline Tilidine & 38.7 & $50 \mathrm{mg}$ i.v. & 906 & 3.314 & 2.320 & 0.060 \\
\hline
\end{tabular}

In order to assess the inhibitory potential of the opioids, we calculated the ratio of the opioids' maximal unbound concentration in the portal vein and the experimentally determined $\mathrm{IC}_{50}$ values. Ratios greater 0.25 indicate inhibitory potential. In parenteral administration, the peripheral plasma concentrations are equivalent to portal venous concentrations; calculating the portal venous concentration was therefore not necessary. Data on 3-hydroxymorphinan, 3-methoxymorphinan, dextrorphan, Ndesmethyltramadol, and nortilidine was not sufficiently available to calculate their ratios. 
Cmax plasma unb., maximal concentrations of the unbound drug in plasma; Cmax portal unb., maximal concentrations of the unbound drug in portal vein; EM, extensive metabolizer (regarding CYP2D6); PM, poor metabolizer (regarding CYP2D6); IR, immediate release; ER, extended (sustained) release; N.A., not available

${ }^{a}$ The maximal plasma concentration of the unbound drug (Cmax plasma unb.) was calculated by multiplying the Cmax by the fraction unbound in plasma. The maximal plasma concentrations and the fraction unbound to plasma proteins were obtained from Gilman and Goodman's The Pharmacological Basis of Therapeutics (Thummel et al. 2005) for fentanyl, morphine, and pethidine; from Gilman and Goodman's The Pharmacological Basis of Therapeutics (Thummel et al. 2005) and Taylor (Taylor et al. 2016) for dextromethorphan; from Hajda et al (Hajda et al. 2002) for tilidine; from the FDA's Professional Drug Information (FDA) and Dixon et al (Dixon et al. 1983) for levorphanol; from Gohler et al (Göhler et al. 2013) for tapentadol; and from Opioids in Cancer Pain (Hall and Hardy 2009) and Schmerztherapie (Standle et al. 2010) for sufentanil.

${ }^{\mathrm{b} C} \mathrm{Cmax}$ portal unb. values were estimated according to the method described before by Ito et al (2002) and Ahlin et al (2011). 


\subsection{Conclusion}

We were able to identify seven novel substrates of OCT1, three of which could be relevant in a clinical context should they be affected by diminished OCT1 transport capacities, and fourteen inhibitors of OCT1, again three of which could affect OCT1-mediated transport in vivo.

From the point of view of OCT1 and its polymorphisms, we were able to identify five opioids -namely codeine, hydrocodone, naltrexone, oxycodone, and oxymorphone- as clinically "safe" opioids, i.e. as opioids that interact neither as substrates nor inhibitors with OCT1. Since they have no touching points with OCT1, we can expect plasma concentrations of these opioids to go unaffected by variegations in OCT1 transport capacities, whether brought about by either genetic variations or by pharmacologic interactions. Nor would we expect them to affect the plasma concentrations of drugs dependent on OCT1-mediated transport. However, we only dealt with wild type OCT1 in our experiments and cannot exclude that these opioids do not interact with certain variations of OCT1. Further testing would be needed in order to elucidate if these opioids are indeed "genetically indifferent" as far as variations in SLC22A1 are concerned.

From a chemical point of view, our results yielded that low lipophilicity -in the semblance of $\operatorname{low} \log \mathrm{D}_{(7.4)}$ and $\mathrm{P}_{\mathrm{e}}$ values- increase the probability that a given opioid will be an OCT1 substrate, a non-inhibitor, and a morphinan, while high lipophilicity can be associated with non-substrates, inhibitors, and synthetic opioids. Additionally, the class of synthetic opioids and the one of dextromethorphan-like morphinans -which are mostly lipophilic substancesturned out to be especially potent inhibitors of OCT1 in vitro, whereas morphine-like morphinans -generally less lipophilic opioids- inhibit OCT1 transport capabilities only to a moderate degree. However, we are as yet unable to pinpoint a specific moiety or structural quirk that flags a drug as either substrate or inhibitor.

All in all, further experiments will be needed to elucidate the interactions between inhibitors and substrates with OCT1 and each other. Inhibitor-substrate interactions should be evaluated in OCT1 non-overexpressing cells (e.g. human hepatocytes) and at therapeutic concentrations (e.g. OCT1 inhibitor tapentadol in combination with OCT1 substrate rocuronium) to elucidate if and to what extent the opioids identified as potent inhibitors of OCT1 affect OCT1-mediated uptake of other substances. The most common OCT1 variants ought also to be assessed with respect to their uptake of the identified substrates. 


\section{$5 \quad$ Abstract}

The organic cation transporter 1 (OCT1) is primarily located in the sinusoidal membranes of hepatocytes and mediates phase 0 biotransformation of xenobiotics, including weak basic and cationic drugs. Variations in SLC22A1, the gene encoding OCT1, are common throughout the Caucasian population. Close to $9 \%$ of Caucasians are homozygotic for OCT1 alleles that encode insufficient transporters, resulting in a partial or complete loss of OCT1 transport activity in affected individuals. Clinical studies have demonstrated that diminished OCT1 transport activity leads to elevated plasma levels of opioids morphine and Odesmethyltramadol (the active metabolite of tramadol). Patients with diminished-activity OCT1 alleles require 20\% less tramadol for efficient postoperative pain management and suffer more adverse effects after morphine consumption. These findings are all the more relevant when considering the high prevalence of diminished-activity OCT1 variants and the extensive use of opioids in clinical practice.

The aim of this study was to perform a systematic screening of opioids in vitro in order to identify substrates and inhibitors of OCT1 beyond morphine and tramadol that might be affected by reduced OCT1 activity. The screening was performed in a four-step process that involved in silicio predictions, membrane permeability testing in an artificial membrane model (so-called parallel artificial membrane permeability assays), inhibition experiments, and transport experiments. For the inhibition experiments, we photometrically determined to what extent our test drugs inhibited the uptake of the fluorescent OCT1 substrate $\mathrm{ASP}^{+}$, while for the transport experiments we measured the uptake of test drugs into OCT1overexpressing HEK293 cells directly via LC-MS/MS. Sixty opioids underwent the initial in silicio predictions; of those, we chose 23 opioids to run the entire course of experiments.

Seven novel substrates and fourteen inhibitors of OCT1 were identified. Three of the substrates -methylnaltrexone, meptazinol, and hydromorphone-are active compounds used in clinical practice. Uptake of methylnaltrexone into OCT1-overexpressing cells was 32 to 85 times higher than that into negative control cells, making it one of the substances most dependent on OCT1-mediated transport so far reported. Inhibitors were defined as substances with $\mathrm{IC}_{50}$ values of $100 \mu \mathrm{M}$ or below; of the fourteen inhibitors identified, nine were especially potent with $\mathrm{IC}_{50}$ values of less than $25 \mu \mathrm{M}$. Notably, dextromethorphan and its metabolites were among the substances with the lowest $\mathrm{IC}_{50}$ values. Three of the inhibitors -namely dextromethorphan, levorphanol, and tapentadol- could, theoretically, reach portal vein concentrations high enough to inhibit OCT1 in vivo. 
We also identified five opioids -codeine, hydrocodone, naltrexone, oxycodone, and oxymorphone- that can be considered pharmacokinetically "safe" with respect to variations in SLC22A1 since they do not seem to interact with OCT1 in any way. Their uptake into OCT1-overexpressing cells was less than two times the uptake into negative control cells, indicating a lack of OCT1-mediated transport. They also failed to inhibit the uptake of ASP ${ }^{+}$ into OCT1-overexpressing cells by $50 \%$ at concentrations of $100 \mu \mathrm{M}$.

Analysis of the in silicio data showed that opioids with $\operatorname{low} \log \mathrm{D}_{(7.4)}$ and $\mathrm{P}_{\mathrm{e}}$ values are more likely to be morphinans, and substrates or non-inhibitors of OCT1 than opioids with high $\log \mathrm{D}_{(7.4)}$ and $\mathrm{P}_{\mathrm{e}}$ values. It also appears that the structures of synthetic opioids and dextromethorphan-like opioids lend themselves to more potent inhibition of OCT1 than the "classic" morphinan structure of morphine and its congeners.

Overall, this study identified at least three substrates and three inhibitors that warrant further research in humans in order to gauge their pharmacological and pharmacokinetic impact on patients with diminished OCT1 transport activity. In addition, our in vitro data suggests five opioids that may be safer to use in patients with diminished OCT1 transport activity. 


\section{Appendix}

\subsection{An overview of the tested drugs}

\subsubsection{3-Hydroxymorphinan}

Colloquially, 3-hydroxymorphinan refers to (+)-3-hydroxymorphinan; its levo isomer, (-)3-hydroxymorphinan, is better known as norlevorphanol. While lacking intrinsic activity with regard to opioid receptors, (+)-3-hydroxymorphinan has emerged as a potent neuroprotective agent in animal models and may be of use in the therapy of Parkinson's disease (Zhang et al. 2005). Ultimately a metabolite of dextromethorphan, (+)-3hydroxymorphinan is metabolized from dextrorphan via CYP3A4 or from 3methoxymorphinan via CYP2D6 (Vengurlekar et al. 2002).

\subsubsection{3-Methoxymorphinan}

A metabolite of dextromethorphan, 3-methoxymorphinan is generated via CYP3A4 mediated N-demethylation in the liver (Vengurlekar et al. 2002).It is currently thought to be inactive, though further processing by CYP2D6 yields 3-hydroxymorphinan.

\subsubsection{Codeine}

Codeine is a prodrug and precursor of the opioid morphine. It is considered a weak opioid that unfolds its analgesic effects after CYP2D6-mediated O-demethylation of the phenylic hydroxyl group transforms it into morphine (Hardy and Jackson 2009). Codeine is administered as an antitussive and as an antidiarrheal agent. Although codeine is part of many antitussive preparations, it is probably no more effective than a placebo at battling coughs (Smith et al. 2014). Loperamide -another opioid commonly employed against diarrheacauses fewer side effects, but codeine is cheaper and therefore more likely to be used in countries where access to superior -and more expensive- opioids is limited (Hardy and Jackson 2009; International Narcotics Control Board 2011)

\subsubsection{Dextromethorphan}

Dextromethorphan is the prodrug of dextrorphan; all its metabolites are dextrorotatory. Though displaying only weak affinity for opioid receptors, it acts agonistically on the sigma 1 receptor and inhibits the uptake of norepinephrine and serotonin (Pioro 2014). In 2010, the FDA approved of a formulation of dextromethorphan in combination with quinidine - 
a CYP2D6 inhibitor that delays metabolization of dextromethorphan-for the treatment of pseudobulbar affect (Pioro 2014). Additionally, dextromethorphan may act as a weak serotonin reuptake inhibitor, though supra-therapeutic doses (as may be encountered in abuse) are required in combination with MAOIs to produce serotonin toxicity (Gillman 2005; Schwartz et al. 2008; Koren-Michowitz et al. 2014). In a study by Reissig, 11 of out 12 participants rated dextromethorphan as a classic hallucinogenic after receiving doses of $400 \mathrm{mg} / 70 \mathrm{~kg}$ BM (Reissig et al. 2012). Because of its antitussive properties, dextromethorphan is a common ingredient in many over-the-counter cough medicines in a range that spans 5-30mg DXM HBr per formula. Cheap and easily accessible when compared to other drugs, recreational abuse of dextromethorphan (called "robo-tripping", after cough medicine-producing brand Robitussin) is no rarity (Wikipedia 2018a). The FDA issued a warning against DXM abuse in 2005 after five teenagers died from consuming pure, powdered dextromethorphan (FDA 2005). DXM abuse has been in decline ever since, though the prevalence of cough medicine abuse among $12^{\text {th }}$ graders still amounts to $4 \%$, one in twenty-five students (NIDA 2015).

\subsubsection{Dextrorphan}

Dextrorphan is a metabolite of dextromethorphan derived from CYP2D6-mediated Odemethylation of the hydroxyl group at the phenolic C3 (Vengurlekar et al. 2002). The dextro-rotatory enantiomer of levorphanol, dextrorphan is not, strictly speaking, an opioid as it does not bind to opioid receptors. It does bind to N-methyl-D-aspartate (NMDA) receptors at the phencyclidine site, though, making it a NMDA receptor antagonist (Davis 2009d). Competitive binding assays in rat forebrain showed that the $\mathrm{IC}_{50}$ of dextrorphan lay below that of ketamine, levorphanol, and dextromethorphan (Franklin and Murray 1992). Dextrorphan can be converted into 3-hydroxymorphinan through CYP3A4-mediated Ndemethylation (Vengurlekar et al. 2002).

\subsubsection{Fentanyl}

Fentanyl is a 4-anilidopipderidine derivative and a highly lipophilic compound, with an analgesic potency estimated to be nearly 100 times that of morphine. Due to its high lipid solubility, it can pass the brain-blood barrier and even the skin, allowing for fentanyl formulations that are unique among the opioids. These include TTS (transdermal therapeutic systems- "patches"), buccal tablets, sublingual and nasal sprays, and the "lozenge", which is basically a fentanyl-containing lollipop (Mandel and Carunchio 2011; Bornemann-Cimenti et al. 2013). These rapid-onset preparations of fentanyl are popular in the treatment of 
breakthrough cancer pain: the application is non-invasive and bypasses the liver, so that ultimately a higher amount of active fentanyl reaches the brain (Bornemann-Cimenti et al. 2013). About 50 to $75 \%$ of orally ingested fentanyl undergoes first-pass metabolism to norfentanly, which is then excreted by the kidneys (Bornemann-Cimenti et al. 2013). Though short-acting in single doses, fentanyl can accumulate within the cells and adipose tissue if given repeatedly. When given continuously, it no longer qualifies as a short-acting opioid (Brayfield 2014).

Fentanyl is currently the most commonly applied opioid worldwide (International Narcotics Control Board 2011).

\subsubsection{Hydrocodone}

Hydrocodone is a semi-synthetic derivative of codeine with approximately the same analgesic potency as morphine. It is, however, considered a weak opioid as it is only commercially available as a compound analgesic, usually with ibuprofen or acetaminophen (Davis 2009a). CYP2D6-mediated O-demethylation of hydrocodone yields the more potent hydromorphone (analogously to codeine and morphine), while CYP3A4-mediated transformation and reduction yield small quantities of norhydrocodone and $6 \beta-/ 6 \alpha-1$ hydromorphol, which also activate MOP (Davis 2009a). Ultra-rapid metabolizers of CYP2D6 are reported to be at greater risk of suffering from adverse reactions against hydrocodone, probably a result of overdosing since greater amounts of the potent hydromorphone will be produced within a shorter time.

\subsubsection{Hydromorphone}

A metabolite of hydrocodone, hydromorphone is a potent congener of morphine used in moderate to severe pain. It has been used for the treatment of cancer pain since 1932 (Quigley and Glare 2009). Analogously to morphine, hydromorphone is glucuronidated to hydromorphone-3-glucuronide and excreted via the kidneys, and like morphine-3glucuronide, HM3G is suspected of being neurotoxic (Quigley and Glare 2009).

\subsubsection{Levorphanol}

Levorphanol (levo-3-hydroxy-N-methylmorphinan) is the levo-rotatory enantiomer of dextrorphan (Davis 2009d). Its analgesic potency is four to eight times that of morphine, and it has an especially high affinity for KOP (Prommer 2007). Like dextromethorphan and its metabolites, levorphanol acts antagonistically upon NMDA receptors. It has also been noted 
for causing spasm of the sphincter of Oddi and for stimulating the hypothalamic-pituitary axis (Davis 2009d). Analogously to morphine and related compounds, levorphanol is mainly metabolized to levorphanol-3-glucuronide (L3G). L3G is thought to be inactive and undergoes enterohepatic circulation in mice (Davis 2009d). Ultimately, all metabolites are excreted via the kidneys, and only small amounts of levorphanol are excreted unchanged (Prommer 2007).

\subsubsection{Meptazinol}

Meptazinol is a synthetic opioid developed in the early nineteen-eighties with an analgesic potency ten times lower than that of morphine. A mixed opioid agonist-antagonist, it may precipitate withdrawal symptoms in opioid-dependent patients and seems to have cholinergic effects, too (Holmes and Ward 1985; Brayfield 2014). Though Meptazinol can cross the placenta -which may occur when the drug is administered as an analgesic to women in labor- it is quickly eliminated from the neonate (Franklin et al. 1981). Only 10\% of meptazinol is excreted unchanged via the kidneys, the rest is metabolized by the liver, mainly via glucuronidation (Franklin et al. 1975).

\subsubsection{Methylnaltrexone}

Methylnaltrexone is a selective MOP antagonist administered as an adjuvant to palliative care patients suffering from opioid-induced constipation (Rodrigues et al. 2013; Brayfield 2014). Due to a quaternary nitrogen atom, it is polar and does not cross the brain-blood barrier (Leppert 2015). Methylnaltrexone undergoes sulfation to methylnaltrexone-3-sulfate and reduction to different methylnaltrexols, though apparently no demethylation to naltrexone (Leppert 2015). Approximately $40 \%$ are excreted unchanged by the kidneys; another $20 \%$ with the feces (Leppert 2015).

\subsubsection{Morphine}

Morphine is an opiate and the prototypic opioid. Analgesic potency is scaled with reference to morphine (analgesic potency of 1) and, along with codeine, it is one of two opioids declared essential drugs by the WHO (Glare 2009a; WHO 2015). Despite the wide offer of alternative opioids, morphine remains the most popular opioid in pediatrics and is the opioid of choice in the treatment of cancer pain (Brayfield 2014). Its main metabolites, morphine3-glucuronide and morphine-6-glucuronide, are formed via UDP-glucuronosyltransferase (UGT). Morphine and all of its metabolites are excreted by the kidneys, which is why 
morphine should be administered with caution in patients with decreased renal clearance(Glare 2009a). Like codeine and pethidine, morphine is known to trigger the release of histamine from mast cells, resulting in erythrema and itching (Blunk et al. 2004). It can also cause spasms of the sphincter of Oddi (Helm et al. 1988).

\subsubsection{Naltrexone}

In contrast to methylnaltrexone, naltrexone is an opioid receptor antagonist that is active peripherally as well as centrally (Barnett et al. 2014). Naltrexone undergoes first-pass metabolism in the liver to 6- $\beta$-naltrexol, which, too, has antagonist properties (Barnett et al. 2014). It is employed in the long-term treatment of cholestatic pruritus, but may counteract the analgesic effects of co-administered opioids and cause typical withdrawal symptoms (Barnett et al. 2014). Administered as an adjunct in the management of alcohol dependence, naltrexone reduces the amounts of alcohol ingested (Volpicelli et al. 1992; Brayfield 2014). It is further under investigation as a therapeutic drug in eating disorders, and may be beneficial in autistic children with self-injurious behavior (Brayfield 2014).

\subsubsection{N-Desmethyltramadol}

N-Desmethyltramadol (M2) is a CYP3A4 and CYP2B6-derived metabolite of tramadol (Leppert 2011). Its effects are unknown.

\subsubsection{Norfentanyl}

Norfentanyl is produced by CYP3A4-mediated N-demethylation of fentanyl (Hall and Hardy 2009). It is considered an inactive metabolite.

\subsubsection{Noroxycodone}

Noroxycodone is a weak opioid receptor agonist derived from oxycodone through CYP3A4mediated N-demethylation (Smith 2011). Its impact on analgesia, however, is negligible. CYP2D6-mediated O-demethylation of noroxycodone can yield noroxymorphone, but most of it will be excreted by the kidneys unchanged (Glare and Davis 2009; Smith 2011).

\subsubsection{Nortilidine}

Nortilidine is the active metabolite of tilidine, produced by CYP3A4-mediated Ndemethylation in the liver (Grun et al. 2012). With an opioid receptor affinity ten times that of the parent drug, nortilidine is about equianalgesic to morphine (Hajda et al. 2002). Apart 
from being an opioid receptor agonist, nortilidine is also an NMDA receptor antagonist and dopamine reuptake inhibitor (Brayfield 2014).

\subsubsection{Oxycodone}

Oxycodone is a thebaine congener with approximately the same analgesic potency as morphine (Glare and Davis 2009). Due to its extensive and varied metabolization, oxycodone is sometimes regarded as a prodrug, exerting its analgesic effects through oxymorphone and noroxymorphone (Smith 2011). CYP2D6-mediated O-demethylation of oxycodone yields oxymorphone; however, CPY3A4-mediated N-demethylation to noroxycodone dominates in vivo (Smith 2011). Along with fentanyl, hydromorphone, and morphine, oxycodone is one of the most commonly applied opioids worldwide (International Narcotics Control Board 2011). Its popularity may be partly grounded in the fact that is has been in use since 1917, and decades of clinical experience have made a wide array of formulations, among them sustained-release tablets, available

\subsubsection{Oxymorphone}

Oxymorphone is a semi-synthetic opioid congener and a metabolite of oxycodone. It is more than six times as potent as morphine, and immediate-release and extended-release tablets made available in 2006 paved the way for more wide-spread use of oxymorphone in the management of cancer pain (Glare 2009b). Oxymorphone has an oral availability of $10 \%$, and analogously to morphine, it is metabolized to and excreted as oxymorphone-3glucuronide, though small amounts of alpha- and beta-6-oxymorphol are produced (Glare 2009b; Smith 2011).

\subsubsection{Pethidine (Meperidine)}

Pethidine (synonym: meperidine) is a synthetic opioid and a peperidine, like fentanyl, and equally lipophilic (Davis 2009c). It has been in clinical use since 1939 (Corbett et al. 2006). Its major metabolite, meperidinic acid, is produced by hydrolysis and then glucuronidated before excretion, while another metabolite, normeperidine, is synthesized through CYP3A4mediated N-demethylation (Smith 2011). Liver and kidney disease lead to an accumulation of these metabolites and a build-up of, a neurotoxic agent known to cause tremors, myoclonus and seizures (Szeto et al. 1977; Kaiko et al. 1983). Adverse side effects were also more common in patient-controlled analgesia (Brayfield 2014). In 2011, the FDA expanded the list of contraindications, highlighting the increased awareness of pethidine side effects 
(FDA 2011). Additionally, pethidine is a weak serotonin reuptake inhibitor, and in combinations with monoamino oxidase (MAO) inhibitors it has been reported to cause fatal serotonin toxicity (Gillman 2005). Although the use of pethidine is currently being discouraged -more so as alternative opioids with less pronounced side effects are availableit is still among the seven most commonly administered opioids worldwide(Latta et al. 2002; Davis 2009c; International Narcotics Control Board 2011). It is widely used in obstreterix (Brayfield 2014).

\subsubsection{Sufentanil}

Sufentanil is a highly lipophilic congener of fentanyl and about 500 times as potent as morphine, making it the most potent opioids administered to humans (Hall and Hardy 2009). Because of its rapid inset and recovery, sufentanil is used as an adjunct in anesthesia, postoperative pain, and labor pain, and, like fentanyl, it may accumulate when given repeatedly, especially in obese patients. About $\%$ are eliminated unchanged via the kidneys, the rest undergoes $\mathrm{N}$-dealkylation and O-demethylation in the liver and small (Hall and Hardy 2009).

\subsubsection{Tapentadol}

Tapentadol is a relatively new opioid that was approved for use by the FDA in 2008 (Singh et al. 2013). It is nearly completely metabolized to tapentadol-O-glucuronide and other minor metabolites, such as N-desmethyltapentadol (Singh et al. 2013). Apart from acting upon opioid receptors, tapentadol inhibits noradrenaline reuptake (Tzschentke et al. 2011). The higher concentrations of noradrenaline contribute to the overall analgesic effect, so that tapentadol, despite a 44-lower binding affinity to MOP than morphine, has an analgesic potency of 0.4 (Tzschentke et al. 2011).

\subsubsection{Tilidine}

Tilidine is a synthetic opioid and prodrug of the active compound nortilidine. Classified as weak opioid, it is employed as analgesic in moderate acute and chronic pain. CYP3A4 and CYP 2C19-mediated demethylation yield nortilidine and bisnortilidine (Grun et al. 2012). It is available as single formulation or in combination with naloxone, an opioid receptor antagonist, to prevent abuse. 


\section{$7 \quad$ References}

Ahlin G, Karlsson J, Pedersen JM, Gustavsson L, Larsson R, Matsson P, Norinder U, Bergstrom CA, Artursson P (2008): Structural requirements for drug inhibition of the liver specific human organic cation transport protein 1. J Med Chem 51(19), $5932-5942$

Ahlin G, Chen L, Lazorova L, Chen Y, Ianculescu AG, Davis RL, Giacomini KM, Artursson P (2011): Genotype-dependent effects of inhibitors of the organic cation transporter, OCT1: predictions of metformin interactions. Pharmacogenomics J 11(6), 400-411

ASAM. Definitions Related to the Use of Opioids for the Treatment of Pain: Consensus Statement of the American Academy of Pain Medicine, the American Pain Society, and the American Society of Addiction Medicine 2001. http://www.asam.org/advocacy/find-a-policy-statement/view-policystatement/public-policy-statements/2011/12/15/definitions-related-to-the-use-ofopioids-for-the-treatment-of-pain-consensus-statement. Accessed 05.04.2016.

Barnett V, Twycross R, Mihalyo M, Wilcock A (2014): Opioid Antagonists. Journal of Pain and Symptom Management 47(2), 341-352

Blunk JA, Schmelz M, Zeck S, Skov P, Likar R, Koppert W (2004): Opioid-induced mast cell activation and vascular responses is not mediated by mu-opioid receptors: an in vivo microdialysis study in human skin. Anesth Analg $\underline{98}(2), 364-370$, table of contents

Bonn B, Masimirembwa CM, Castagnoli N (2010): Exploration of Catalytic Properties of CYP2D6 and CYP3A4 Through Metabolic Studies of Levorphanol and Levallorphan. Drug Metab Dispos $\underline{38(1), 187-199}$

Bornemann-Cimenti H, Wejbora M, Szilagyi IS, Sandner-Kiesling A (2013): Fentanyl for the Treatment of Tumor-Related Breakthrough Pain. Dtsch Ärztebl Int 110(16), 271277

Boxberger KH, Hagenbuch B, Lampe JN (2014): Common drugs inhibit human organic cation transporter 1 (OCT1)-mediated neurotransmitter uptake. Drug Metab Dispos 42(6), 990-995

Brayfield A. Martindale: The complete drug reference, Pharmaceutical Press2014.

Brownstein MJ (1993): A brief history of opiates, opioid peptides, and opioid receptors. Proc Natl Acad Sci U S A 90(12), 5391-5393

Busch AE, Quester S, Ulzheimer JC, Gorboulev V, Akhoundova A, Waldegger S, Lang F, Koepsell H (1996a): Monoamine neurotransmitter transport mediated by the polyspecific cation transporter rOCT1. FEBS Lett $\underline{395}(2-3), 153-156$

Busch AE, Quester S, Ulzheimer JC, Waldegger S, Gorboulev V, Arndt P, Lang F, Koepsell $\mathrm{H}$ (1996b): Electrogenic properties and substrate specificity of the polyspecific rat cation transporter rOCT1. J Biol Chem 271(51), 32599-32604

Chen J, Brockmoller J, Seitz T, Konig J, Tzvetkov MV, Chen X (2017): Tropane alkaloids as substrates and inhibitors of human organic cation transporters of the SLC22 (OCT) and the SLC47 (MATE) families. Biol Chem $\underline{398}(2), 237-249$

Chen L, Takizawa M, Chen E, Schlessinger A, Segenthelar J, Choi JH, Sali A, Kubo M, Nakamura S, Iwamoto Y et al. (2010): Genetic Polymorphisms in Organic Cation 
Transporter 1 (OCT1) in Chinese and Japanese Populations Exhibit Altered Function. J Pharmacol Exp Ther $\underline{335}$ (1), 42-50

Chen L, Shu Y, Liang X, Chen EC, Yee SW, Zur AA, Li S, Xu L, Keshari KR, Lin MJ et al. (2014): OCT1 is a high-capacity thiamine transporter that regulates hepatic steatosis and is a target of metformin. Prc Natl Acad Sci U S A 111(27), 9983-9988

Ciarimboli G, Struwe K, Arndt P, Gorboulev V, Koepsell H, Schlatter E, Hirsch JR (2004): Regulation of the human organic cation transporter hOCT1. J Cell Physiol 201(3), 420-428

Ciszkowski C, Madadi P, Phillips MS, Lauwers AE, Koren G (2009): Codeine, ultrarapidmetabolism genotype, and postoperative death. N Engl J Med 361(8), 827-828

Claridge JA, Fabian TC (2005): History and development of evidence-based medicine. World J Surg 29(5), 547-553

Conway BR, Fogarty DG, Nelson WE, Doherty CC (2006): Opiate toxicity in patients with renal failure. BMJ (Clinical research ed) $\underline{332}$ (7537), 345-346

Cooreman S, Deprez C, Martens F, Van Bocxlaer J, Croes K (2010): A comprehensive LCMS-based quantitative analysis of fentanyl-like drugs in plasma and urine. J Sep Sci $\underline{33}(17-18), 2654-2662$

Corbett AD, Henderson G, McKnight AT, Paterson SJ (2006): 75 years of opioid research: the exciting but vain quest for the Holy Grail. Br J Pharmacol 147(Suppl 1), S153162

Coulter C, Taruc M, Tuyay J, Moore C (2010): Determination of tapentadol and its metabolite $\mathrm{N}$-desmethyltapentadol in urine and oral fluid using liquid chromatography with tandem mass spectral detection. J Anal Toxicol 34(8), 458-463

Crews KR, Gaedigk A, Dunnenberger HM, Klein TE, Shen DD, Callaghan JT, Kharasch ED, Skaar TC (2012): Clinical Pharmacogenetics Implementation Consortium (CPIC) Guidelines for Codeine Therapy in the Context of Cytochrome P450 2D6 (CYP2D6) Genotype. Clin Pharmacol Ther 91(2), 321-326

Davis MP: Hydrocodone. In: Davis MP, Glare P, Quigley C, Hardy JR (eds.): Opioids in Cancer Pain. 2nd ed; Oxford University Press. 2009a, 89-98.

Davis MP: Opioid dosing strategies for chronic pain and the management of opioid side effects. In: Davis MP, Glare P, Quigley C, Hardy JR (eds.): Opioids in Cancer Pain. 2nd ed; Oxford University Press. 2009b, 247-366.

Davis MP: Liver disease and exogenous opioid pharmacokinetics. In: Davis MP, Glare P, Quigley C, Hardy JR (eds.): Opioids in Cancer Pain. 2nd ed; Oxford University Press. 2009c, 39-68.

Davis MP: Levorphanol. In: Davis MP, Glare P, Quigley C, Hardy JR (eds.): Opioids in Cancer Pain. 2nd ed; Oxford University Press. 2009d, 253-262.

Davis MP, Pasternak GW: Opioid receptors and opioid pharmacodynamics. In: Davis MP, Glare P, Quigley C, Hardy JR (eds.): Opioids in Cancer Pain. 2nd ed; Oxford University Press. 2009, 1-28.

Dickens D, Owen A, Alfirevic A, Giannoudis A, Davies A, Weksler B, Romero IA, Couraud PO, Pirmohamed M (2012): Lamotrigine is a substrate for OCT1 in brain endothelial cells. Biochem Pharmacol 83(6), 805-814

Dietis N, Rowbotham DJ, Lambert DG (2011): Opioid receptor subtypes: fact or artifact? Br J Anaesth 107(1), 8-18 
Dixon R, Crews T, Inturrisi C, Foley K (1983): Levorphanol: pharmacokinetics and steadystate plasma concentrations in patients with pain. Res Commun Chem Pathol Pharmacol 41 $\underline{\text { (1), 3-17 }}$

Eckhardt K, Li S, Ammon S, Schanzle G, Mikus G, Eichelbaum M (1998): Same incidence of adverse drug events after codeine administration irrespective of the genetically determined differences in morphine formation. Pain $\underline{76}(1-2), 27-33$

Egenberger B, Gorboulev V, Keller T, Gorbunov D, Gottlieb N, Geiger D, Mueller TD, Koepsell H (2012): A substrate binding hinge domain is critical for transport-related structural changes of organic cation transporter 1. J Biol Chem 287(37), 31561-31573

Eichhold TH, Greenfield LJ, Hoke SH, 2nd, Wehmeyer KR (1997): Determination of dextromethorphan and dextrorphan in human plasma by liquid chromatography/tandem mass spectrometry. J Mass Spectrom 32(11), 1205-1211

Fang WB, Lofwall MR, Walsh SL, Moody DE (2013): Determination of oxycodone, noroxycodone and oxymorphone by high-performance liquid chromatographyelectrospray ionization-tandem mass spectrometry in human matrices: in vivo and in vitro applications. J Anal Toxicol 37(6), 337-344

FDA. Professional Drug Information: Levorphanol. https://www.drugs.com/pro/levorphanol.html. Accessed 29.06.2017.

FDA. Safety Alerts for Human Medical Products: Dextromethorphan. 2005. www.fda.gov/safety/medwatch/safetyinformation/safetyalertsforhumanmedicalpr oducts/ucm151133.htm. Accessed 21.08.2013.

FDA. Demerol (meperidine hydrochloride) Prescribing Information October 2011. 2011; http://www.accessdata.fda.gov/drugsatfda docs/label/2011/005010s051lbl.pdf. Accessed 07.07.2015.

Fernandez Mdel M, Wille SM, Kummer N, Di Fazio V, Ruyssinckx E, Samyn N (2013): Quantitative analysis of 26 opioids, cocaine, and their metabolites in human blood by ultra performance liquid chromatography-tandem mass spectrometry. Ther Drug Monit $\underline{35}(4), 510-521$

Franklin PH, Murray TF (1992): High affinity [3H]dextrorphan binding in rat brain is localized to a noncompetitive antagonist site of the activated N-methyl-D-aspartate receptor-cation channel. Mol Pharmacol 41(1), 134-146

Franklin RA, Aldridge A, White CB (1975): Preliminary metabolic studies on the new analgesic meptazinol. Br J Clin Pharmacol 2(5), 472-473

Franklin RA, Frost T, Robson PJ, Jackson MB (1981): Preliminary studies on the disposition of meptazinol in the neonate. Br J Clin Pharmacol 12(1), 88-90

Freye E, Levy JV. Opioids in Medicine, Springer, Dordrecht 2008.

Fukuda T, Chidambaran V, Mizuno T, Venkatasubramanian R, Ngamprasertwong P, Olbrecht V, Esslinger HR, Vinks AA, Sadhasivam S (2013): OCT1 genetic variants influence the pharmacokinetics of morphine in children. Pharmacogenomics 14(10), $1141-1151$

Gene: SLC22A1. National Center for Biotechnology Information, U.S. National Library of Medicine. http://www.ncbi.nlm.nih.gov/gene/6580. Accessed 24.02.2016.

Giacomini K, Huang S, Tweedie D, Benet L, Brouwer K, Chu X, Dahlin A, Evers R, Fischer V, Hillgren K et al. (2010): Membrane transporters in drug development. Nat Rev Drug Discov $\underline{9}(3), 215-236$ 
Gillman PK (2005): Monoamine oxidase inhibitors, opioid analgesics and serotonin toxicity. Br J Anaesth 95(4), 434-441

Glare P: Morphine. In: Davis MP, Glare P, Quigley C, Hardy JR (eds.): Opioids in Cancer Pain. 2nd ed; Oxford University Press. 2009a, 127-154.

Glare P: Oxymorphone. In: Davis MP, Glare P, Quigley C, Hardy JR (eds.): Opioids in Cancer Pain. 2nd ed; Oxford University Press. 2009b, 269-274.

Glare P, Davis MP: Oxycodone. In: Davis MP, Glare P, Quigley C, Hardy JR (eds.): Opioids in Cancer Pain. 2nd ed; Oxford University Press. 2009, 155-174.

Godoy AL, De Moraes NV, Martinez EZ, Carvalho TM, Marques MP, Lanchote VL (2011): Simultaneous analysis of tramadol, O-desmethyltramadol, and N-desmethyltramadol enantiomers in rat plasma by high-performance liquid chromatography-tandem mass spectrometry: application to pharmacokinetics. Chirality 23 (4), 287-293

Göhler K, Brett M, Smit JW, Rengelshausen J, Terlinden R (2013): Comparative pharmacokinetics and bioavailability of tapentadol following oral administration of immediate- and prolonged-release formulations. Int J Clin Pharmacol Ther 51(4), $338-348$

Gorboulev V, Ulzheimer JC, Akhoundova A, Ulzheimer-Teuber I, Karbach U, Quester S, Baumann C, Lang F, Busch AE, Koepsell H (1997): Cloning and characterization of two human polyspecific organic cation transporters. DNA Cell Biol 16 (7), 871-881

Gorbunov D, Gorboulev V, Shatskaya N, Mueller T, Bamberg E, Friedrich T, Koepsell H (2008): High-affinity cation binding to organic cation transporter 1 induces movement of helix 11 and blocks transport after mutations in a modeled interaction domain between two helices. Mol Pharmacol 73(1), 50-61

Gouaux E (2009): The molecular logic of sodium-coupled neurotransmitter transporters. Philos Trans R Soc Lond B Biol Sci 364(1514), 149-154

Grun B, Merkel U, Riedel KD, Weiss J, Mikus G (2012): Contribution of CYP2C19 and CYP3A4 to the formation of the active nortilidine from the prodrug tilidine. $\mathrm{Br} \mathrm{J}$ Clin Pharmacol 74(5), 854-863

Grundemann D, Gorboulev V, Gambaryan S, Veyhl M, Koepsell H (1994): Drug excretion mediated by a new prototype of polyspecific transporter. Nature $\underline{372(6506), 549-552}$

Gulyas P, Payne T (2011). Determination of Opiates and Other Drugs of Abuse Using the Agilent 500 Ion Trap LC/MS. Agilent Technologies I. agilent.com/cs/library/applications/SI-01284.pdf.

Hajda JP, Jahnchen E, Oie S, Trenk D (2002): Sequential first-pass metabolism of nortilidine: the active metabolite of the synthetic opioid drug tilidine. J Clin Pharmacol 42(11), $1257-1261$

Hall A, Hardy JR: The lipophilic opioids: fentanyl, alfentanil, sufentanil, and remifentanil. In: Davis MP, Glare P, Quigley C, Hardy JR (eds.): Opioids in Cancer Pain. 2nd ed; Oxford University Press. 2009, 175-192.

Hardy JR, Jackson KCI: Codeine. In: Davis MP, Glare P, Quigley C, Hardy JR (eds.): Opioids in Cancer Pain. 2nd ed; Oxford University Press. 2009, 81-88.

Helm JF, Venu RP, Geenen JE, Hogan WJ, Dodds WJ, Toouli J, Arndorfer RC (1988): Effects of morphine on the human sphincter of Oddi. Gut 29(10), 1402-1407

Hendrickx R, Johansson JG, Lohmann C, Jenvert RM, Blomgren A, Borjesson L, Gustavsson L (2013): Identification of novel substrates and structure-activity 
relationship of cellular uptake mediated by human organic cation transporters 1 and 2. J Med Chem $\underline{56}(18), 7232-7242$

Hermens JM, Ebertz JM, Hanifin JM, Hirshman CA (1985): Comparison of histamine release in human skin mast cells induced by morphine, fentanyl, and oxymorphone. Anesthesiology 62(2), 124-129

Holmes B, Ward A (1985): Meptazinol. A review of its pharmacodynamic and pharmacokinetic properties and therapeutic efficacy. Drugs 30(4), 285-312

International Narcotics Control Board 2010: Special Report on the Availability of Internationally Controlled Drugs: Ensuring Adequate Access for Medical and Scientific Purpose. https://www.incb.org/incb/en/publications/annualreports/annual-report-2001-2010.html: United Nations Publications;2011.

Ito K, Chiba K, Horikawa M, Ishigami M, Mizuno N, Aoki J, Gotoh Y, Iwatsubo T, Kanamitsu S, Kato M et al. (2002): Which concentration of the inhibitor should be used to predict in vivo drug interactions from in vitro data? AAPS pharmSci 4 (4), E25

Kaiko RF, Foley KM, Grabinski PY, Heidrich G, Rogers AG, Inturrisi CE, Reidenberg MM (1983): Central nervous system excitatory effects of meperidine in cancer patients. Ann Neurol 13(2), 180-185

Keller T, Egenberger B, Gorboulev V, Bernhard F, Uzelac Z, Gorbunov D, Wirth C, Koppatz S, Dotsch V, Hunte C et al. (2011): The large extracellular loop of organic cation transporter 1 influences substrate affinity and is pivotal for oligomerization. J Biol Chem 286(43), 37874-37886

Kirchheiner J, Schmidt H, Tzvetkov M, Keulen JT, Lotsch J, Roots I, Brockmoller J (2007): Pharmacokinetics of codeine and its metabolite morphine in ultra-rapid metabolizers due to CYP2D6 duplication. Pharmacogenomics J Z(4), 257-265

Kirsh KL, Starr TD, Rogak LJ, Passik SD: Cancer pain and substance abuse. In: Davis MP, Glare P, Quigley C, Hardy JR (eds.): Opioids in Cancer Pain. 2nd ed; Oxford University Press. 2009, 461-477.

Koepsell H (2011): Substrate recognition and translocation by polyspecific organic cation transporters. Biol Chem $\underline{392}(1-2)$, 95-101

Kohler C, Grobosch T, Binscheck T (2011): Rapid quantification of tilidine, nortilidine, and bisnortilidine in urine by automated online SPE-LC-MS/MS. Anal Bioanal Chem $\underline{400}(1), 17-23$

Koren-Michowitz M, Buzaglo Z, Ribakovsky E, Schwarz M, Pessach I, Shimoni A, Beider K, Amariglio N, le Coutre P, Nagler A (2014): OCT1 genetic variants are associated with long term outcomes in imatinib treated chronic myeloid leukemia patients. Eur J Haematol 22(4), 283-288

Laine JE, Auriola S, Pasanen M, Juvonen RO (2009): Acetaminophen bioactivation by human cytochrome P450 enzymes and animal microsomes. Xenobiotica 39(1), 1121

Latta KS, Ginsberg B, Barkin RL (2002): Meperidine: a critical review. Am J Ther 9(1), 5368

Leppert W (2011): CYP2D6 in the metabolism of opioids for mild to moderate pain. Pharmacology $\underline{\text { 87}(5-6), ~ 274-285 ~}$ 
Leppert W (2015): Emerging therapies for patients with symptoms of opioid-induced bowel dysfunction. Drug Des Devel Ther $\underline{9}$, 2215-2231

Lutz PE, Kieffer BL (2013): Opioid receptors: distinct roles in mood disorders. Trends in neurosciences $\underline{36}(3), 195-206$

Mandel L, Carunchio MJ (2011): Rampant caries from oral transmucosal fentanyl citrate lozenge abuse. J Am Dent Assoc 142(4), 406-409

Matthaei J, Kuron D, Faltraco F, Knoch T, Dos Santos Pereira JN, Abu Abed M, Prukop T, Brockmoller J, Tzvetkov MV (2016): OCT1 mediates hepatic uptake of sumatriptan and loss-of-function OCT1 polymorphisms affect sumatriptan pharmacokinetics. Clin Pharmacol Ther 99(6), 633-641

Motulsky AG, Qi M (2006): Pharmacogenetics, pharmacogenomics and ecogenetics. J Zhejiang Univ Sci B $\underline{\text { 7(2), 169-170 }}$

Namisaki T, Schaeffeler E, Fukui H, Yoshiji H, Nakajima Y, Fritz P, Schwab M, Nies AT (2014): Differential expression of drug uptake and efflux transporters in Japanese patients with hepatocellular carcinoma. Drug Metab Dispos 42 (12), 2033-2040

NIDA. Monitoring the Future Study: Trends in Prevalence of Various Drugs. 2015; https://www.drugabuse.gov/trends-statistics/monitoring-future/monitoringfuture-study-trends-in-prevalence-various-drugs. Accessed 04.03.2016.

Nies AT, Koepsell H, Winter S, Burk O, Klein K, Kerb R, Zanger UM, Keppler D, Schwab M, Schaeffeler E (2009): Expression of organic cation transporters OCT1 (SLC22A1) and OCT3 (SLC22A3) is affected by genetic factors and cholestasis in human liver. Hepatology $\underline{50}(4), 1227-1240$

Oswald S, Schumacher G, Siegmund W (2011): Quantitative determination of methylnaltrexone in human serum using liquid chromatography-tandem mass spectrometry. J Pharm Biomed Anal 56(5), 1079-1084

Pelis RM, Wright SH (2014): SLC22, SLC44, and SLC47 transporters--organic anion and cation transporters: molecular and cellular properties. Curr Top Membr 73, 233-261

Pioro EP (2014): Review of Dextromethorphan $20 \mathrm{mg} /$ Quinidine $10 \mathrm{mg}$ (NUEDEXTA(®)) for Pseudobulbar Affect. Neurol Ther $\underline{3}(1), 15-28$

Popp C, Gorboulev V, Muller TD, Gorbunov D, Shatskaya N, Koepsell H (2005): Amino acids critical for substrate affinity of rat organic cation transporter 1 line the substrate binding region in a model derived from the tertiary structure of lactose permease. Mol Pharmacol 67(5), 1600-1611

Prommer E (2007): Levorphanol: the forgotten opioid. Support Care Cancer 15(3), 259-264

The PubChem Project. National Center for Biotechnology Information. https://pubchem.ncbi.nlm.nih.gov/. Accessed 20.03.2015.

Qiao J, Tan Z, Li W, Huang L, Ge M (2009): Liquid chromatography/positive ion electrospray tandem mass spectrometry method for the quantification of hydrochloride meptazinol in human plasma: application to a pharmacokinetic study. J Chromatogr B Analyt Technol Biomed Life Sci $\underline{877(30), 3787-3791}$

Quigley C, Glare P: Hydromorphone. In: Davis MP, Glare P, Quigley C, Hardy JR (eds.): Opioids in Cancer Pain. 2nd ed; Oxford University Press. 2009, 245-252.

Ramirez J, Innocenti F, Schuetz EG, Flockhart DA, Relling MV, Santucci R, Ratain MJ (2004): CYP2B6, CYP3A4, and CYP2C19 are responsible for the in vitro N- 
demethylation of meperidine in human liver microsomes. Drug Metab Dispos $\underline{32}(9)$, 930-936

Reissig CJ, Carter LP, Johnson MW, Mintzer MZ, Klinedinst MA, Griffiths RR (2012): High doses of dextromethorphan, an NMDA antagonist, produce effects similar to classic hallucinogens. Psychopharmacology 223(1), 1-15

Rodrigues A, Wong C, Mattiussi A, Alexander S, Lau E, Dupuis LL (2013): Methylnaltrexone for Opioid-Induced Constipation in Pediatric Oncology Patients. Pediatr Blood Cancer $\underline{60}(10), 1667-1670$

Rosenblum A, Marsch LA, Joseph H, Portenoy RK (2008): Opioids and the Treatment of Chronic Pain: Controversies, Current Status, and Future Directions. Exp Clin Psychopharmacol 16(5), 405-416

Schlatter E, Monnich V, Cetinkaya I, Mehrens T, Ciarimboli G, Hirsch JR, Popp C, Koepsell $\mathrm{H}$ (2002): The organic cation transporters rOCT1 and hOCT2 are inhibited by cGMP. J Membr Biol $\underline{189}$ (3), 237-244

Schwartz AR, Pizon AF, Brooks DE (2008): Dextromethorphan-induced serotonin syndrome. Clin Toxicol (Phila) 46 (8), 771-773

Seitz T, Stalmann R, Dalila N, Chen J, Pojar S, Dos Santos Pereira JN, Kratzner R, Brockmoller J, Tzvetkov MV (2015): Global genetic analyses reveal strong interethnic variability in the loss of activity of the organic cation transporter OCT1. Genome Med I(1), 56

Singh DR, Nag K, Shetti AN, Krishnaveni N (2013): Tapentadol hydrochloride: A novel analgesic. Saudi J Anaesth $\mathbf{7}(3), 322-326$

Smith HS (2011): The metabolism of opioid agents and the clinical impact of their active metabolites. Clin J Pain 27(9), 824-838

Smith SM, Schroeder K, Fahey T (2014): Over-the-counter (OTC) medications for acute cough in children and adults in community settings. Cochrane Database Syst Rev $\underline{11}$, CD001831

Stamer UM, Musshoff F, Stuber F, Brockmoller J, Steffens M, Tzvetkov MV (2016): Lossof-function polymorphisms in the organic cation transporter OCT1 are associated with reduced postoperative tramadol consumption. Pain $\underline{157(11), 2467-2475}$

Standle T, Schulte am Esch J, Treede R, Schaefer M, Bardenheuer B. Schmerztherapie, Thieme2010.

Szeto HH, Inturrisi CE, Houde R, Saal S, Cheigh J, Reidenberg MM (1977): Accumulation of normeperidine, an active metabolite of meperidine, in patients with renal failure of cancer. Ann Intern Med $\underline{86}(6), 738-741$

Taylor CP, Traynelis SF, Siffert J, Pope LE, Matsumoto RR (2016): Pharmacology of dextromethorphan: Relevance to dextromethorphan/quinidine (Nuedexta(R)) clinical use. Pharmacol Ther $\underline{164}, 170-182$

Thummel KE, Shen DD, Isoherranen N, Smith HE: Design and Optimization of Dosage Regimens; Pharmacokinetic Data. In: Brunton LL, Lazo JS, Parker KL (eds.): Goodman \& Gilman's The Pharmacological Basis of Therapeutics. 11th ed; McGraw-Hill, New York. 2005, 1816, 1829, 1846, 1851.

Transporter Classification Database. Saier Lab Bioinformatics Group. http://www.tcdb.org/. Accessed December 9, 2017. 
Tzschentke TM, Christoph T, Schroder W, Englberger W, De Vry J, Jahnel U, Kogel BY (2011): [Tapentadol: with two mechanisms of action in one molecule effective against nociceptive and neuropathic pain. Preclinical overview]. Schmerz 25(1), 19-25

Tzvetkov MV, Vormfelde SV, Balen D, Meineke I, Schmidt T, Sehrt D, Sabolic I, Koepsell $\mathrm{H}$, Brockmoller J (2009): The effects of genetic polymorphisms in the organic cation transporters OCT1, OCT2, and OCT3 on the renal clearance of metformin. Clin Pharmacol Ther $\underline{\text { 86}}$ (3), 299-306

Tzvetkov MV, Saadatmand AR, Lotsch J, Tegeder I, Stingl JC, Brockmoller J (2011): Genetically polymorphic OCT1: another piece in the puzzle of the variable pharmacokinetics and pharmacodynamics of the opioidergic drug tramadol. Clin Pharmacol Ther 90(1), 143-150

Tzvetkov MV, Saadatmand AR, Bokelmann K, Meineke I, Kaiser R, Brockmoller J (2012): Effects of OCT1 polymorphisms on the cellular uptake, plasma concentrations and efficacy of the 5-HT(3) antagonists tropisetron and ondansetron. Pharmacogenomics $\mathrm{J} \underline{12}(1), 22-29$

Tzvetkov MV, dos Santos Pereira JN, Meineke I, Saadatmand AR, Stingl JC, Brockmoller J (2013): Morphine is a substrate of the organic cation transporter OCT1 and polymorphisms in OCT1 gene affect morphine pharmacokinetics after codeine administration. Biochem Pharmacol $\underline{86}(5), 666-678$

Vengurlekar SS, Heitkamp J, McCush F, Velagaleti PR, Brisson JH, Bramer SL (2002): A sensitive LC-MS/MS assay for the determination of dextromethorphan and metabolites in human urine--application for drug interaction studies assessing potential CYP3A and CYP2D6 inhibition. J Pharm Biomed Anal 30(1), 113-124

Volkow ND, McLellan AT (2016): Opioid Abuse in Chronic Pain--Misconceptions and Mitigation Strategies. N Engl J Med $\underline{374(13), 1253-1263}$

Volpicelli JR, Alterman AI, Hayashida M, O'Brien CP (1992): Naltrexone in the treatment of alcohol dependence. Archives of General Psychiatry $\underline{49}$ (11), 876-880

WHO. Cancer pain relief. 1996; World Health Organization (WHO).

WHO. Model List of Essential Medicines. 2015; World Health Organization (WHO).

Wikipedia. Recreational use of dextromethorphan. 2018a. https://en.wikipedia.org/wiki/Recreational use of dextromethorphan. Accessed 11.12.2018.

Wikipedia. Morphine. 2018b. https://en.wikipedia.org/wiki/Morphine. Accessed 11.12.2018.

Yee SW, Chen L, Giacomini KM (2010): Pharmacogenomics of Membrane Transporters: Past, present and future. Pharmacogenomics 11(4), 475-479

Zhang L, Dresser MJ, Gray AT, Yost SC, Terashita S, Giacomini KM (1997): Cloning and functional expression of a human liver organic cation transporter. Mol Pharmacol 51(6), 913-921

Zhang W, Qin L, Wang T, Wei SJ, Gao HM, Liu J, Wilson B, Liu B, Zhang W, Kim HC et al. (2005): 3-hydroxymorphinan is neurotrophic to dopaminergic neurons and is also neuroprotective against LPS-induced neurotoxicity. FASEB J 19 (3), 395-397 


\section{Acknowledgments}

First and foremost, I would like to thank my tutor Mladen Tzvetkov for his excellent supervision and guidance throughout the course of this work. I profited especially from his tutelage in scientific writing. Communicating the results of one's experiments in clear, precise language is a skill that is often underestimated. Thank you, Mladen, for introducing me to the craft of scientific writing!

I would also like to convey my deepest gratitude to Ellen Bruns, without whom I would never have unlocked the mysterious inner workings of the mass spectrometer and its software. I credit her with the bulk of methods we developed for our LC-MS/MS measurements. Thank you, Ellen!

Special thanks also go to my colleagues Karoline Jobst, Jiayin Chen, Tina Seitz, Marleen Meyer, and Helen Massy for their support in all the little ways that count and for making my time at the lab such an enjoyable experience. 